\title{
Elevation-Derived Hydrography Acquisition Specifications
}

Chapter 11 of Section B, U.S. Geological Survey Standards, of Book 11, Collection and Delineation of Spatial Data

C
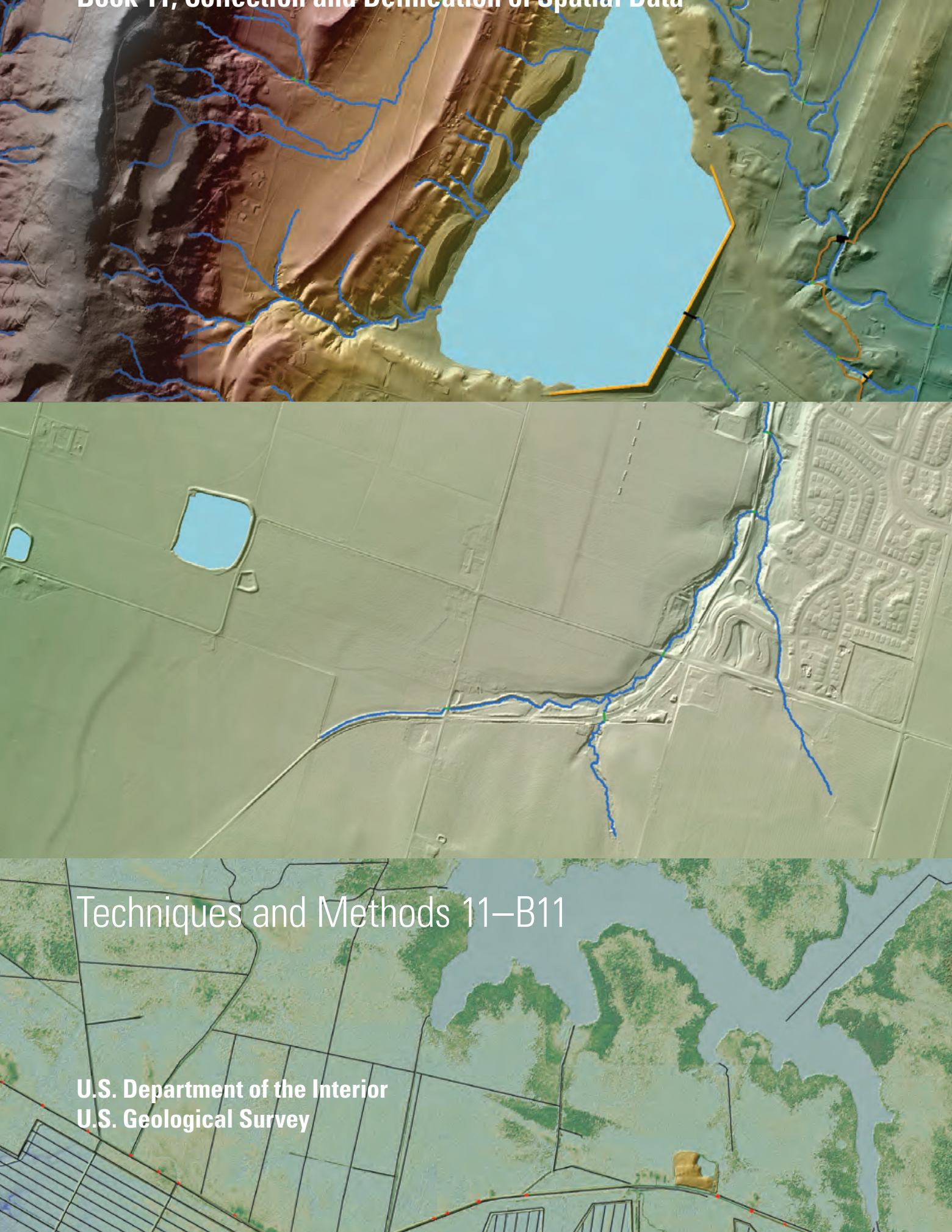

Techniques and Methods $11-B 11$ 
Cover. Examples of elevation-derived hydrography in different landscapes. From top to bottom, (1) a stream network running through mountains in Virginia; (2) stream channels flowing from a mountainous area, through a lake, and into farmland in Colorado; (3) stream channels in an arid location in Colorado; and (4) canals and other water features along the coast of North Carolina. 


\section{Elevation-Derived Hydrography Acquisition Specifications}

By Silvia Terziotti and Christy-Ann M. Archuleta

Chapter 11 of

Section B, U.S. Geological Survey Standards, of

Book 11, Collection and Delineation of Spatial Data

Techniques and Methods 11-B11 


\title{
U.S. Department of the Interior \\ DAVID BERNHARDT, Secretary
}

\author{
U.S. Geological Survey \\ James F. Reilly II, Director
}

U.S. Geological Survey, Reston, Virginia: 2020

For more information on the USGS - the Federal source for science about the Earth, its natural and living resources, natural hazards, and the environment—visit https://www.usgs.gov or call 1-888-ASK-USGS.

For an overview of USGS information products, including maps, imagery, and publications, visit https://store.usgs.gov/.

Any use of trade, firm, or product names is for descriptive purposes only and does not imply endorsement by the U.S. Government.

Although this information product, for the most part, is in the public domain, it also may contain copyrighted materials as noted in the text. Permission to reproduce copyrighted items must be secured from the copyright owner.

Suggested citation:

Terziotti, S., and Archuleta, C.M., 2020, Elevation-Derived Hydrography Acquisition Specifications: U.S. Geological Survey Techniques and Methods, book 11, chap. B11, 74 p., https://doi.org/10.3133/tm11B11.

ISSN 2328-7055 (online) 


\section{Contents}

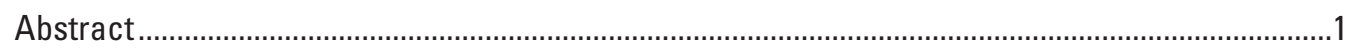

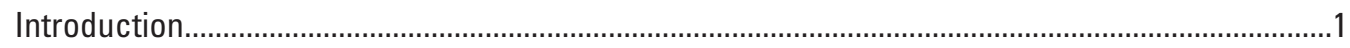

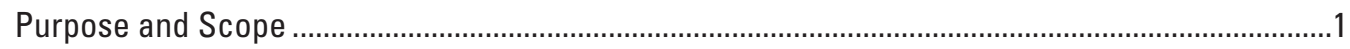

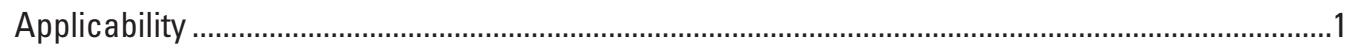

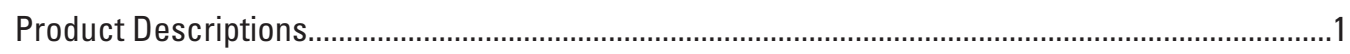

Hydroflattening Breakline Feature Collection.....................................................................

Elevation-Derived Hydrography Feature Collection ...............................................................

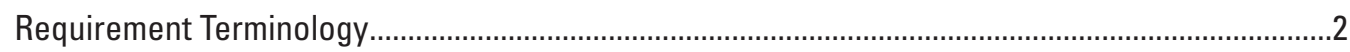

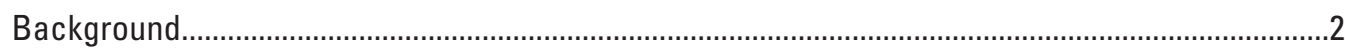

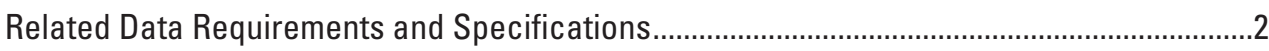

3D Elevation Program Light Detection and Ranging Base Specification..........................2

National Hydrography Dataset Specifications Explorer ....................................................

Elevation-Derived Hydrography Acquisition Specifications ...........................................................

Collection Area ................................................................................................................

Collection Concurrent with Elevation ...............................................................................

Collection Area from Existing Elevation Data ...................................................................

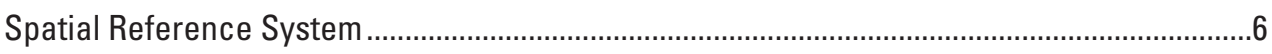

Datums

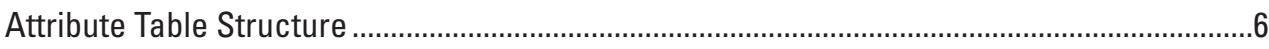

Feature Codes and Values................................................................................................

3D Elevation Program Light Detection and Ranging Base Specification

Required Hydroflattening Features ....................................................................

Additional User-Defined Features..................................................................................

Features Outside the Scope of this Specification ....................................................

Refinement of FCode with National Hydrography Dataset Feature Codes...............8

Delineation of Hydrographic Features ............................................................................. 10

3D Elevation Program Light Detection and Ranging Base Specification

Required Hydroflattening Collection ....................................................................10

Elevation-Derived Hydrography Feature Collection ....................................................10

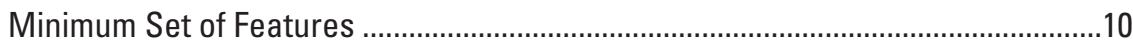

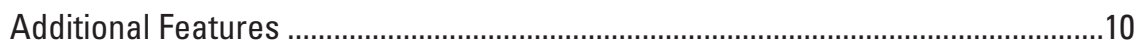

Ancillary Data Sources ........................................................................................ 16

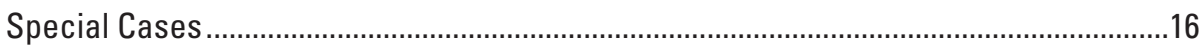

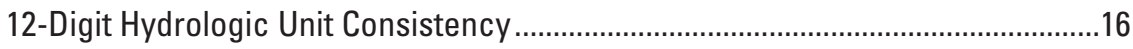

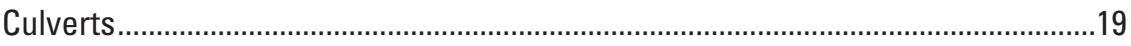

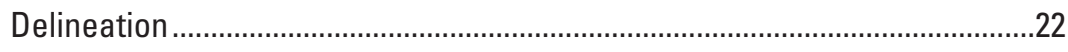

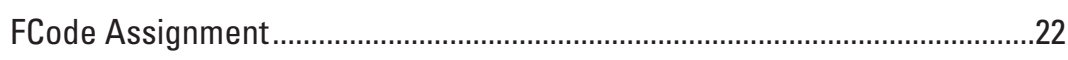

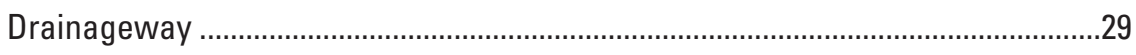

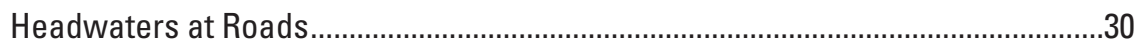

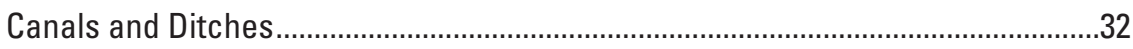

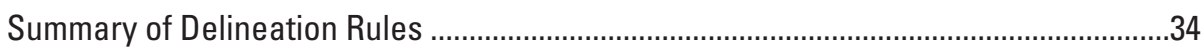

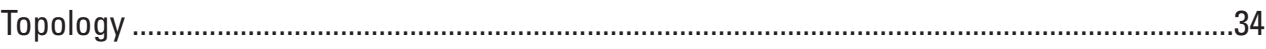

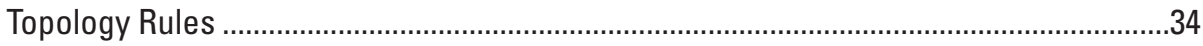

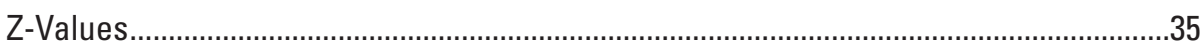




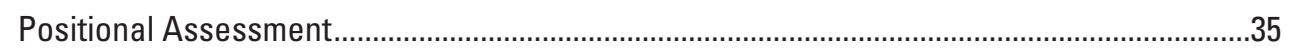

Elevation-Derived Hydrography Positional Evaluation and Reporting ............................35

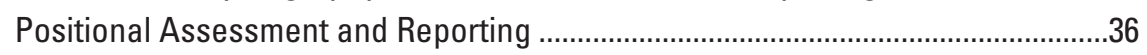

Hydroflattening Polygon Exception .............................................................36

Vertical Positional Assessment of Hydrographic Features Relative to the Digital Elevation Model .....................................................................................36

Horizontal Positional Assessment of Elevation-Derived Hydrography.....................36

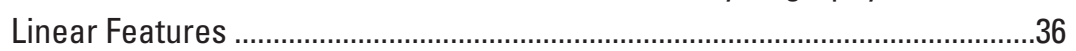

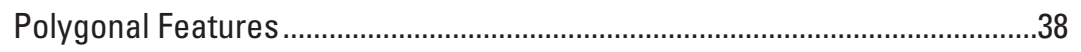

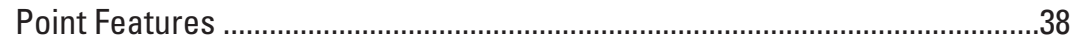

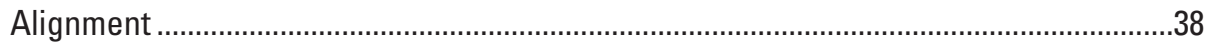

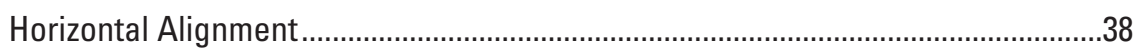

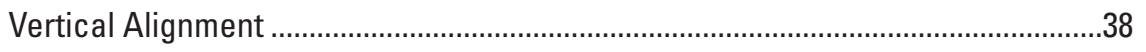

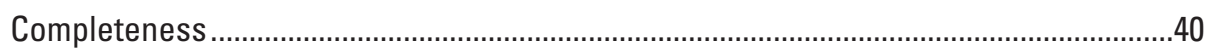

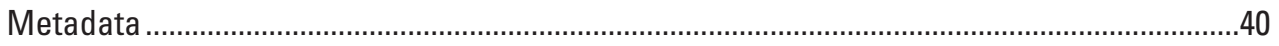

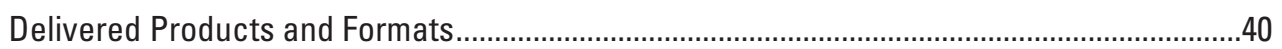

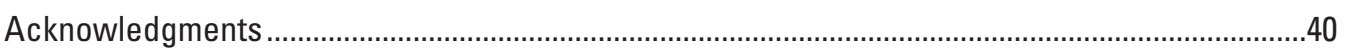

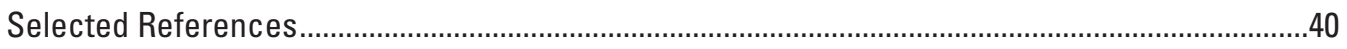

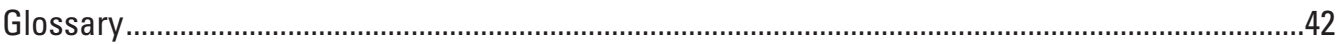

Appendix 1 Elevation Hydrography Features in 3D Elevation Program Light Detection

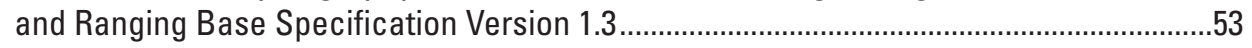

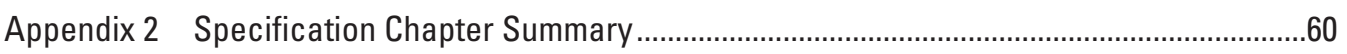

\section{Figures}

1. Hydrography collection within a defined project area based on political boundaries

2. Hydrography collection from existing light detection and ranging source

3. Minimum set of hydrographic features compared to the original National Hydrography Dataset...

4. Additional features with visible channels captured from the light detection and ranging-derived elevation surface.

5. Artifacts within National Hydrography Dataset density inherited from original quadrangle map delineation of hydrography

6. The hydrography within the southern quadrangles of this 12-digit hydrologic unit must be densified to be consistent with the northern quadrangles.

7. The streams within the Roaring River watershed indicate density disparity because of the collection differences between Jackson, Overton, and Putnam Counties, Tennessee

8. Overland flow affected by elevation surface features, corrected with the placement of culvert features

9. Bridge treatment in the bare-earth digital elevation model ..........................................21

10. Proper delineation of a culvert feature within a stream segment ...................................22

11. Schematic drawing of culverts within a hydrologic network ........................................24

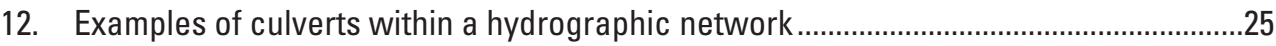

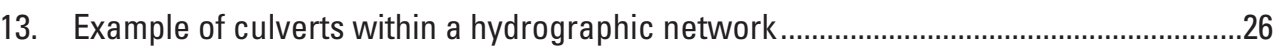




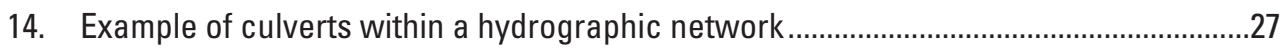

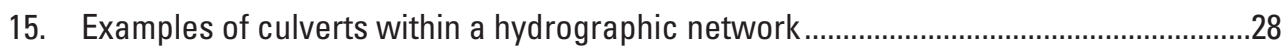

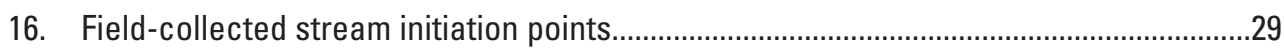

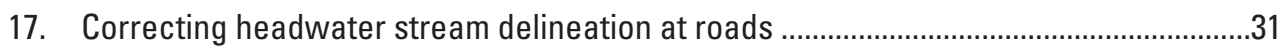

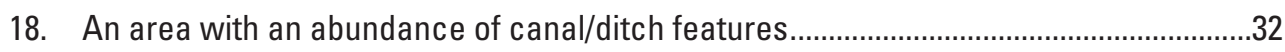

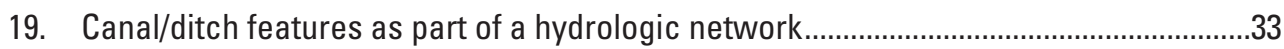

20. Two cross-sectional views of transects intersecting two stream/river segments ..........37

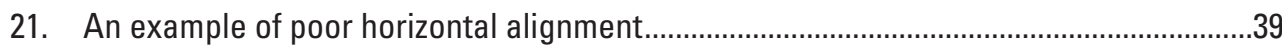

\section{Tables}

1. Geometry of elevation-derived hydrography feature types ...........................................7

2. Attribute table structure for elevation-derived hydrography features...............................7

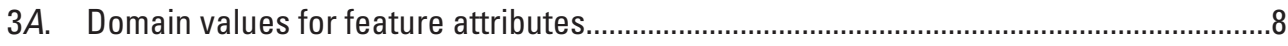

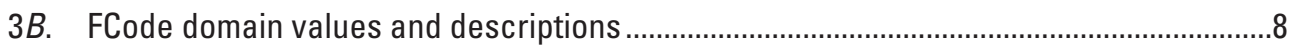

4. Polygon features used for hydroflattening an elevation surface ....................................8

5. Hydroflattening feature and updated code ................................................................

6. Attribute coding used to add a user-defined feature, outside the scope of this specification .......................................................................................................................

7. Attribute coding used to add detailed National Hydrography Dataset feature codes, outside the scope of this specification ............................................................10

8. Feature type description, associated geometry, and use classification..........................11

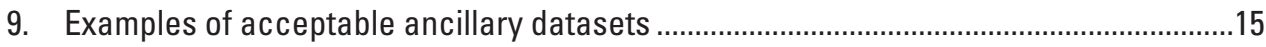

10. Example of the effect of culverts for hydroenforcement on drainage area

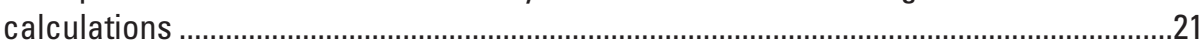

11. Example of correct coding for a culvert that spans two stream/river segments ............23

12. Attribution rules for culvert feature code when two features are connected by

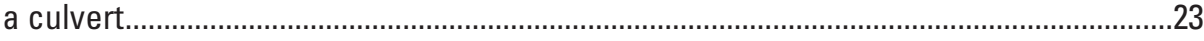

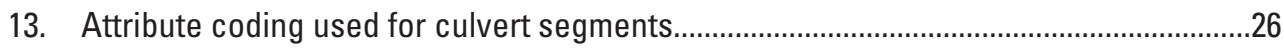

14. Attribute coding used for segments adjacent to a culvert segment ...............................27

15. Attribute coding used for polygon feature that contains a culvert.................................28

16. Attribute coding used for culvert segments................................................................ 


\section{Conversion Factors}

International System of Units to U.S. customary units

\begin{tabular}{lll}
\hline & \multicolumn{1}{c}{ Multiply } & \multicolumn{1}{c}{ Bo obtain } \\
\hline meter $(\mathrm{m})$ & \multicolumn{1}{c}{ Length } & \\
meter $(\mathrm{m})$ & 3.281 & foot $(\mathrm{ft})$ \\
$\operatorname{meter}(\mathrm{m})$ & $1 / 0.3048$ & International foot $(\mathrm{ft})$ \\
kilometer $(\mathrm{km})$ & 1.094 & yard $(\mathrm{yd})$ \\
\hline & 0.6214 & mile $(\mathrm{mi})$ \\
\hline hectare & \multicolumn{1}{c}{ Area } & \\
square meter $\left(\mathrm{m}^{2}\right)$ & 2.471 & acre \\
square meter $\left(\mathrm{m}^{2}\right)$ & 0.0002471 & acre \\
\hline
\end{tabular}

\section{Datum}

Vertical coordinate information is referenced to the North American Vertical Datum of 1988 (NAVD 88).

Horizontal coordinate information is referenced to the North American Datum of 1983 (NAD 83).

\section{Supplemental Information}

Elevation, as used in this specification, refers to the distance above the geoid, unless specifically referenced to the ellipsoid. 


\section{Abbreviations}

$\begin{array}{ll}\text { 3D } & \text { three-dimensional } \\ \text { 3DEP } & \text { 3D Elevation Program } \\ \text { DEM } & \text { digital elevation model } \\ \text { DPA } & \text { defined project area } \\ \text { DSM } & \text { digital surface model } \\ \text { DTM } & \text { digital terrain model } \\ \text { EClass } & \text { feature class (elevation) } \\ \text { EDH } & \text { elevation-derived hydrography } \\ \text { EleHydro } & \text { Elevation Hydrography } \\ \text { FClass } & \text { feature class } \\ \text { FCode } & \text { feature code } \\ \text { GPS } & \text { global positioning system } \\ \text { IfSAR } & \text { Interferometric Synthetic Aperture Radar } \\ \text { lidar } & \text { light detection and ranging } \\ \text { LBS } & \text { Lidar Base Specification } \\ \text { NGP } & \text { National Geospatial Program } \\ \text { NHD } & \text { National Hydrography Dataset } \\ \text { NPD } & \text { nominal pulse density } \\ \text { READ Rules } & \text { Representation, Extraction, Attribution, and Delineation Rules } \\ \text { RMSD } & \text { root mean square difference } \\ \text { RMSE } & \text { root mean square error } \\ \text { Spec-X } & \text { Specifications Explorer } \\ \text { TIN } & \text { triangulated irregular network } \\ \text { UserCode } & \text { user-defined code } \\ \text { USGS } & \text { U.S. Geological Survey } \\ \text { WBD } & \text { Watershed Boundary Dataset } \\ & \end{array}$





\title{
Elevation-Derived Hydrography Acquisition Specifications
}

\author{
By Silvia Terziotti and Christy-Ann M. Archuleta
}

\begin{abstract}
Hydrographic features derived from U.S. Geological Survey (USGS) 3D Elevation Program data, and collected for use by the USGS, must meet the specifications described in this document. The specifications described herein pertain to the final product delivered to the USGS, not to methods used to derive the hydrographic features. The specifications describe the collection area, spatial reference system, attribute table structure, feature codes and values, delineation of hydrographic features, topology, positional assessment, metadata, and delivery formats. A companion document, Elevation-Derived Hydrography-Representation, Extraction, Attribution, and Delineation Rules, defines the fields, domains, and minimum feature collection requirements for hydrography features derived from elevation data. Hydrographic features collected to this specification will be suitable for using as breaklines to hydroflatten digital elevation models, processing for preconflation of features to the National Hydrography Dataset, and using for hydroenforcement of digital elevation models.
\end{abstract}

\section{Introduction}

This document provides requirements and specifications for acquisition of high-resolution hydrographic features from elevation data for use by the U.S. Geological Survey (USGS). Elevation-derived hydrography (EDH) data are collected as points, lines, and polygons that form a drainage network that is horizontally and vertically integrated into an elevation surface. Minimum requirements for spatial reference system, feature content, horizontal and vertical accuracy, and topology are defined for each required hydrographic feature type within the drainage network.

\section{Purpose and Scope}

The purpose of this document is to supply detailed specifications for EDH data collected for USGS elevation and hydrography data products. A hydrologic network created using these specifications is suitable as input for light detection and ranging (lidar) surface derivatives, such as hydroflattened digital elevation models (DEMs), and as a source layer suitable for preconflation of features to the National Hydrography Dataset (NHD). This specification does not replace procurement requirements for lidar point cloud data acquisition and derivative product generation. Lidar specifications are defined in separate documents (Heidemann, 2018; U.S. Geological Survey, 2019a).

\section{Applicability}

These requirements and specifications apply to EDH features acquired through contracts or agreements between the USGS and data suppliers. These requirements and specifications are supplemental to those in the 3D Elevation Program (3DEP) Lidar Base Specification (LBS). The specifications pertain to data collected over the conterminous United States, Hawaii, Alaska, and the U.S. territories.

\section{Product Descriptions}

Two categories of EDH features may be acquired for use by the USGS: those that are required solely for use as breaklines for hydroflattening elevation surfaces and the EDH set of hydrographic features suitable for preparation for conflation into the NHD. This specification combines both types of features into one set of EDH, but features used strictly for hydroflattening will be assigned codes so they can be separated from the complete dataset and used for that purpose.

\section{Hydroflattening Breakline Feature Collection}

As mentioned previously, certain hydrographic features are required to be collected according to the LBS for hydroflattening purposes and are used as breaklines for cartographic treatments during the production of DEMs made from lidar data. Features such as streams and waterbodies must fall within a certain size range for use as breaklines, whereas the general hydrography dataset may have a wider variety of hydrographic feature sizes. These hydrographic features include the following (see Heidemann [2018] for more information): 
- Inland ponds and lakes with a surface area of 0.8 hectare (2 acres) or greater (approximately equal to a round pond 100 meters $[\mathrm{m}]$ in diameter),

- Inland streams and rivers with a 30-m or greater nominal width,

- Nontidal boundary waterbodies (waterbodies that contain some or all the defined project area [DPA] boundary), and

- Tidal waterbodies (any waterbody that is affected by tidal variations, including oceans, seas, gulfs, bays, inlets, salt marshes, and large lakes).

\section{Elevation-Derived Hydrography Feature Collection}

EDH feature collections are captured for a variety of reasons but primarily to improve the integration and alignment of USGS 3DEP bare-earth DEMs and hydrography data. The EDH set of features includes those collected to improve the geometry of previously collected hydrographic features, to enrich the NHD by adding new higher resolution features to the existing features in the dataset, and to collect features with codes that can be used for surface-elevation derivatives. These features must be detectable from bare-earth DEMs derived from lidar-source data with minimal need to research or review outside sources.

\section{Requirement Terminology}

Individual requirements that are defined in this report use "shall" or "will" statements, which have a specific meaning in the context of a specification requirement:

- A "shall" statement means that the requirement must be met.

- A "will" statement indicates that the requirement is expected to be met wherever possible, but exceptions to implementation may exist.

\section{Background}

In 2013, the USGS National Geospatial Program (NGP) established the 3DEP as an interagency group to produce and distribute nationwide coverage of high-resolution elevation data (derived from lidar and interferometric synthetic aperture radar [commonly known as IfSAR] sources) for the United States. In 2020, an effort is underway to improve the positional quality of the USGS NHD to be more closely aligned with the 1-m 3DEP DEMs, which are being derived from lidar and, in
Alaska, the 5-m DEMs, which are being derived from IfSAR. The improved integration of elevation and hydrography is an integral part of the future vision of The National Map.

As part of the effort to advance hydrography feature data collection and attribution, an optional Elevation Hydrography (EleHydro) breakline data dictionary was included in the LBS 1.3 (Heidemann, 2018) to provide a framework for hydrography data collection. Elevation and hydrography codes were defined to allow the user to collect features and assign attributes that can be used to either produce a networked hydrography layer suitable for conflation to the NHD, an elevation surface with only waterbodies and wide streams altered (a hydroflattened surface), or a hydrologically enforced elevation surface that contains flowlines with continuity and downstream flow direction.

As noted elsewhere in this document, the requirements and specifications listed herein are in addition to those specified in the LBS 1.3. The hydroflattening requirements of the 3DEP LBS, defined in the LBS 1.3, "Digital Elevation Model Surface Treatments: Hydro-Flattening" section (Heidemann, 2018), must be adhered to. However, the "EleHydro Breakline GIS Data Dictionary" and "Attribute table structure for EleHydro breakline features," also documented in the LBS 1.3 "Digital Elevation Model Surface Treatments" section, are superseded by the requirements in this report. To distinguish the optional EleHydro definitions from those in this document, the EDH features will be referred to as an "EDH feature collection." The differences between the LBS 1.3 optional requirements and the requirements listed in this report are listed in appendix 1 for reference.

\section{Related Data Requirements and Specifications}

The requirements and specifications reported in this document are to be used in conjunction with existing USGSNGP requirements and specifications. These requirements and specifications are in addition to those documented in the 3DEP LBS and reference the NHD program capture conditions defined in Specifications Explorer (Spec-X) (U.S. Geological Survey, 2019a).

\section{D Elevation Program Light Detection and Ranging Base Specification}

The most current 3DEP LBS should be used as guidance for lidar accuracy requirements. The accuracy of hydrographic features that are derived from a lidar surface that adheres to the LBS will be defined relative to the lidar-source data. The optional features defined in the LBS 1.3 are superseded by this document. 


\section{National Hydrography Dataset Specifications Explorer}

The NHD Spec-X features and definitions contain all accepted codes for a full NHD dataset. Only a subset pertinent to elevation and hydrography integration is used within this specification. The Watershed Boundary Dataset (WBD) is not addressed in this document. WBD requirements will be addressed at the time the hydrographic lines are incorporated into the full NHD dataset. Edits to the WBD should be made using DEMs from the same lidar source from which the hydrography features were created. Feature capture conditions from the NHD Spec-X standard are translated into real world coordinates and used as a minimum level of collection specifications.

\section{Elevation-Derived Hydrography Acquisition Specifications}

The following specifications (hereafter referred to as "EDH Acquisition Specifications") shall be implemented for acquisition of hydrographic features for the USGS with the goal of vertically and horizontally integrating the hydrographic features with the 3DEP lidar-elevation products. Meeting the following specifications will result in EDH appropriate for hydroflattening and hydroenforcement and a set of hydrographic features appropriate for NHD conflation.

\section{Collection Area}

The collection area refers to the geographic extent where the elevation source exists and from which hydrography will be derived. Hydrographic features can be collected at the same time elevation source data are being processed or taken from an existing 3DEP collection, when available. Collection areas from multiple sources of elevation data should be inspected and tile and collection area boundaries shall edge-match seamlessly and without gap prior to deriving hydrography.

\section{Collection Concurrent with Elevation}

The collection of hydrographic features should be completed within the same extent as the DPA of the elevation source data (U.S. Geological Survey, 2019a). Hydrographic features are best collected within a subbasin (8-digit hydrologic unit) or watershed (10-digit hydrologic unit) extent but given the varied DPAs defined by project specific goals, this method of collection is not always possible (fig. 1). Hydrologic unit boundaries may be truncated by the DPA, making it impossible to have complete network connectivity. All features that are present within the DPA and are present in the NHD should be collected so that connectivity can be established in future updates. The lidar-delineated features along the edges of the DPA should not be moved to snap to adjacent, less accurate NHD features. Features will be adjusted when hydrography is incorporated into the NHD dataset.

Within the collection area, the following guidelines apply:

1. Hydrography should be delineated for the entire DPA.

2. Parts of the DPA within a complete 10-digit hydrologic unit should have complete network connectivity.

3. Areas outside a 10-digit hydrologic unit, but within the DPA, should be connected and network connectivity should be created where possible.

a. Linework should not be snapped to less accurate features outside of the DPA.

b. A complete set of features shall be captured up to the boundary, but topology and network connectivity may need to be corrected later.

4. If EDH exists adjacent to the DPA, linework should be snapped and merged to preexisting EDH to create continuous features that do not stop at the DPA boundary.

\section{Collection Area from Existing Elevation Data}

Hydrographic features should be collected within watersheds, as defined by the WBD. A 10-digit hydrologic unit is the minimum unit size recommended for collection (fig. 2). A national layer of 10-digit hydrologic units is available through The National Map (U.S. Geological Survey, 2019b).

The 10-digit hydrologic unit watershed boundaries published within the WBD may not be as accurate as the lidar data source being used for hydrographic features and should therefore only be used as a guide for delineation of features. A buffered area around each 10-digit hydrologic unit should be used to review and delineate features. The positional accuracy of the lidar-delineated features along the edges of the 10-digit hydrologic unit should not be moved to snap to adjacent, less accurate NHD features. Features will be adjusted when hydrography is incorporated into the NHD dataset.

In summary, for areas with an existing lidar data source,

1. Features shall be collected within a minimum 10-digit hydrologic unit area.

2. Features that flow from one 10-digit hydrologic unit area to another that contains lidar-derived hydrography shall be snapped and topology shall be corrected between hydrologic units.

a. Linear features shall be merged based on feature code (FCode).

b. Polygons shall be merged with the same FCode. 


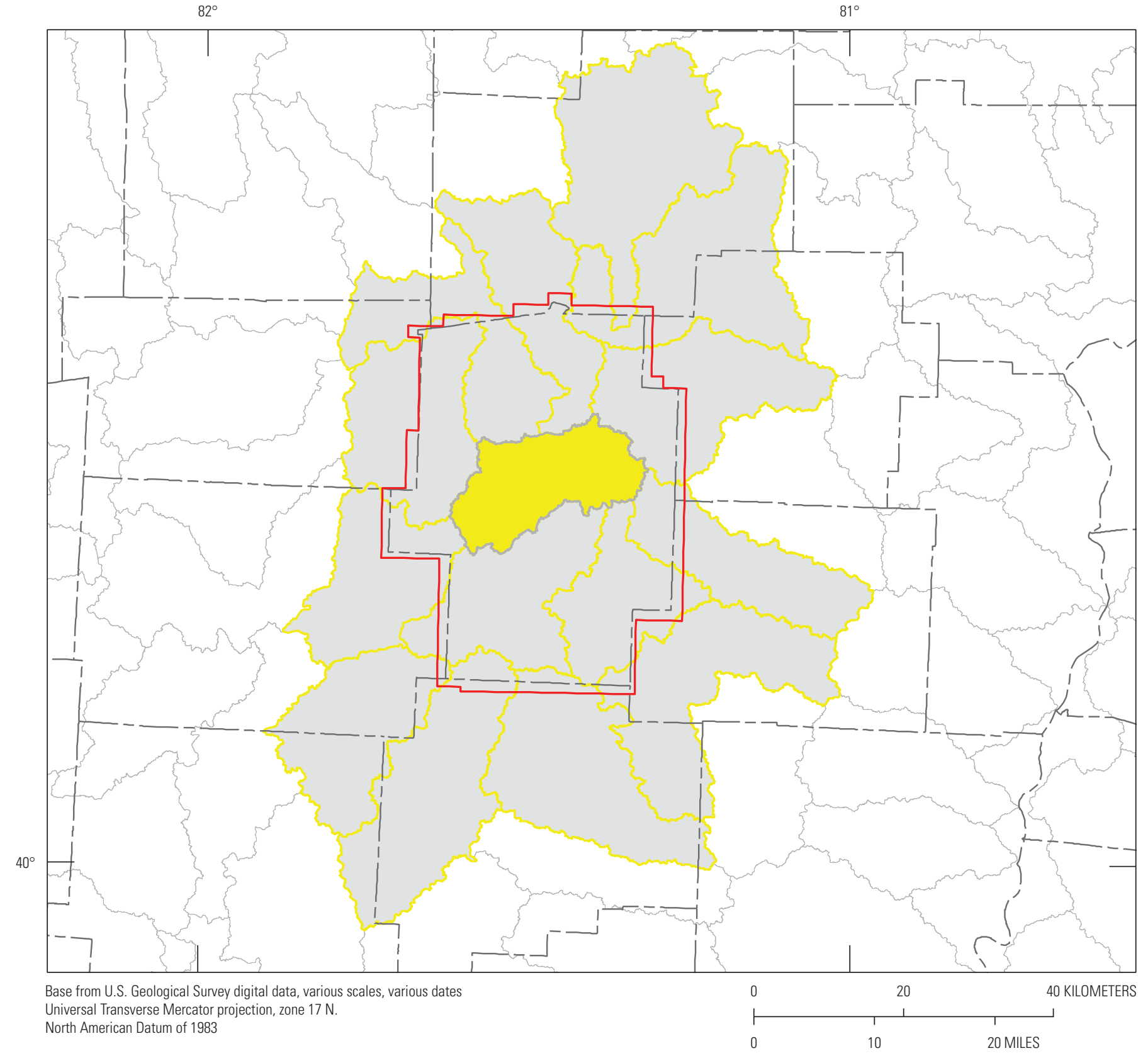

EXPLANATION

[WBD, Watershed Boundary Dataset; HU10, 10-digit hydrologic unit; lidar, light detection and ranging; 3DEP, 3D Elevation Program; DPA, defined project area]

WBD HU10 with complete lidar coverage

WBD HU10 with incomplete lidar coverage

WBD HU10 not overlapping DPA
3DEP DPA boundary

HU10 watershed boundary

County boundary

Figure 1. Hydrography collection within a defined project area based on political boundaries. 
$82^{\circ}$

$81^{\circ}$

$80^{\circ}$

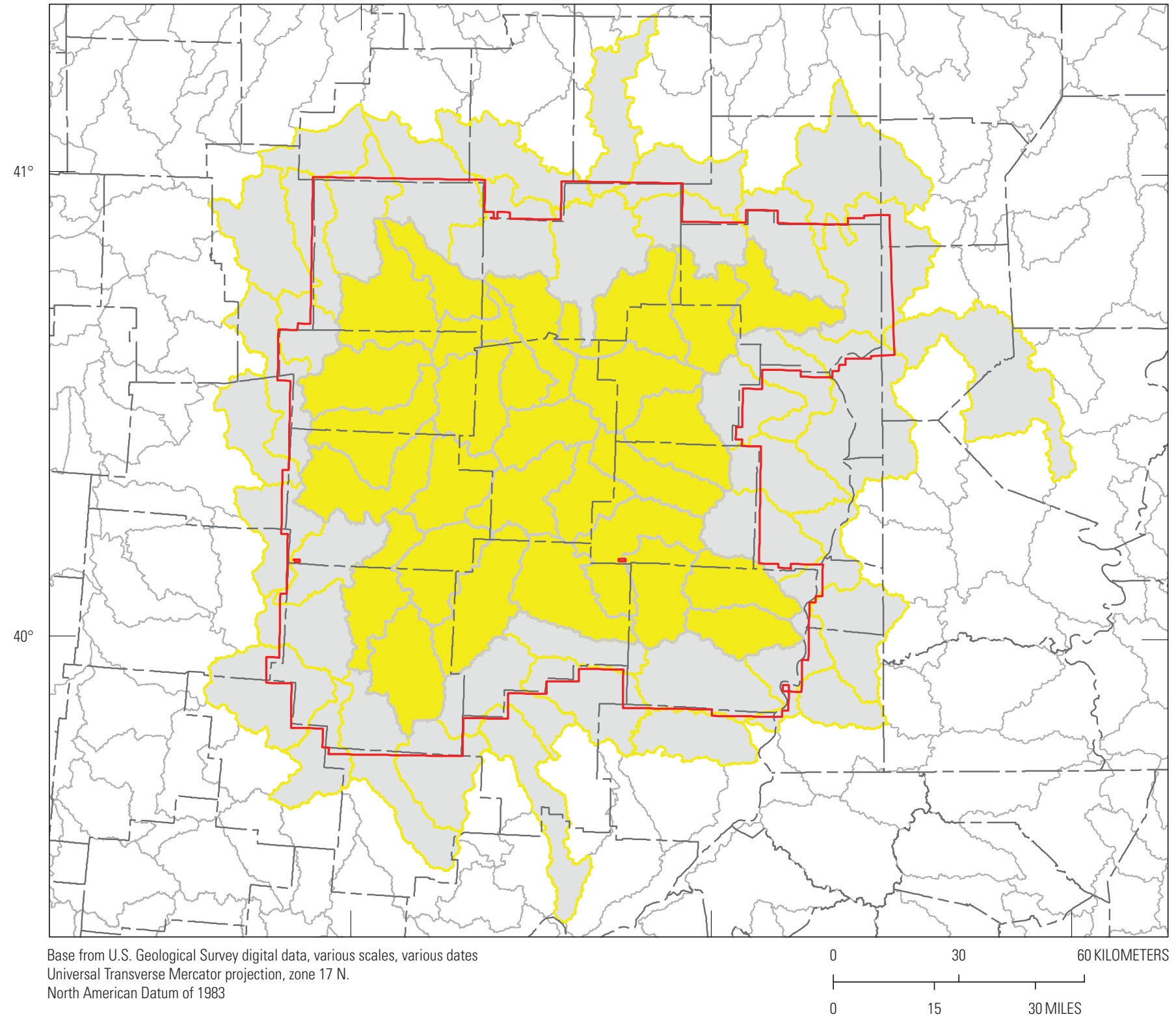

EXPLANATION

[WBD, Watershed Boundary Dataset; HU10, 10-digit hydrologic unit; lidar, light detection and ranging; 3DEP, 3D Elevation Program;

DPA, defined project area]

WBD HU10 with complete lidar coverage

WBD HU10 with incomplete lidar coverage

WBD HU10 not overlapping DPA
3DEP DPA boundary

HU10 watershed boundary

County boundary

Figure 2. Hydrography collection from existing light detection and ranging source. 
3. If less accurate hydrologic features are the only ones that exist outside of a hydrologic unit, features should not be snapped or adjusted to match those adjacent features.

\section{Spatial Reference System}

Final products shall be in the spatial reference system that matches the source data as defined in the LBS (U.S. Geological Survey, 2019a). If a collection area is composed of multiple sources of elevation data, all elevation data shall be processed to one common coordinate reference system prior to EDH compilation.

\section{Datums}

As specified in the most current LBS, to maximize the usability of 3DEP lidar and elevation products, all data collected shall be tied to the datums listed below:

1. For the conterminous United States, unless otherwise specified by the user and agreed to in advance by the USGS-NGP,

- The horizontal datum for latitude and longitude and ellipsoid heights will be the North American Datum of 1983 (NAD 83) using the most recent National Geodetic Survey published adjustment (currently NAD 83, epoch 2010.00, realization of 2011).

- The vertical datum for orthometric heights will be the North American Vertical Datum of 1988.

- The geoid model used to convert between ellipsoid heights and orthometric heights will be the latest hybrid geoid model of the National Geodetic Survey, supporting the latest realization of NAD 83 (for example, [2017] GEOID12b model, GEOID18, or most current [National Geodetic Survey, 2019]).

2. For Alaska, American Samoa, Commonwealth of the Northern Mariana Islands, Guam, Hawaii, Puerto Rico, U.S. Virgin Islands, and other U.S. territories,

- USGS-NGP and all collection partners shall agree to and specify horizontal and vertical datums, ellipsoids, and geoids in advance of data collection.

\section{Attribute Table Structure}

The structure of the attribute tables is described in tables 1 and 2. An important component of the EDH features is that they have three-dimensional (3D) geometry. Each feature type must be z-enabled, with z-values assigned to each point, vertex, and node. The feature classes (pointZ, polylineZ, and polygonZ) are 3D geometry.
The table structures for all three feature classes (point, line, and polygon) are identical. Each table contains the attribute feature class (FClass), elevation feature class (EClass), FCode, description (Desc), source, method, user-defined code (UserCode), and comments. A brief definition of each attribute follows:

- FClass-A short integer one-digit code defining whether a feature is intended for use as an NHD feature (1, will be used for conflation), a non-NHD feature (2, outside of the collection criteria and not intended to be used for conflation), or a nonhydrography feature (3, elevation dataset limitation). An example of FClass equal to 1 would be a line feature that represents a stream/river and is suitable for conflation to NHD. An example of FClass equal to 2 would be a canal/ ditch that adds too much complexity to the NHD but is collected to fulfill the needs of a funding partner. If a feature is not an NHD feature, and is necessary for elevation processing, a 9 is used as the FClass. A polygon representing a low-confidence area is an example of a feature that would not be used in the NHD but may be useful for elevation processing.

- EClass-A short integer one-digit code indicating whether a feature is not used for elevation derivatives; used for hydroflattening or for other nonspecified elevation purposes; used for hydroflattening; or an elevation dataset limitation feature. For instance, a low-confidence area is coded as a 9. A culvert is a special case with no associated NHD coding but is necessary for some elevation treatments. Culverts shall be coded as an EClass of 3.

- FCode-A long integer field containing a coded value. Most of the FCodes are equivalent to the NHD FCode value, which is a five-digit integer code representing various hydrologic feature types. For instance, a lake/ pond has FCode type 39000, and a stream/river has an FCode of 46000 . The codes that do not have a corresponding NHD code are included to differentiate features that may be useful in describing limitations in the elevation dataset, potentially affecting hydrography and elevation derivatives.

- Desc-A 250-character free-text field with a text description of FCode or used for user-defined features not included in the domain list.

- Source-A 128-character free-text field with a text description of the elevation source data used for deriving the hydrography. Lidar-source data should include collection name, date, and quality level. 
- Method-A 250-character free-text field with a text description of the method used for deriving the hydrography. For instance, software or models could be listed, or digitizing techniques, if used. Ancillary datasets could be noted here.

- UserCode-A 25-character free-text field with a code designated by the acquisition entity to identify features collected outside the scope of features described in this specification document. It is intended to be used as a key to join tables with attributes outside of this specification. Not required.

- Comments-A 250-character free-text field for user comments.

\section{Feature Codes and Values}

Hydrographic features collected under the scope of this specification document represent a subset of the features included within the NHD. Where appropriate, the FCode values and descriptions match the NHD specifications. Elevation features used as breaklines for hydroflattening, or for other elevation surface treatments, are identified with an elevation

Table 1. Geometry of elevation-derived hydrography feature types.

[3D, three dimensional]

\begin{tabular}{lcc}
\hline \multicolumn{3}{c}{ Geometry of each feature type } \\
\hline \multicolumn{1}{c}{ Feature type } & \multicolumn{1}{c}{ Format } & \multicolumn{1}{c}{ Geometry } \\
\hline Point & Vector shape & 3D point, pointZ \\
Line & Vector shape & 3D line, polylineZ \\
Polygon & Vector shape & 3D polygon, polygonZ \\
\hline
\end{tabular}

class as well as a hydrography FCode. The complete set of domain values required with this specification is provided in table 3. The companion document "Elevation-Derived Hydrography-Representation, Extraction, Attribution, and Delineation Rules" (READ Rules) further defines the fields, domains, and minimum feature collection requirements for each required feature (Archuleta and Terziotti, 2020).

\section{D Elevation Program Light Detection and Ranging Base Specific ation Required Hydroflattening Features}

The features that shall be collected for hydroflattening breaklines are identified in table 4 . The LBS does not require coding on the breaklines, but to easily extract a subset of features that can be used for hydroflattening, codes that correspond to lake/pond, reservoir, sea/ocean, and stream/river are recommended.

The features required for hydroflattening defined within the LBS 1.3 (Heidemann, 2018) are reprinted here for reference in table 5. The EDH FCodes that correspond to hydroflattening features are cross-referenced so the appropriate code can be used to adhere to the hydroflattening requirements of the LBS (U.S. Geological Survey, 2019a). EClass=1, which is used for hydroflattening (3D polygon), shall be used to identify the polygons in the EDH data.

\section{Additional User-Defined Features}

There are two primary uses for the UserCode field:

- to identify features that are outside the scope of this specification but are required by the user and

- to refine the FCode classification with additional NHD FCode values.

Table 2. Attribute table structure for elevation-derived hydrography features.

[NHD, National Hydrography Dataset]

\begin{tabular}{lllcc}
\hline \multicolumn{4}{c}{ Attributes for each feature type } \\
\hline \multirow{2}{*}{ Attribute description } & \multicolumn{3}{c}{ Table items } \\
\cline { 2 - 5 } & \multicolumn{1}{c}{ Item name } & Item & Item type & Item precision \\
\hline Feature class (NHD) & FClass & Integer & Short & 4 \\
Feature class (elevation) & EClass & Integer & Short & 4 \\
Feature code (NHD) & FCode & Integer & Long & 5 \\
Description & Desc & Text & Text & 250 \\
Elevation source data & Source & Text & Text & 128 \\
Hydrography delineation method & Method & Text & Text & 250 \\
User-defined code & UserCode & Text & Text & 25 \\
Free-text space for user comments & Comments & Text & Text & 250 \\
\hline
\end{tabular}


Table 3A. Domain values for feature attributes.

[FClass, feature class; NHD, National Hydrography Dataset; EClass, feature class (elevation); 3D, three dimensional]

\begin{tabular}{|c|c|}
\hline $\begin{array}{l}\text { Domain } \\
\text { value }\end{array}$ & $\begin{array}{c}\text { Feature } \\
\text { description }\end{array}$ \\
\hline \multicolumn{2}{|r|}{ FClass } \\
\hline 1 & NHD feature (will be used for conflation). \\
\hline 2 & Non-NHD feature (outside of collection criteria). \\
\hline 9 & $\begin{array}{l}\text { Nonhydrography feature (elevation dataset } \\
\text { limitation). }\end{array}$ \\
\hline \multicolumn{2}{|r|}{ EClass } \\
\hline 0 & Not used for elevation derivatives. \\
\hline 1 & Used for hydroflattening (3D polygon). \\
\hline 2 & $\begin{array}{l}\text { Hydrographic feature used for elevation purposes, } \\
\text { other than culverts or those used for } \\
\text { hydroflattening. }\end{array}$ \\
\hline 3 & Culvert—used for hydroenforcement. \\
\hline 9 & Elevation dataset limitation. \\
\hline
\end{tabular}

Table 3B. FCode domain values and descriptions.

[FCode, feature code; Desc, description]

\begin{tabular}{cl}
\hline FCode & \\
\hline 0 & User-defined feature ${ }^{1}$ \\
33400 & Connector \\
33600 & Canal/ditch \\
34300 & Dam/weir \\
36100 & Playa \\
37800 & Ice mass \\
39000 & Lake/pond \\
42800 & Pipeline \\
43600 & Reservoir \\
44500 & Sea/ocean \\
45000 & Sink/rise \\
46000 & Stream/river \\
46800 & Drainageway ${ }^{1}$ \\
53700 & Area of complex channels \\
55800 & Artificial path \\
Assigned based on & Culvert 1 -adjacent feature description \\
adjacent features ${ }^{2}$ & \\
991 & Low-confidence area (predetermined) \\
992 & Low-confidence area (sparse bare earth) \\
993 & Low-confidence area (snow covered) \\
\hline &
\end{tabular}

1 New feature.

${ }^{2}$ FCodes include $33400,42800,33600,46000,46800$, and 55800 . See figure 11 and table 12.
Table 4. Polygon features used for hydroflattening an elevation surface.

[Desc, description; FCode, feature code]

\begin{tabular}{lc}
\hline & Features required for hydroflattening \\
\hline \multicolumn{1}{c}{ Desc } & FCode \\
\hline Lake/pond & 39000 \\
Reservoir & 43600 \\
Sea/ocean & 44500 \\
Stream/river & 46000 \\
\hline
\end{tabular}

\section{Features Outside the Scope of this Specification}

If a feature is collected outside of these specifications, either because of density requirements or feature type, userdefined codes may be used. No FCode from table 3 should be used in the UserCode field to identify these features.

If a feature is added outside of the specification requirements, and is not intended for conflation to NHD, FClass, EClass, and FCode should be coded as 2, 0 (unless collected to produce an elevation derivative, then 2 ), and 0 , respectively (table 6). The Desc field may be used to provide a text description. A user-defined code should be added to the UserCode field. Codes should not duplicate other defined features or coding needed for NHD conflation.

An example of a feature that would fall outside of this specification would be the collection of dense ditches and canals for high precision agricultural use. Canal and ditch features that are too detailed for a hydrologic network (see "Canals and Ditches" subsection of "Special Cases" in the "Delineation of Hydrographic Features" section) should not be coded as FCode $=33600$. These features should be coded as described previously for "additional user-defined features," and a UserCode should be added to the table to distinguish these features. Text that describes the feature, such as "canal or ditch for project use" may be added to the Desc field.

\section{Refinement of FCode with National Hydrography Dataset Feature Codes}

If the user requires a more descriptive FCode, compatible with the feature catalog for the NHD, the UserCode may be used to identify the FCode defined within the NHD "Complete FCode List for NHD Hydrography Features" (https://nhd.usgs.gov/userGuide/Robohelpfiles/ index.htm\#NHD_User_Guide/Feature_Catalog/Hydrography_ Dataset/Complete_FCode_List.htm). The FCode/UserCode enhanced coding can be used to retain the existing FCode values from the source NHD that are not included within the EDH Acquisition Specifications, or to add newly refined FCode information to the EDH, updating the NHD source attribution. 
Table 5. Hydroflattening feature and updated code.

[3DEP, 3D Elevation Program; 2D, two dimensional; ha, hectare; m, meter; DPA, defined project area]

\begin{tabular}{|c|c|c|c|c|}
\hline \multicolumn{2}{|c|}{$\begin{array}{l}\text { Hydroflattening requirements from 3DEP } \\
\text { Lidar Base Specification }\end{array}$} & \multicolumn{3}{|c|}{$\begin{array}{l}\text { Elevation-Derived Hydrography Acquisition } \\
\text { Specifications codes for hydroflattening }\end{array}$} \\
\hline $\begin{array}{l}\text { Hydroflattening } \\
\text { feature }\end{array}$ & $\begin{array}{l}\text { Hydroflattening short description (see } \\
\text { Lidar Base Specification for all cases) }\end{array}$ & $\begin{array}{c}\text { Elevation-derived } \\
\text { hydrographic feature }\end{array}$ & FCode & $\begin{array}{l}\text { Elevation-derived hydrographic } \\
\text { feature } 2 D \text { (polygon) description }\end{array}$ \\
\hline $\begin{array}{l}\text { Inland ponds and } \\
\text { lakes }\end{array}$ & $\begin{array}{l}\text { Waterbodies with a surface area of } \\
0.8 \text { ha ( } 2 \text { acres) or greater (approxi- } \\
\text { mately equal to a round pond } 100 \mathrm{~m} \\
\text { in diameter) at the time of collec- } \\
\text { tion shall be flattened. }\end{array}$ & Lake/pond & 39000 & $\begin{array}{l}\text { A standing body of water with a } \\
\text { predominantly natural shoreline } \\
\text { surrounded by land. }\end{array}$ \\
\hline $\begin{array}{l}\text { Inland streams and } \\
\text { rivers }\end{array}$ & $\begin{array}{l}\text { Streams and rivers of a } 30 \mathrm{~m} \text { or } \\
\text { greater nominal width shall be } \\
\text { flattened. }\end{array}$ & Stream/river & 46000 & A body of flowing water. \\
\hline Tidal waterbodies & $\begin{array}{l}\text { Tidal waterbodies are defined as any } \\
\text { waterbody that is affected by tidal } \\
\text { variations, including oceans, seas, } \\
\text { gulfs, bays, inlets, salt marshes, and } \\
\text { large lakes. }\end{array}$ & Sea/ocean & 44500 & $\begin{array}{l}\text { The great body of saltwater that } \\
\text { covers much of the Earth. }\end{array}$ \\
\hline $\begin{array}{l}\text { Nontidal boundary } \\
\text { waterbodies }\end{array}$ & $\begin{array}{l}\text { Boundary waterbodies are waterbod- } \\
\text { ies that contain some or all of the } \\
\text { DPA. } \\
\text { - Boundary waterbodies may be any } \\
\text { type of waterbody but are virtually } \\
\text { always large in area or width. } \\
\text { - A boundary waterbody shall } \\
\text { be represented as a polygon that } \\
\text { follows the shore throughout the } \\
\text { project and is then closed using } \\
\text { arbitrary line segments as needed } \\
\text { across the waterbody. Boundary } \\
\text { waterbodies do not include the } \\
\text { natural far shoreline. }\end{array}$ & $\begin{array}{l}\text { Any large } 2 \mathrm{D} \text { features at } \\
\text { the edge of the DPA. } \\
\text { Exceptions are tidal } \\
\text { waterbodies: sea/ocean. }\end{array}$ & $\begin{array}{l}39000 \\
43600 \\
46000\end{array}$ & $\begin{array}{l}\text { A } 2 \mathrm{D} \text { feature that is not wholly } \\
\text { contained within the DPA } \\
\text { and is therefore only partially } \\
\text { delineated. }\end{array}$ \\
\hline
\end{tabular}

Table 6. Attribute coding used to add a user-defined feature, outside the scope of this specification.

[FClass, feature class; EClass, feature class (elevation); FCode, feature code; Desc, description; UserCode, user-defined code; NHD, National Hydrography Dataset]

\begin{tabular}{|c|c|c|c|c|c|c|}
\hline \multicolumn{2}{|c|}{ FClass } & \multicolumn{2}{|r|}{ EClass } & \multirow[b]{2}{*}{ FCode } & \multirow[b]{2}{*}{ Desc } & \multirow[b]{2}{*}{ UserCode } \\
\hline $\begin{array}{l}\text { Domain } \\
\text { value }\end{array}$ & Feature attribute & $\begin{array}{l}\text { Domain } \\
\text { value }\end{array}$ & Feature attribute & & & \\
\hline 2 & $\begin{array}{l}\text { Non-NHD fea- } \\
\text { ture (outside } \\
\text { of collection } \\
\text { criteria) }\end{array}$ & 0 & $\begin{array}{l}\text { Not used for eleva- } \\
\text { tion derivatives }\end{array}$ & 0 & $\begin{array}{l}\text { User-defined } \\
\text { feature }\end{array}$ & $\begin{array}{l}\text { Code defined by contrac- } \\
\text { tor/steward that does not } \\
\text { match table } 3 B \text { FCode } \\
\text { values. }\end{array}$ \\
\hline
\end{tabular}

An example of use would be when a user has collected perennial/intermittent/ephemeral stream classifications in the field and would like to identify the EDH stream/river features with the classification used by the NHD (46003, stream/ river, hydrographic category/intermittent; 46006, stream/ river, hydrographic category/perennial; or 46007, stream/ river, hydrographic category/ephemeral). The FCodes from NHD can be used within the UserCode field, and the appropriate code from table 3 used in the FCode field. The FClass and EClass should be coded such that the feature is included in the product for conflation; for example, if a stream/river has been captured, and ancillary data have identified it as an 
Table 7. Attribute coding used to add detailed National Hydrography Dataset feature codes, outside the scope of this specification.

[FClass, feature class; EClass, feature class (elevation); FCode, feature code; UserCode, user-defined code; NHD, National Hydrography Dataset]

\begin{tabular}{cccccccc}
\hline & FClass & & EClass & FCode & Desc & UserCode \\
\cline { 1 - 4 } $\begin{array}{c}\text { Domain } \\
\text { value }\end{array}$ & Feature attribute & & $\begin{array}{c}\text { Domain } \\
\text { value }\end{array}$ & Feature attribute & & Stream/river & 46003 \\
\hline 1 & $\begin{array}{c}\text { NHD feature (will be } \\
\text { used for conflation) }\end{array}$ & 2 & $\begin{array}{c}\text { Hydrographic feature } \\
\text { used for elevation } \\
\text { purposes, other than } \\
\text { culverts or those used } \\
\text { for hydroflattening }\end{array}$ & & 46000 & & \\
\hline
\end{tabular}

intermittent stream that the user wants to store in the EDH, then coding would be FClass $=1$, EClass $=2$, FCode $=46000$, and UserCode $=46003$ (table 7).

\section{Delineation of Hydrographic Features}

The delineation of features refers to the way in which features are captured to populate the hydrographic network. A minimum set of features, based primarily on the size of the feature, is presented as the base requirement. A more dense or complete set of features may be captured but must meet the specifications described in the "Additional Features" subsection. Features that do not meet the "Additional Features" specifications may be captured, but must be identified using the codes described in the "Additional User-Defined Features" subsection of the "Feature Codes and Values" section.

Hydrographic features will be captured as either 3D point, line, or polygon geometry (table 8). Some features may be collected either as 3D points, 3D lines, or 3D polygons, determined by minimum area or length of shortest access (Archuleta and Terziotti, 2020). EClass indicates how the features are used in elevation surface treatments. FClass indicates how the features are used in a hydrography product.

\section{D Elevation Program Light Detection and Ranging Base Specification Required Hydroflattening Collection}

The features required to meet the hydroflattening requirement for 3DEP lidar DEMs are defined within the most current version of the LBS. The required features may be collected using the specifications outlined within this document. The subset of features identified in table 5 can be used to fulfill the hydroflattening requirement.

\section{Elevation-Derived Hydrography Feature Collection}

This section describes the set of criteria required to delineate the full set of EDH features. The "minimum set of features" requirement, based on the features present in the most recent version of the NHD, and criteria for collection of additional hydrography features are described. Ancillary data sources that are required and recommended are presented. Five common special cases are also presented with corresponding rules and guidelines.

\section{Minimum Set of Features}

Hydrographic features shall have, at a minimum, corrected geometry for features currently in the NHD (U.S. Geological Survey, 2019a). A subset of the NHD, composed of the features required in the EDH Acquisition Specifications, shall be used as a guide for collection of features. The companion document to this specification, "Elevation-Derived Hydrography - Representation, Extraction, Attribution, and Delineation Rules" (Archuleta and Terziotti, 2020), is modeled after the NHD specifications and defines each feature's minimum length or size to capture (in feet or meters on the ground), geometry specifications, examples, and any special considerations when capturing the feature. Note that not all NHD features are included in this document; only the requisite set of features for EDH as specified in table 3.

When delineating a minimum set of features, current NHD content should be used as a guide but not to determine the definitive set of features to update. If a feature is no longer present on the elevation surface or in imagery, the feature can be removed from the updated collection. Additional features, not present in the NHD, may be visible in the elevationderived surface and meet the minimum mapping requirements. These features should be captured in the updated collection.

An example of stream/river features that have been updated is provided in figure 3. The blue lines are the original NHD and the red lines are the updated hydrographic features. The NHD was used as a guide for collection with improvements made to the geometry of the newly delineated features. Additional stream/river segments that had not been present in the NHD and meet the minimum length requirement of $300 \mathrm{~m}$ shall be included in the collection of features.

\section{Additional Features}

Often, compared to the hydrographic features populated in the NHD, an elevation-derived surface reveals many more apparent stream channels; however, it is often difficult 
Table 8. Feature type description, associated geometry, and use classification.

[Desc, description; FCode, feature code; EClass, feature class (elevation); FClass, feature class; 3D, three dimensional; NHD, National Hydrography Dataset]

\begin{tabular}{|c|c|c|c|c|c|c|}
\hline \multicolumn{7}{|c|}{ Feature type descriptions, associated geometry, and coding } \\
\hline \multirow[b]{2}{*}{ Desc } & \multirow[b]{2}{*}{ FCode } & \multirow[b]{2}{*}{ Geometry type } & \multicolumn{2}{|r|}{ EClass } & \multicolumn{2}{|r|}{ FClass } \\
\hline & & & $\begin{array}{l}\text { Domain } \\
\text { value }\end{array}$ & Feature attribute & $\begin{array}{l}\text { Domain } \\
\text { value }\end{array}$ & Feature attribute \\
\hline Artificial path & 55800 & 3D line, polyline Z & 2 & $\begin{array}{l}\text { Hydrographic feature used for elevation } \\
\text { purposes, other than culverts or those } \\
\text { used for hydroflattening }\end{array}$ & 1 & $\begin{array}{l}\text { NHD feature (will be used for confla- } \\
\text { tion). }\end{array}$ \\
\hline \multirow[t]{2}{*}{ Canal/ditch } & 33600 & $\begin{array}{l}\text { 3D line, polylineZ (does not } \\
\text { connect primary network } \\
\text { features) }\end{array}$ & 0 & Not used for elevation derivatives & 2 & $\begin{array}{l}\text { Non-NHD feature (outside of collec- } \\
\text { tion criteria). }\end{array}$ \\
\hline & & $\begin{array}{l}\text { 3D line, polylineZ (creates } \\
\text { network connectivity) }\end{array}$ & 2 & $\begin{array}{l}\text { Hydrographic feature used for elevation } \\
\text { purposes, other than culverts or those } \\
\text { used for hydroflattening }\end{array}$ & 1 & $\begin{array}{l}\text { NHD feature (will be used for confla- } \\
\text { tion). }\end{array}$ \\
\hline $\begin{array}{l}\text { Area of complex } \\
\text { channels }\end{array}$ & 53700 & 3D polygon, polygonZ & 0 & Not used for elevation derivatives & 1 & $\begin{array}{l}\text { NHD feature (will be used for confla- } \\
\text { tion). }\end{array}$ \\
\hline Connector & 33400 & 3D line, polyline Z & 2 & $\begin{array}{l}\text { Hydrographic feature used for elevation } \\
\text { purposes, other than culverts or those } \\
\text { used for hydroflattening }\end{array}$ & 1 & $\begin{array}{l}\text { NHD feature (will be used for confla- } \\
\text { tion). }\end{array}$ \\
\hline Culvert & $\begin{array}{l}\text { Dependent on } \\
\text { connecting } \\
\text { features }\end{array}$ & 3D line, polyline Z & 3 & Culvert-used for hydroenforcement & 1 & $\begin{array}{l}\text { NHD feature (will be used for confla- } \\
\text { tion). }\end{array}$ \\
\hline \multirow[t]{3}{*}{ Dam/weir } & 34300 & 3D point, point $Z$ & 0 & Not used for elevation derivatives & 2 & $\begin{array}{l}\text { Non-NHD feature (outside of collec- } \\
\text { tion criteria). }\end{array}$ \\
\hline & & 3D line, polyline Z & 0 & Not used for elevation derivatives & 1 & $\begin{array}{l}\text { NHD feature (will be used for confla- } \\
\text { tion). }\end{array}$ \\
\hline & & 3D polygon, polygonZ & 0 & Not used for elevation derivatives & 1 & $\begin{array}{l}\text { NHD feature (will be used for confla- } \\
\text { tion). }\end{array}$ \\
\hline Drainageway & 46800 & 3D line, polyline Z & 2 & $\begin{array}{l}\text { Hydrographic feature used for elevation } \\
\text { purposes, other than culverts or those } \\
\text { used for hydroflattening }\end{array}$ & 1 & $\begin{array}{l}\text { NHD feature (will be used for confla- } \\
\text { tion). }\end{array}$ \\
\hline Ice mass & 37800 & 3D polygon, polygonZ & 0 & Not used for elevation derivatives & 1 & $\begin{array}{l}\text { NHD feature (will be used for confla- } \\
\text { tion). }\end{array}$ \\
\hline Lake/pond & 39000 & 3D polygon, polygonZ & 1 & Used for hydroflattening & 1 & $\begin{array}{l}\text { NHD feature (will be used for confla- } \\
\text { tion). }\end{array}$ \\
\hline $\begin{array}{l}\text { Low-confidence area } \\
\text { (predetermined) }\end{array}$ & 991 & $\begin{array}{l}\text { 3D polygon, polygon } \mathrm{Z} \text { (accu- } \\
\text { rate } \mathrm{Z} \text {-values not required) }\end{array}$ & 9 & Elevation dataset limitation & 9 & $\begin{array}{l}\text { Nonhydrography feature (elevation } \\
\text { dataset limitation). }\end{array}$ \\
\hline $\begin{array}{l}\text { Low-confidence area } \\
\text { (snow covered) }\end{array}$ & 993 & $\begin{array}{l}\text { 3D polygon, polygonZ (accu- } \\
\text { rate } \mathrm{Z} \text {-values not required) }\end{array}$ & 9 & Elevation dataset limitation & 9 & $\begin{array}{l}\text { Nonhydrography feature (elevation } \\
\text { dataset limitation). }\end{array}$ \\
\hline
\end{tabular}


Table 8. Feature type description, associated geometry, and use classification.-Continued

[Desc, description; FCode, feature code; EClass, feature class (elevation); FClass, feature class; 3D, three dimensional; NHD, National Hydrography Dataset]

\begin{tabular}{|c|c|c|c|c|c|c|}
\hline \multicolumn{7}{|c|}{ Feature type descriptions, associated geometry, and coding } \\
\hline \multirow[b]{2}{*}{ Desc } & \multirow[b]{2}{*}{ FCode } & \multirow[b]{2}{*}{ Geometry type } & \multicolumn{2}{|r|}{ EClass } & \multicolumn{2}{|r|}{ FClass } \\
\hline & & & $\begin{array}{l}\text { Domain } \\
\text { value }\end{array}$ & Feature attribute & $\begin{array}{l}\text { Domain } \\
\text { value }\end{array}$ & Feature attribute \\
\hline $\begin{array}{r}\text { Low-confidence area } \\
\text { (sparse bare earth) }\end{array}$ & 992 & $\begin{array}{l}\text { 3D polygon, polygon } Z \text { (accu- } \\
\text { rate } \mathrm{Z} \text {-values not required) }\end{array}$ & 9 & Elevation dataset limitation & 9 & $\begin{array}{l}\text { Nonhydrography feature (elevation } \\
\text { dataset limitation). }\end{array}$ \\
\hline \multirow[t]{2}{*}{ Pipeline } & 42800 & $\begin{array}{l}\text { 3D line, polylineZ (does not } \\
\text { connect primary network } \\
\text { features) }\end{array}$ & 0 & Not used for elevation derivatives & 1 & $\begin{array}{l}\text { NHD feature (will be used for confla- } \\
\text { tion). }\end{array}$ \\
\hline & & $\begin{array}{l}\text { 3D line, polylineZ (creates } \\
\text { network connectivity) }\end{array}$ & 2 & $\begin{array}{l}\text { Hydrographic feature used for elevation } \\
\text { purposes, other than culverts or those } \\
\text { used for hydroflattening }\end{array}$ & 1 & $\begin{array}{l}\text { NHD feature (will be used for confla- } \\
\text { tion). }\end{array}$ \\
\hline Playa & 36100 & $3 \mathrm{D}$ polygon, polygonZ & 0 & Not used for elevation derivatives & 1 & $\begin{array}{l}\text { NHD feature (will be used for confla- } \\
\text { tion). }\end{array}$ \\
\hline \multirow[t]{2}{*}{ Reservoir } & 43600 & Polygon (less than 2 acres) & 0 & Not used for elevation derivatives & 1 & $\begin{array}{l}\text { NHD feature (will be used for confla- } \\
\text { tion). }\end{array}$ \\
\hline & & $\begin{array}{l}\text { Polygon (greater than or equal } \\
\text { to } 2 \text { acres) }\end{array}$ & 1 & Used for hydroflattening & 1 & $\begin{array}{l}\text { NHD feature (will be used for confla- } \\
\text { tion). }\end{array}$ \\
\hline Sea/ocean & 44500 & 3D polygon, polygonZ & 1 & Used for hydroflattening & 1 & $\begin{array}{l}\text { NHD feature (will be used for confla- } \\
\text { tion). }\end{array}$ \\
\hline Sink/rise & 45000 & 3D point, point $Z$ & 0 & Not used for elevation derivatives & 1 & $\begin{array}{l}\text { NHD feature (will be used for confla- } \\
\text { tion). }\end{array}$ \\
\hline \multirow[t]{2}{*}{ Stream/river } & 46000 & 3D line, polylineZ & 2 & $\begin{array}{l}\text { Hydrographic feature used for elevation } \\
\text { purposes, other than culverts or those } \\
\text { used for hydroflattening }\end{array}$ & 1 & $\begin{array}{l}\text { NHD feature (will be used for confla- } \\
\text { tion). }\end{array}$ \\
\hline & & 3D polygon, polygonZ & 1 & Used for hydroflattening & 1 & $\begin{array}{l}\text { NHD feature (will be used for confla- } \\
\text { tion). }\end{array}$ \\
\hline
\end{tabular}




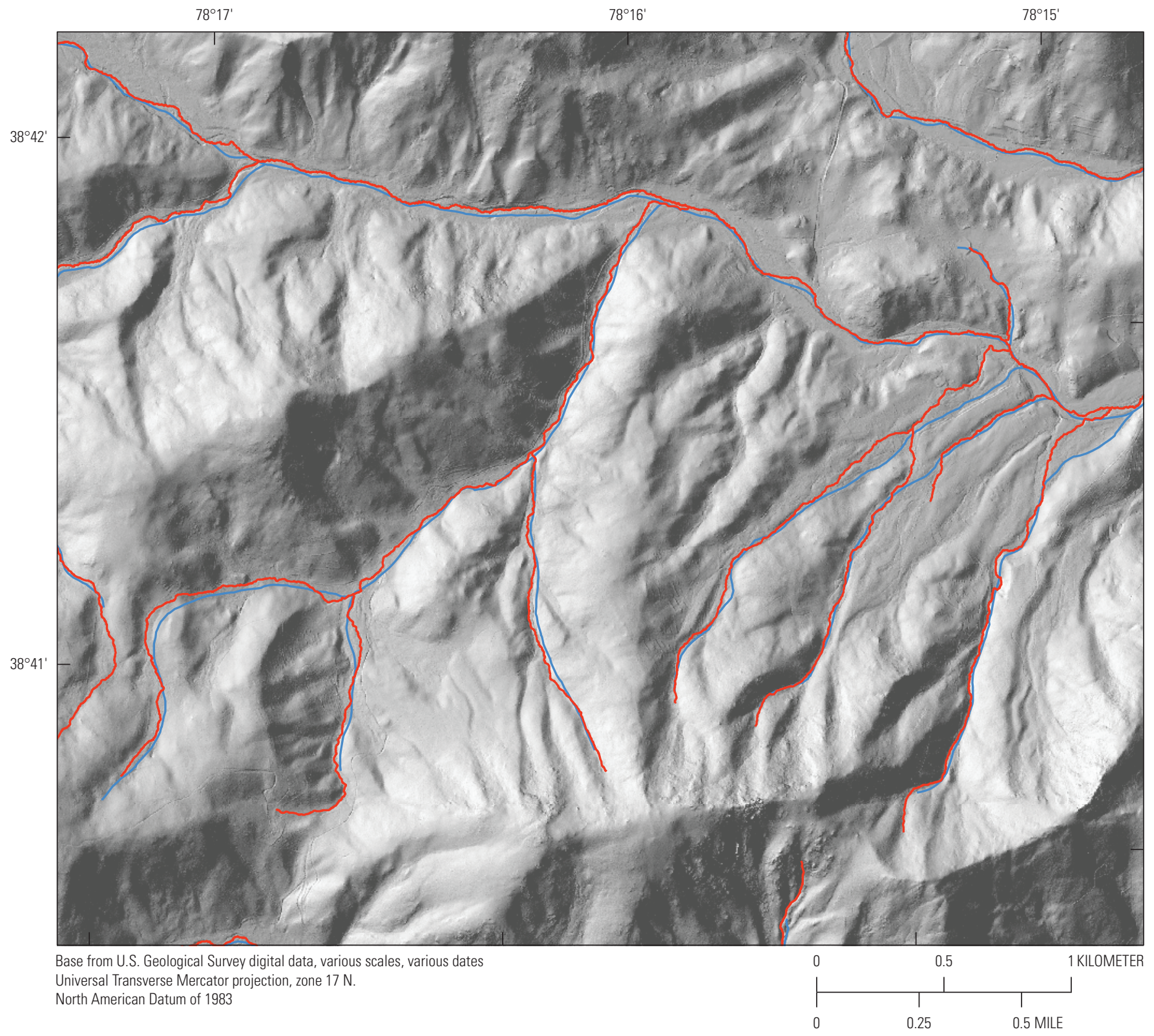

EXPLANATION

[NHD, National Hydrography Dataset]

Original NHDFlowline

Elevation-derived hydrography

Figure 3. Minimum set of hydrographic features compared to the original National Hydrography Dataset.

to discern which of the apparent channels are actual hydrographic features. Geology, topographic position, climate, soil types, and land cover are some of the factors that determine if a stream forms on the landscape. These factors are complex and difficult to model, so simpler methods have been developed to generate a hydrography network from an elevation surface. The most common automated process delineates a flowline solely based on flow from one cell to another, at a minimum flow accumulation, or drainage area threshold.
Because the flow accumulation threshold process does not include other geomorphic, climatic, or landscape characteristics, it is not a recommended method for stream delineation. To capture features that are likely to be true hydrographic features, additional features must be collected with some criteria other than solely a minimum drainage area requirement.

Features shall be visible on the elevation surface to be included as a hydrographic feature (fig. 4). If features are not visible in the elevation surface but are present in ancillary 


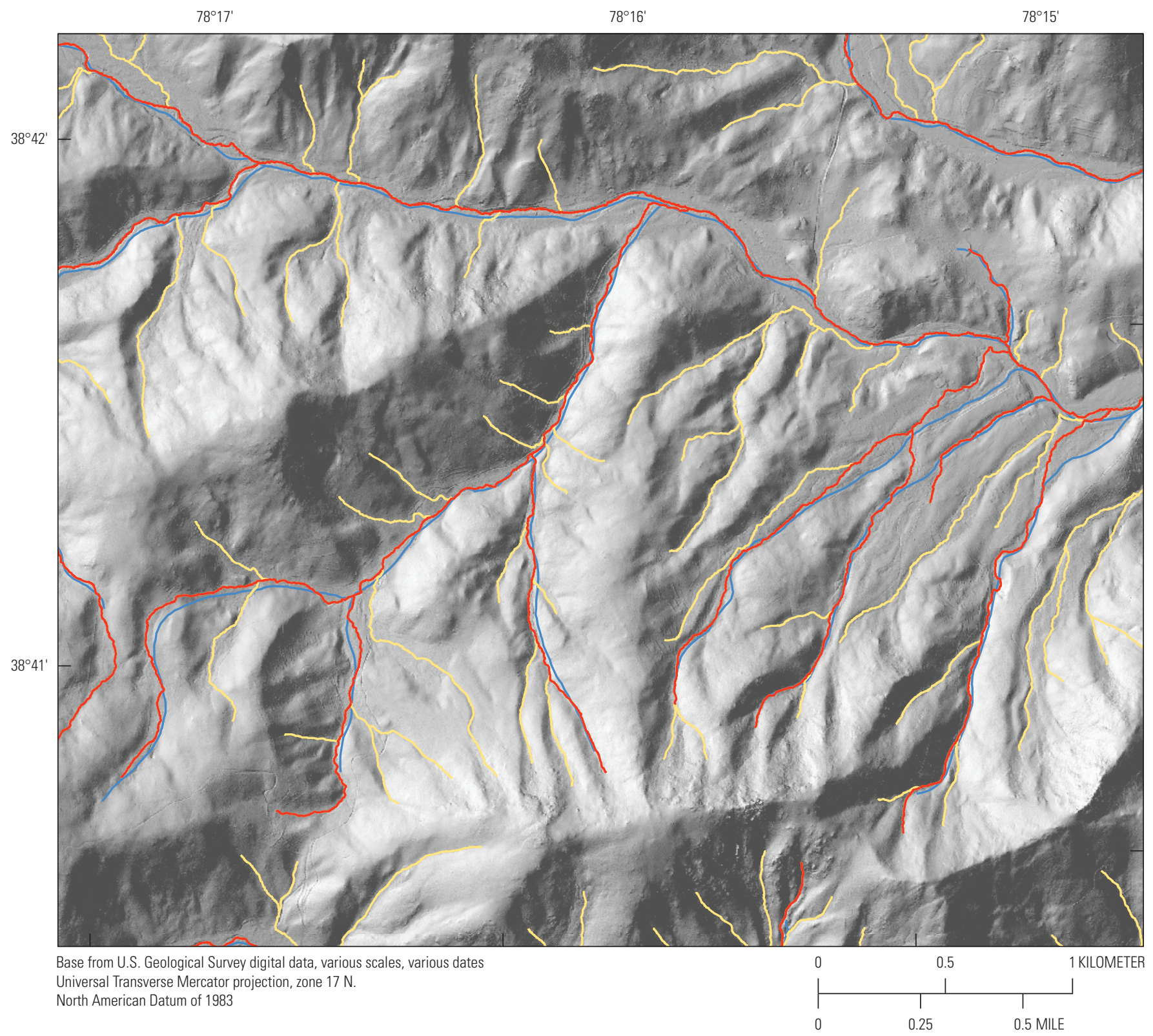

EXPLANATION

[NHD, National Hydrography Dataset]

Original NHDFlowline

Elevation-derived hydrography

Elevation-derived hydrography—Additional features

Figure 4. Additional features with visible channels captured from the light detection and ranging-derived elevation surface.

sources such as aerial orthoimagery or other imagery (see table 9 for commonly used ancillary data sources), a hydrographic feature that follows the most likely location within the elevation surface may be delineated. If features (such as a culvert, underground pipe, or other subsurface feature) are not visible in the elevation data, imagery, or other sources but are necessary to connect a hydrologic network (that is not a valid isolated network), they shall be collected.

Collection criteria include the following:

- Visible on DEM or; 
Table 9. Examples of acceptable ancillary datasets.

[NHD, National Hydrography Dataset; EDH-AS, Elevation-Derived Hydrography Acquisition Specifications; FCode, feature code; $\leq$, less than or equal to; DOT, Department of Transportation]

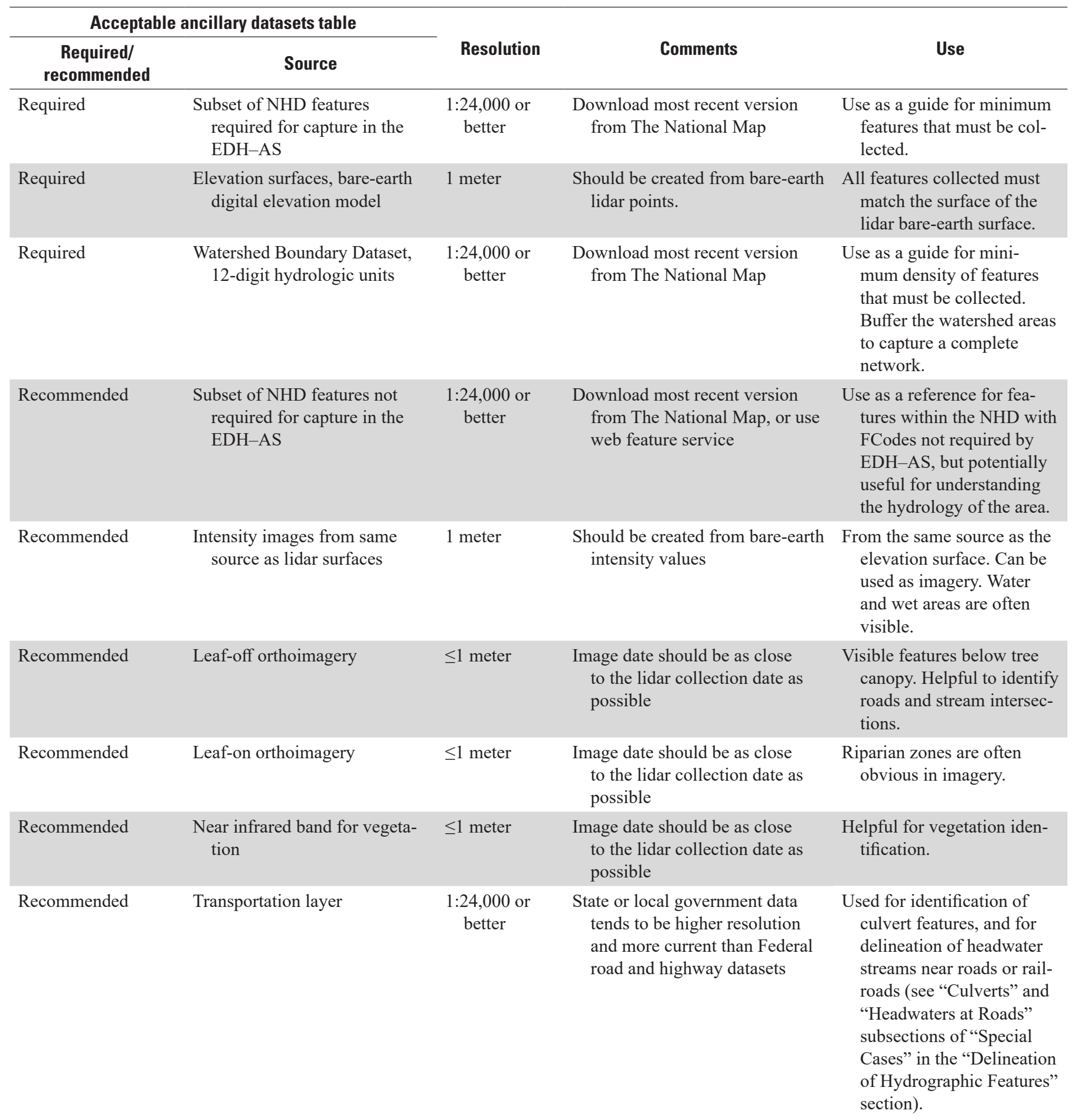


Table 9. Examples of acceptable ancillary datasets.-Continued

[NHD, National Hydrography Dataset; EDH-AS, Elevation-Derived Hydrography Acquisition Specifications; FCode, feature code; $\leq$, less than or equal to; DOT, Department of Transportation]

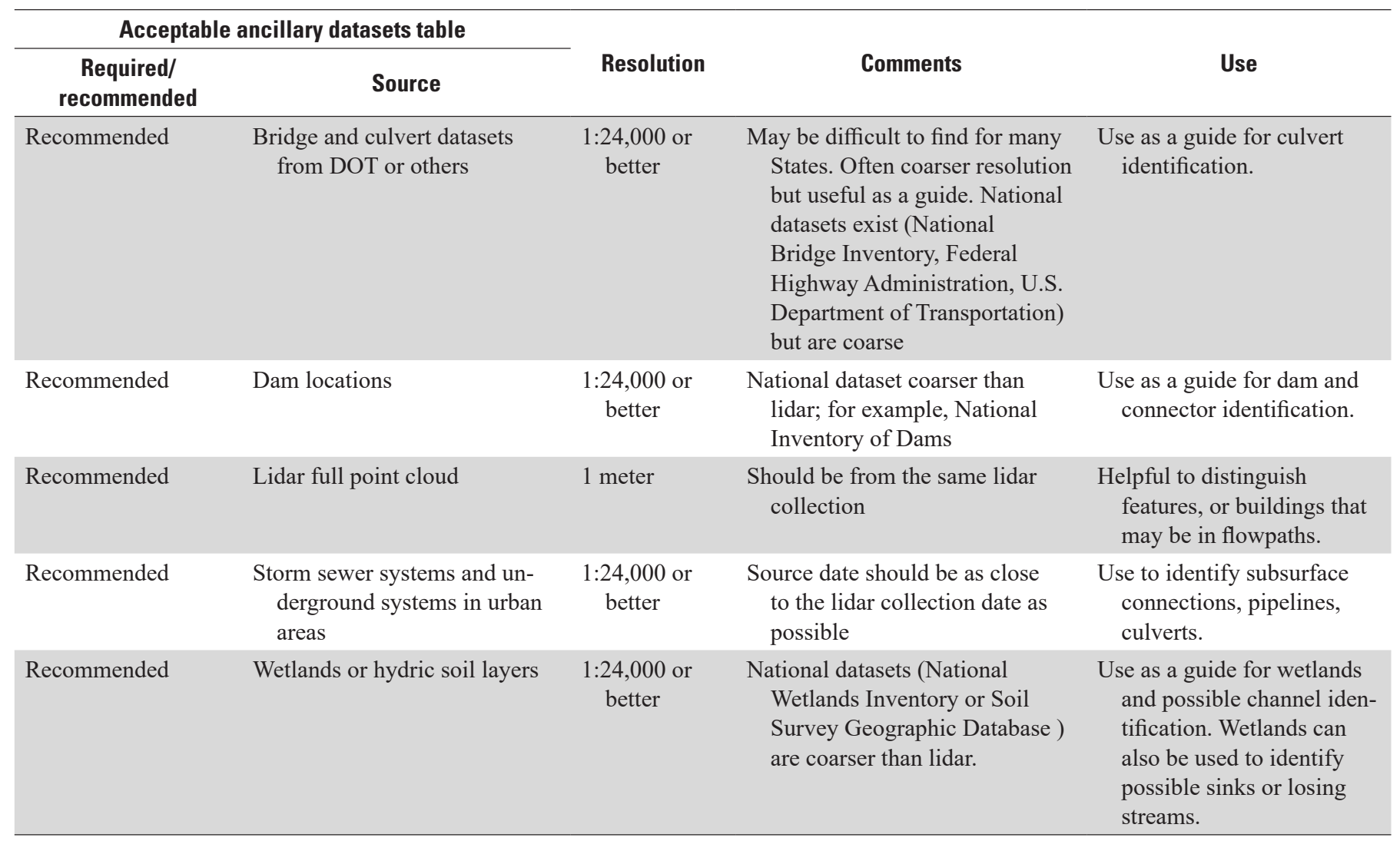

- Not visible on DEM but present in the ancillary data source or;

- Not visible on DEM or ancillary data source but necessary to connect a hydrologic network, and other evidence indicates this is not a valid isolated network.

The method used to define feature extents must be identified in the method field. Examples include a regression model to determine headwaters, curvature (or other geomorphic algorithm) to delineate stream reaches, or flow direction and accumulation of a drainage path. The features should be compared to the 3DEP bare-earth elevation surface to check the accuracy of the method used. A feature shall be coded with one of the FCodes described in the "Feature Codes and Values" section. If the delineation method is not able to identify the feature type, the drainageway code can be used for features that require further distinction.

\section{Ancillary Data Sources}

Several ancillary data sources can be useful for helping identify and classify features. Datasets that should be considered to aid delineation and feature coding are listed in table 9. If lidar data accuracy is reported to be greater than the ancillary data accuracy, ancillary data should be used as a guide for feature inclusion and classification and not for positional accuracy.

\section{Special Cases}

There are several special cases that need further clarification when delineating hydrographic features. Certain conditions require guidance to maintain a consistent set of features or to avoid issues with connectivity, network navigation, or elevation surface treatments. These five special cases are not exhaustive but may be used as a guide for other related issues that may arise.

\section{2-Digit Hydrologic Unit Consistency}

The original NHD was digitized from individual 7.5-minute quadrangle map sheets that were compiled at different times, by many individuals, using varied sources; therefore, some areas of the country have hydrography that is represented at different densities. These discrepancies are due to differing source material or standards and procedures and are not due to differences in geomorphology or hydrologic conditions (fig. 5). To create a more consistent and 
representative depiction of the national hydrography, new features shall be collected within 12-digit hydrologic unit boundaries and inconsistencies in line density shall be made consistent with the most densely collected part of the 12-digit hydrologic unit (fig. 6).

In cases where actual geologic formations create an abrupt change in hydrology, professional judgement shall be used to capture the appropriate density of features. In cases where a prior local resolution or lidar-derived project exists, a similar discontinuity between features can occur. These discrepancies are often detected along a county or other political boundary (fig. 7). The same rules would apply as those with quadrangle-line differences: linework shall match the densest area of hydrography within a 12-digit hydrologic unit. Where geomorphology, geology, or other terrain features create actual differences in stream density, the natural representation of features that depicts the disparity in density should be captured.

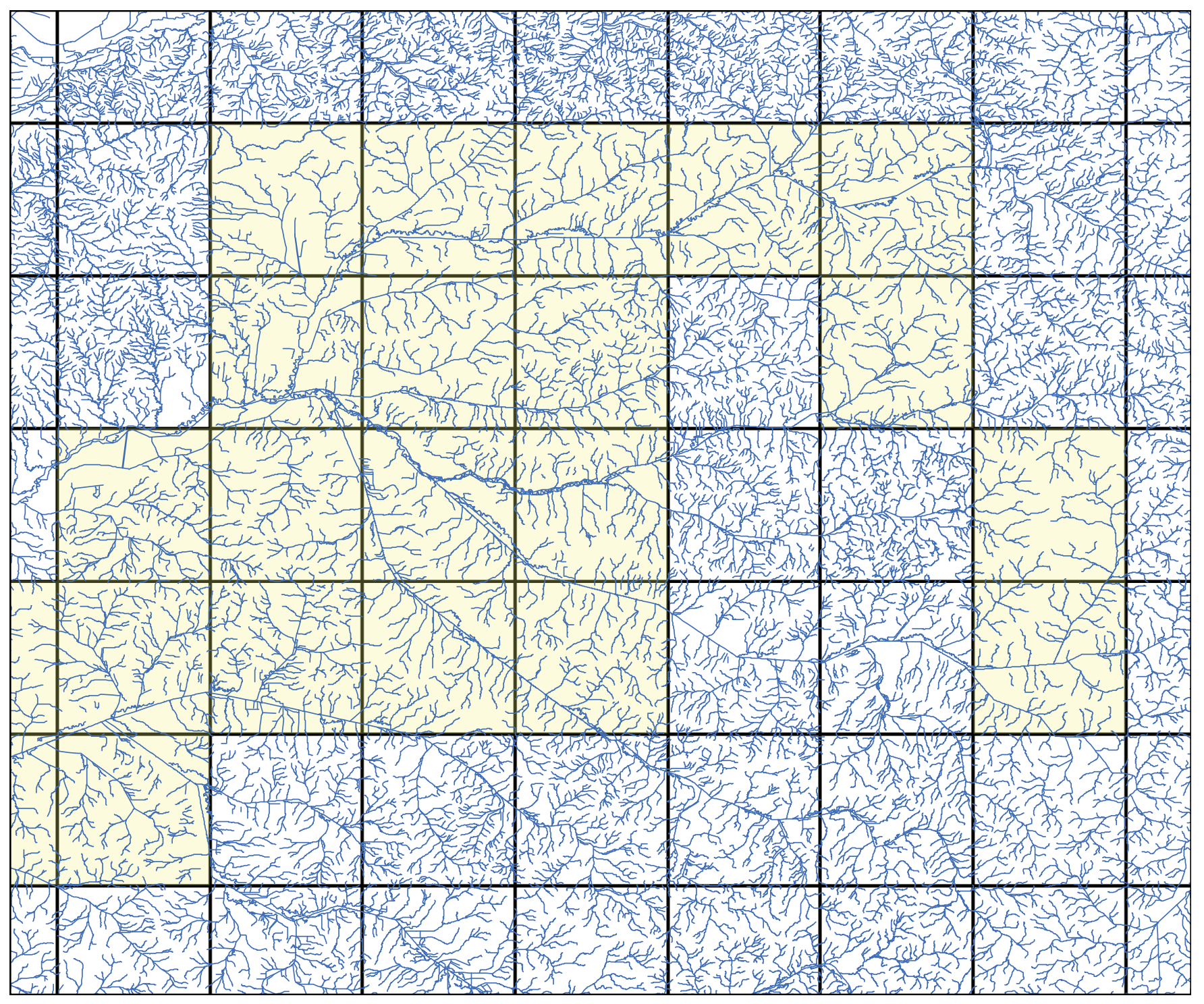

EXPLANATION

[USGS, U.S. Geological Survey; NHD, National Hydrography Dataset]

Density disparity by quadrangle boundary

USGS 1:24,000-scale topographic map boundary

NHDFlowline

Figure 5. Artifacts within National Hydrography Dataset density inherited from original quadrangle map delineation of hydrography. 
If a geographic area, particularly an urban area, has an extremely dense stream network collected to meet local needs, some flexibility may be warranted in matching to the density of the extremely detailed hydrographic network. A less detailed depiction of adjacent areas is allowed, but connectivity with major networks shall be maintained.

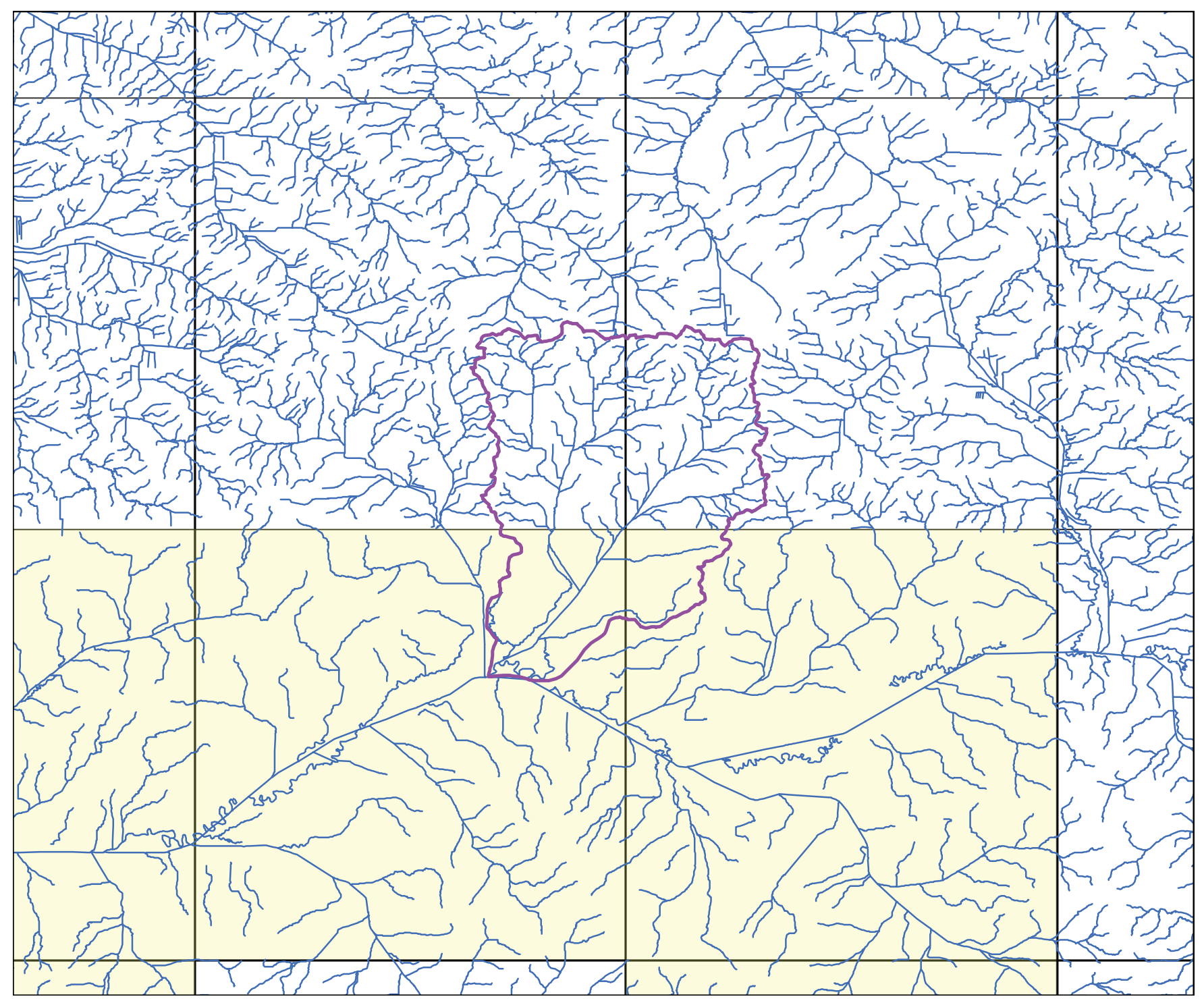

\section{EXPLANATION}

[USGS, U.S. Geological Survey; NHD, National Hydrography Dataset; WBD, Watershed Boundary Dataset; HU12, 12-digit hydrologic unit]

\section{Density disparity by quadrangle boundary}

USGS 1:24,000-scale topographic map boundary

NHDFlowline

\section{WBD HU12}

Figure 6. The hydrography within the southern quadrangles of this 12-digit hydrologic unit must be densified to be consistent with the northern quadrangles. 


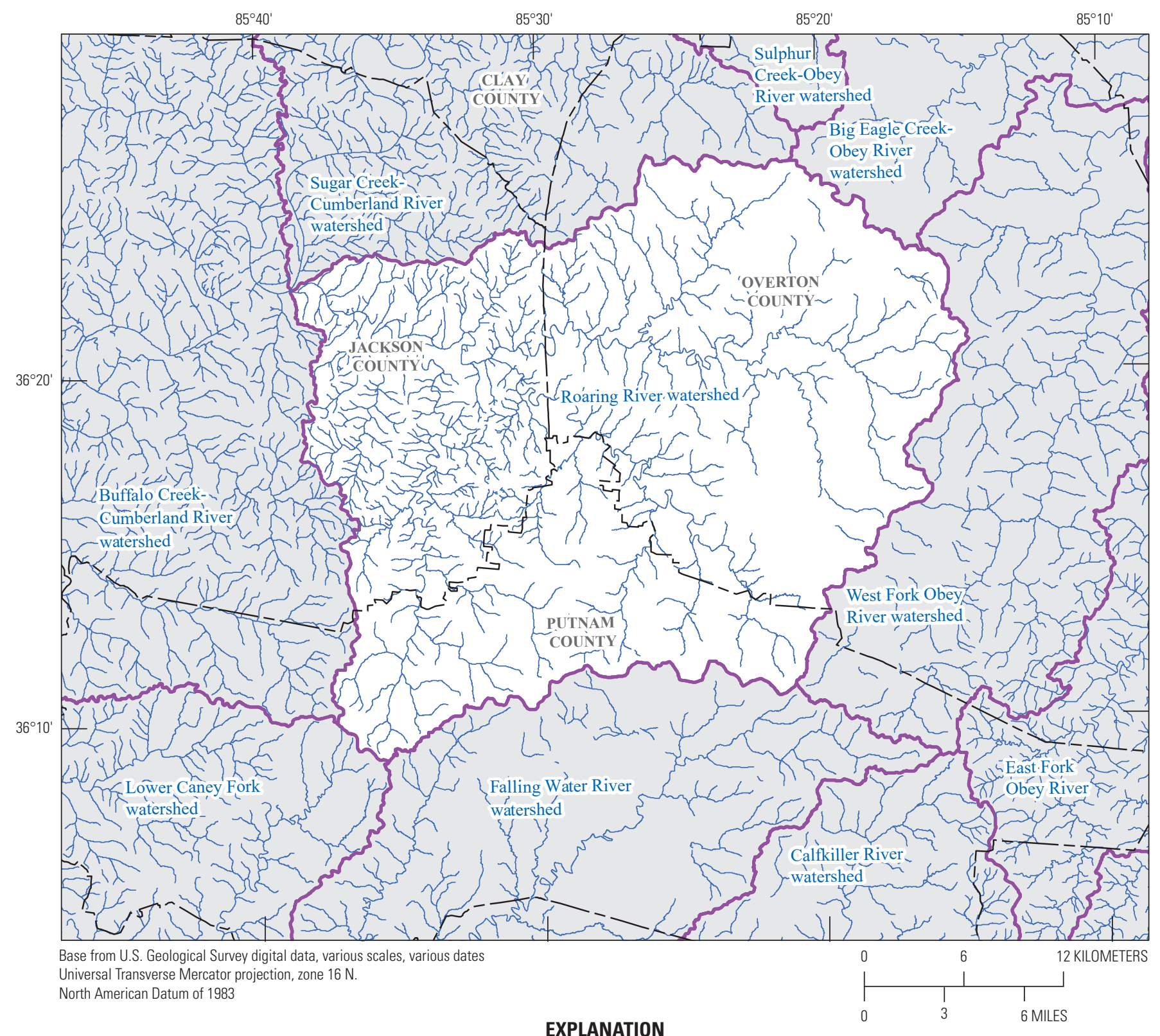

[WBD, Watershed Boundary Dataset;

HU10, 10-digit hydrologic unit;

NHD, National Hydrography Dataset]

WBD HU10 watershed boundary

County boundary

NHDFlowline

Figure 7. The streams within the Roaring River watershed indicate density disparity because of the collection differences between Jackson, Overton, and Putnam Counties, Tennessee.

\section{Culverts}

The hydrographic features defined by this specification are intended to be suitable for elevation surface treatments such as hydroenforcement. A hydroenforced elevation surface is used to model the flow of water over the surface. For a surface to be suitable to model the flow of water, areas within a bare-earth DEM that create a blockage to flow through the surface must be removed. The most common surface features that block flow across a DEM are roads or railroads. Finding 
the location of culverts and small bridges within a surface beneath transportation corridors or other features is a critical step in hydroenforcement.

In figure 8 , the black lines illustrate the direction of flow over the surface without hydroenforcement (fig. 8A) and after the culverts (in red) are used to hydroenforce the surface (fig. $8 B$ ). The drainage area that flows into the upstream and downstream points of the stream segment highlighted in blue is substantially affected by hydroenforcement with culverts. The modeled drainage area flowing into the segment changes
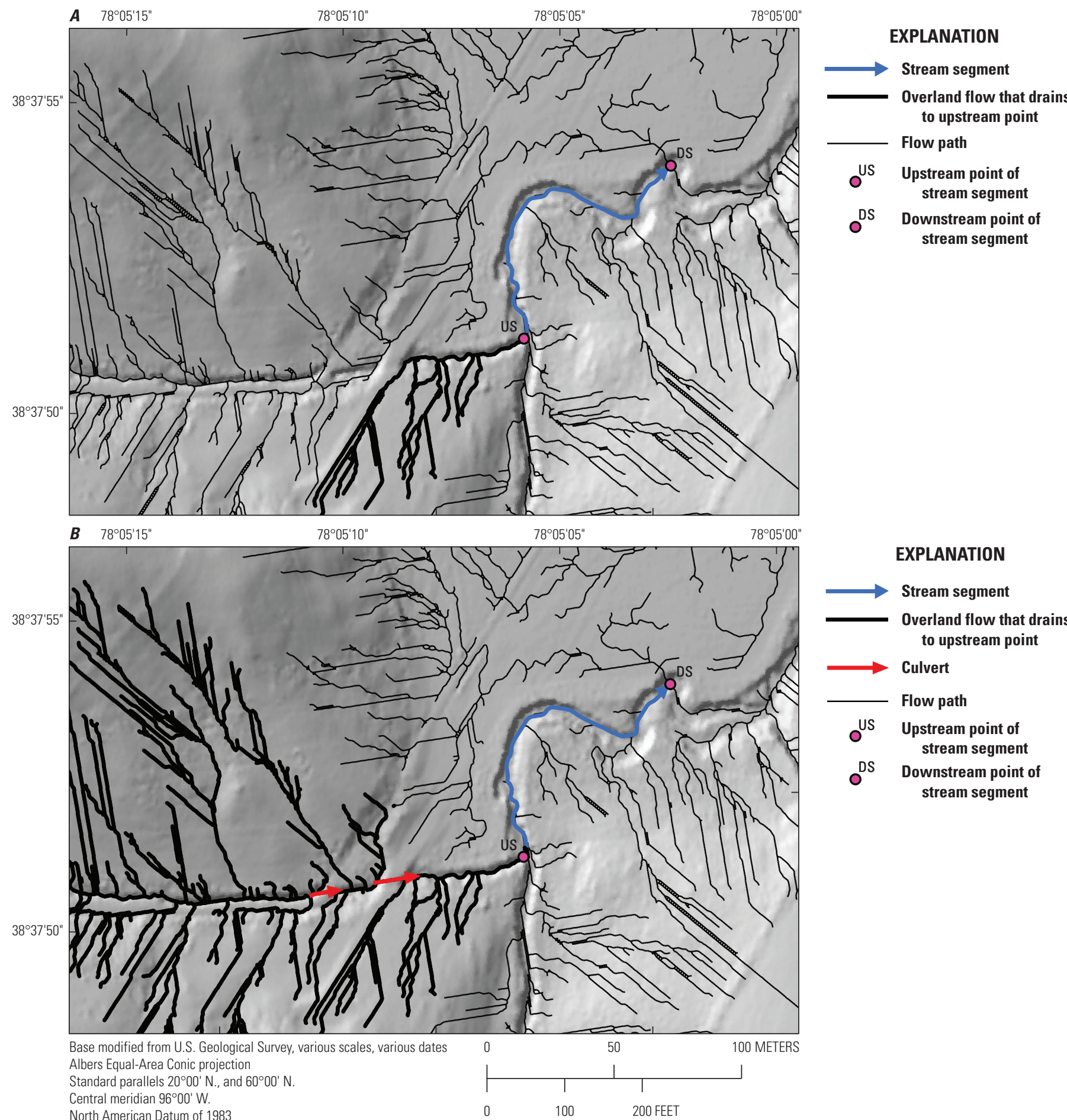

$78^{\circ} 05^{\prime} 05^{\prime \prime}$
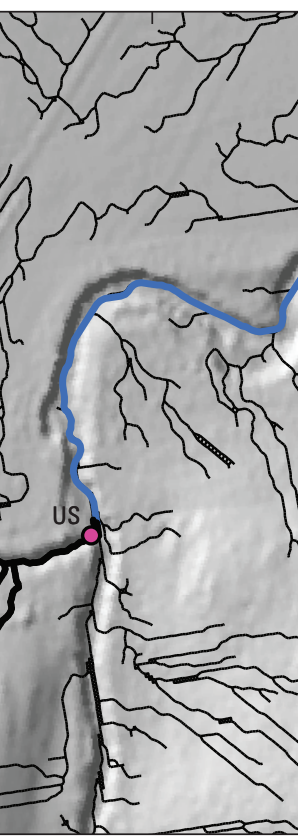
Table 10. Example of the effect of culverts for hydroenforcement on drainage area calculations.

\begin{tabular}{lcc}
\hline \multirow{2}{*}{ Location } & \multicolumn{2}{c}{ Acres draining to stream segment } \\
\cline { 2 - 3 } & No hydroenforcement & With hydroenforcement of culverts \\
\hline Upstream & 2 & 43 \\
Downstream & 51 & 10 \\
\hline
\end{tabular}

from 2 to 43 acres at the upstream point after hydroenforcement and from 51 to 10 acres entering at the downstream point (table 10).

The LBS has specific instructions for the removal of bridge features from a bare-earth DEM. All bridges should be removed, and water surfaces shall be continuous beneath them. The most important criteria from the LBS for this specification are as follows:

- The bare-earth surface below the bridge shall be a continuous, logical interpolation of the apparent terrain lateral to the bridge deck.

- Streams, rivers, and waterbodies meeting the criteria for hydroflattening shall be monotonically continuous where bridge decks have been removed.

- Bridges, as defined in the glossary, shall be removed from the bare-earth surface.
The removal of surface points at bridges ensures that water features beneath bridges are continuous and shorelines are followed, not the edges of a bridge feature (fig. 9).

The LBS excludes culverts from required elevation surface treatment. It is not always possible to distinguish a culvert from a bridge on a small stream. Bridges are primarily used to cross wide streams and rivers, but many small rivers also are crossed by bridges. The LBS states that "when the identification of a structure as a bridge or culvert cannot be made definitively, the feature shall be regarded as a culvert" (Heidemann, 2018, p. 16). This is also the rule for the purposes of this specification: when a transportation feature crosses a hydrography feature, and it is impossible to determine whether the feature is a bridge or culvert, the feature will be treated as a culvert.

The LBS explains how culverts are coded differently from other hydrographic features. "In the NHD, a stream passing through a culvert under a road fill is not broken out as a separate line; it remains coded as a stream. For elevation purposes, the culvert portion must be differentiated from

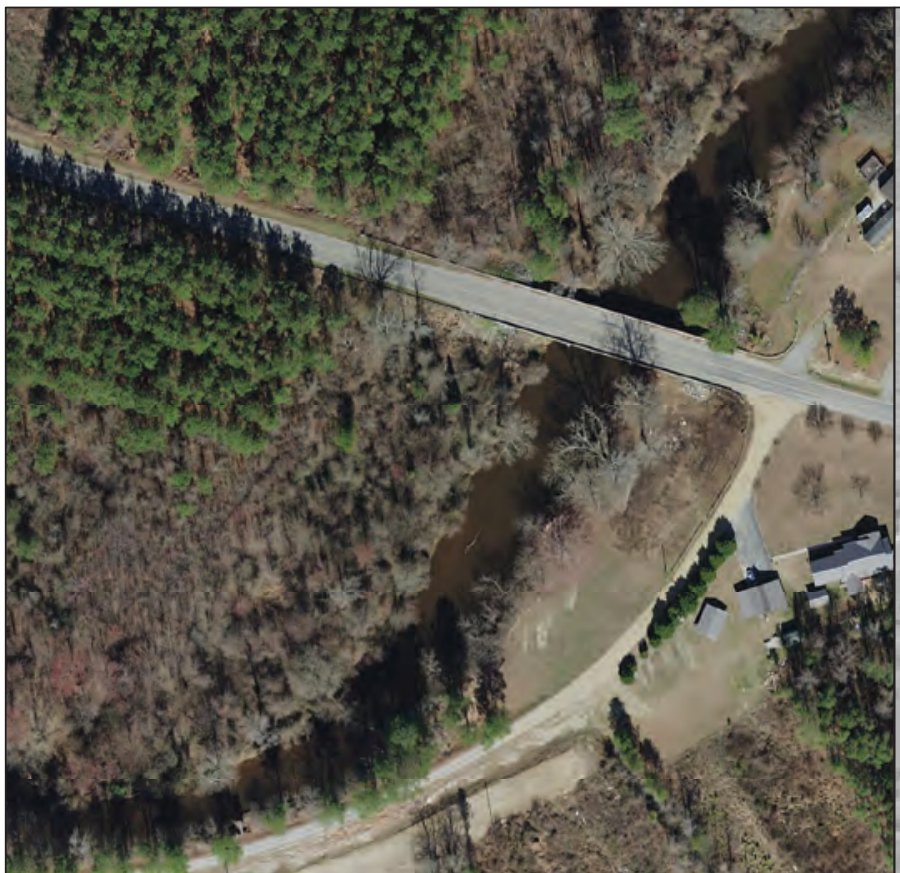

Base modified from U.S. Geological Survey digital data North Carolina OneMap, North Carolina Center for Geographic Information and Analysis North Carolina 911 Board

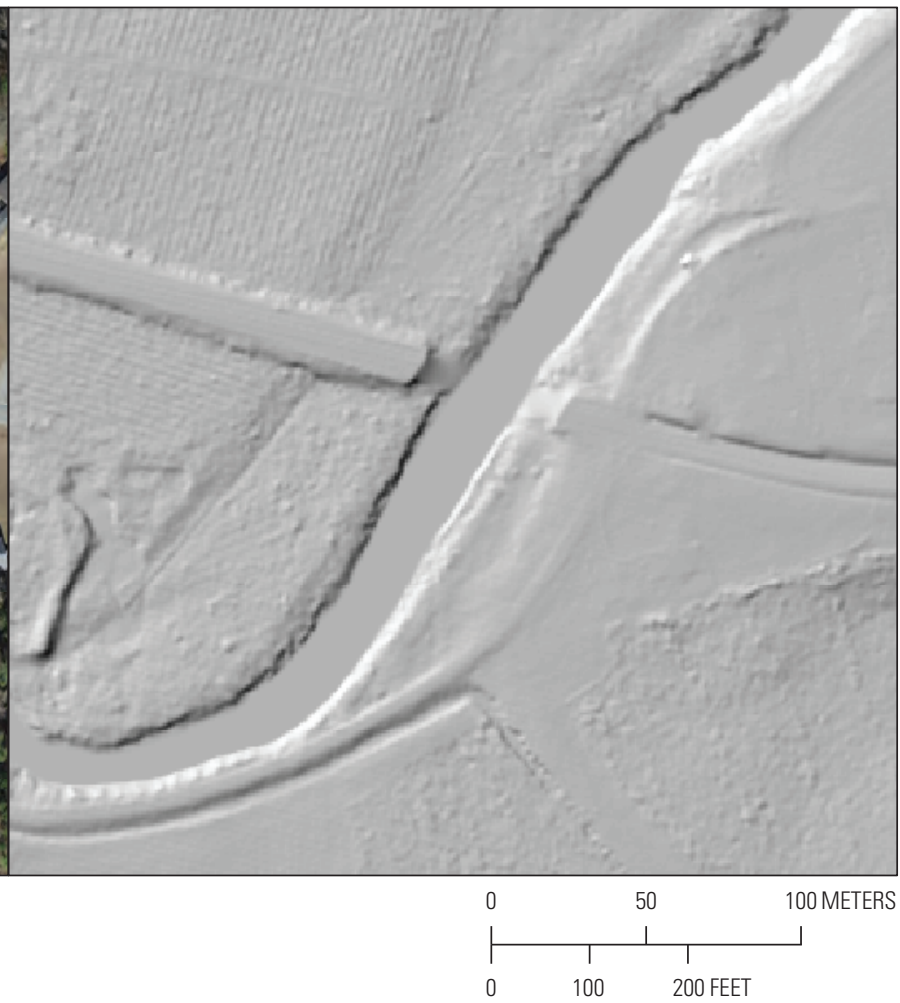

Figure 9. Bridge treatment in the bare-earth digital elevation model. The bridge deck is removed, and water surface is interpolated beneath the bridge to maintain a monotonic, continuous water feature. 
the stream; thus, for collection, a culvert must be a separate feature, nodematched (snapped) at each end to the up and downstream stream features. Elevation attribution will identify the culvert separately; NHD attribution will be the same for both the streams and the culvert, allowing the NHD to merge the features and thereafter use them in the traditional NHD manner." (Heidemann, 2018, p. 19).

\section{Delineation}

An important aspect of delineating a culvert is to extend the segment completely across the transportation feature that is blocking overland flow. If the culvert does not extend across the higher elevation part of the DEM, hydroenforcement may fail at that location. Creating a shaded relief representation of the surface helps to visualize the low points on the surface where a culvert is likely to be. Additionally, processing the surface using hydrologic "pit filling" tools and analyzing the resulting filled areas, particularly near roads, can help to identify locations requiring culvert delineation. A correctly delineated culvert feature is shown in figure 10. The proper coding of the culvert feature is provided in table 11.

\section{FCode Assignment}

The FCode value of a culvert is dependent on the connecting feature type that flows into or out of the culvert. Only linear features (artificial path, canal/ditch, connector, drainageway, pipeline, and stream/river) may contain culverts. Culverts within a drainageway should be a rare occurrence because "little to no apparent channel" defines a drainageway feature, and therefore, it would be unlikely to have the precision needed to identify a culvert location within the segment.

In general, a culvert maintains the FCode value of the features it is connecting. There are, however, many cases in which the culvert connects two features of different types. As summarized in table 12, the FCode value for a culvert feature is based on the priority ranking of the features separated by the culvert. Feature types not included in the table (area of complex channels, dam/weir, ice mass, playa, reservoir, sea/ ocean, and sink/rise) do not typically contain a culvert. If there is an exception, the culvert FCode should be assigned the connector FCode (33400).

Listed in table 12 is the priority for choosing the FCode for the culvert feature when the FCode changes from one feature type to another as the water passes through

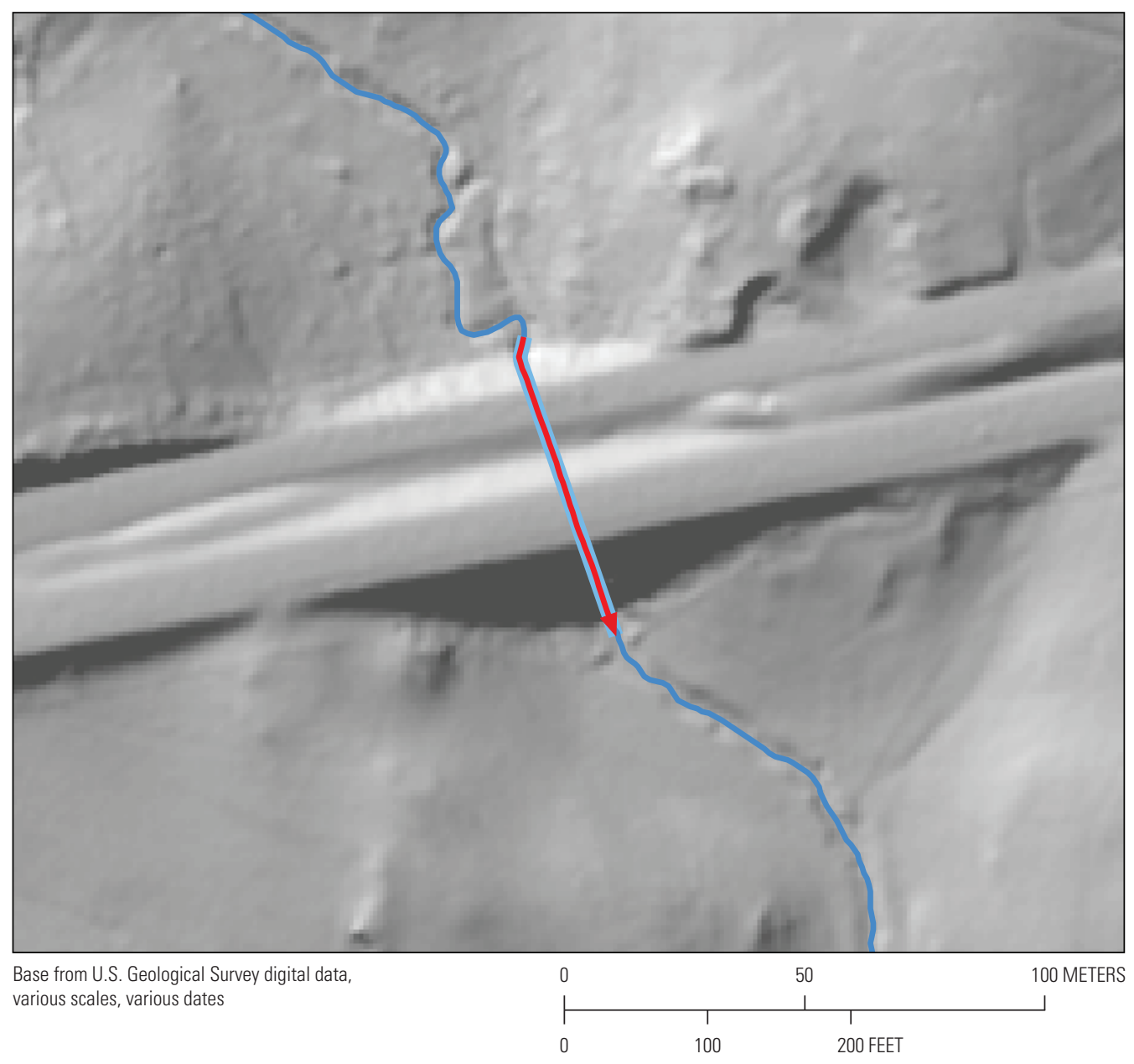

\section{EXPLANATION}

\section{Elevation-derived hydrography}

Stream/river

Stream/river culvert

Figure 10. Proper delineation of a culvert feature within a stream segment. 
Table 11. Example of correct coding for a culvert that spans two stream/river segments.

[FClass, feature class; EClass, feature class (elevation); FCode, feature code; Desc, description; NHD, National Hydrography Dataset]

\begin{tabular}{cccccc}
\hline & FClass & & EClass & FCode & Desc \\
\cline { 1 - 2 } $\begin{array}{c}\text { Domain } \\
\text { value }\end{array}$ & Feature attribute & Domain value & Feature attribute & Stream/river \\
\hline 1 & $\begin{array}{c}\text { NHD feature (will be used for } \\
\text { conflation) }\end{array}$ & 3 & $\begin{array}{c}\text { Culvert-used for hydroenforce- } \\
\text { ment }\end{array}$ & 46000 \\
\hline
\end{tabular}

the culvert. The priority established in table 12 considers the hydrologic modification that culverts create. Canals, pipelines, and connectors tend to function more like a culvert than natural hydrologic features, so they should be used as the FCode value if adjoining a culvert (see "priority ranking for two features separated by a culvert," table 12; fig. 11). In the case where one of the features separated by a culvert is a polygon, the FCode of the linear feature should be used as the culvert FCode: an artificial path may not be assigned to a linear feature outside a polygon. If a feature contains a culvert within a polygon, the artificial path within the polygon is split at the culvert location and is coded with the EClass for culvert and FCode for artificial path; the polygon is not split. Examples are shown in figures 12-15.

There may also be occurrences where multiple features converge upstream or diverge downstream from a culvert feature. In these cases, it is important to retain the primary feature within the flow network. Primary features are ranked in level of importance as follows: (1) stream/river, (2) canal/ ditch, (3) pipeline, and (4) connector (see "priority ranking for more than two features separated by a culvert," table 12). For example, where a stream/river and canal both enter a culvert at the same point, and both exit the culvert, the culvert should retain the stream/river FCode of 46000 . If a canal and pipeline both enter and exit a culvert at the same point, the culvert should retain the canal FCode of 33600. Artificial paths and drainageway features should rarely occur at an intersection with three or more line features, but if this happened, the priority ranking would still apply (fig. 11). In cases where multiple features enter and exit the culvert but no feature is present both upstream and downstream from the culvert, the priority ranking for two features with different FCodes in table 12 should be used to assign the FCode to the culvert (fig. 11).

When a culvert is within a polygon feature that is not hydroflattened (primarily stream/river polygon feature less than $30 \mathrm{~m}$ wide), the stream/river polygon will not be broken by the transportation feature. The culvert shall be identified as part of the artificial path that connects the artificial path of the upstream polygon to the downstream artificial path (fig. 14). The culvert segment shall be coded as shown in table 13. The upstream and downstream segments of the artificial path will

Table 12. Attribution rules for culvert feature code when two features are connected by a culvert.

[When a culvert separates two features with different FCodes, the FCode of the culvert should be coded based on the "priority ranking for two features separated by a culvert" ranked list. Whichever one of the two features separated by a culvert has a higher priority on the list should be used as the FCode for the culvert. When a culvert separates more than two features that form a confluence or divergence, maintain the connection of the primary feature. If no feature exists on both sides of the culvert, follow priority ranking for two features separated by a culvert, else the FCode of the culvert should be coded based on the "priority ranking for more than two features separated by a culvert" ranked list. FCode, feature code]

\begin{tabular}{|c|c|c|}
\hline Ranked priority & Feature & FCode \\
\hline \multicolumn{3}{|c|}{ Priority ranking for two features separated by a culvert } \\
\hline 1 & Connector & 33400 \\
\hline 3 & Canal/ditch & 33600 \\
\hline 4 & Stream/river & 46000 \\
\hline \multicolumn{3}{|c|}{ Priority ranking for more than two features separated by a culvert } \\
\hline 1 & Stream/river & 46000 \\
\hline 2 & Canal/ditch & 33600 \\
\hline 3 & Pipeline & 42800 \\
\hline
\end{tabular}




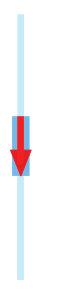

Culvert should be coded with FCode $=$ stream/river

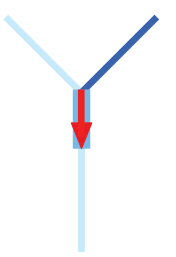

Culvert should be coded with $\mathrm{FCode}=$ stream $/$ river

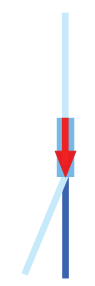

Culvert should be coded with FCode $=$ stream $/$ river

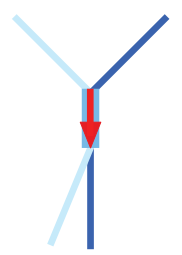

Culvert should be coded with FCode $=$ stream $/$ river

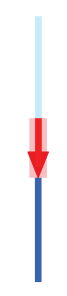

Culvert should be coded with FCode $=$ canal $/$ ditch

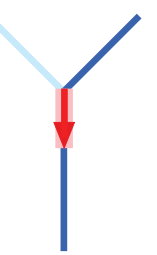

Culvert should be coded with FCode $=$ canal/ditch

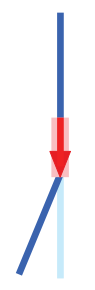

Culvert should be coded with FCode $=$ canal $/$ ditch

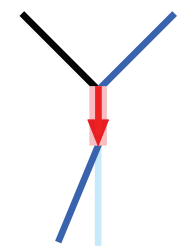

Culvert should be coded with FCode $=$ canal/ditch
Culvert should be coded with FCode $=$ canal $/$ ditch

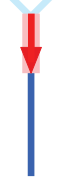

Culvert should be coded with FCode $=\mathrm{canal} / \mathrm{ditch}$ Reverts to two features with different codes

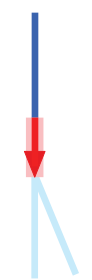

Culvert should be coded with FCode $=$ canal $/$ ditch Reverts to two features with different codes

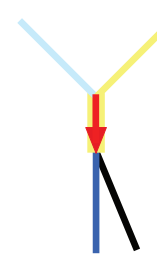

Culvert should be coded with FCode = connector Reverts to two features with different codes

\section{EXPLANATION}

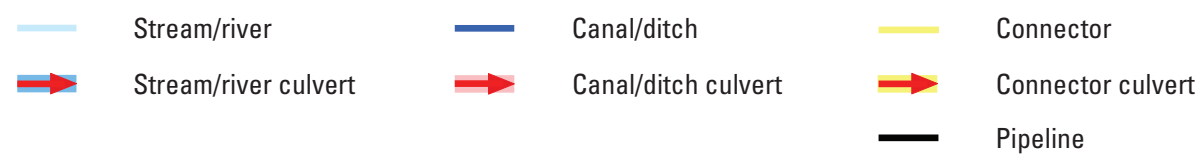

Figure 11. Schematic drawing of culverts within a hydrologic network. Examples of feature code (FCode) attribution for culverts based on adjoining features. 


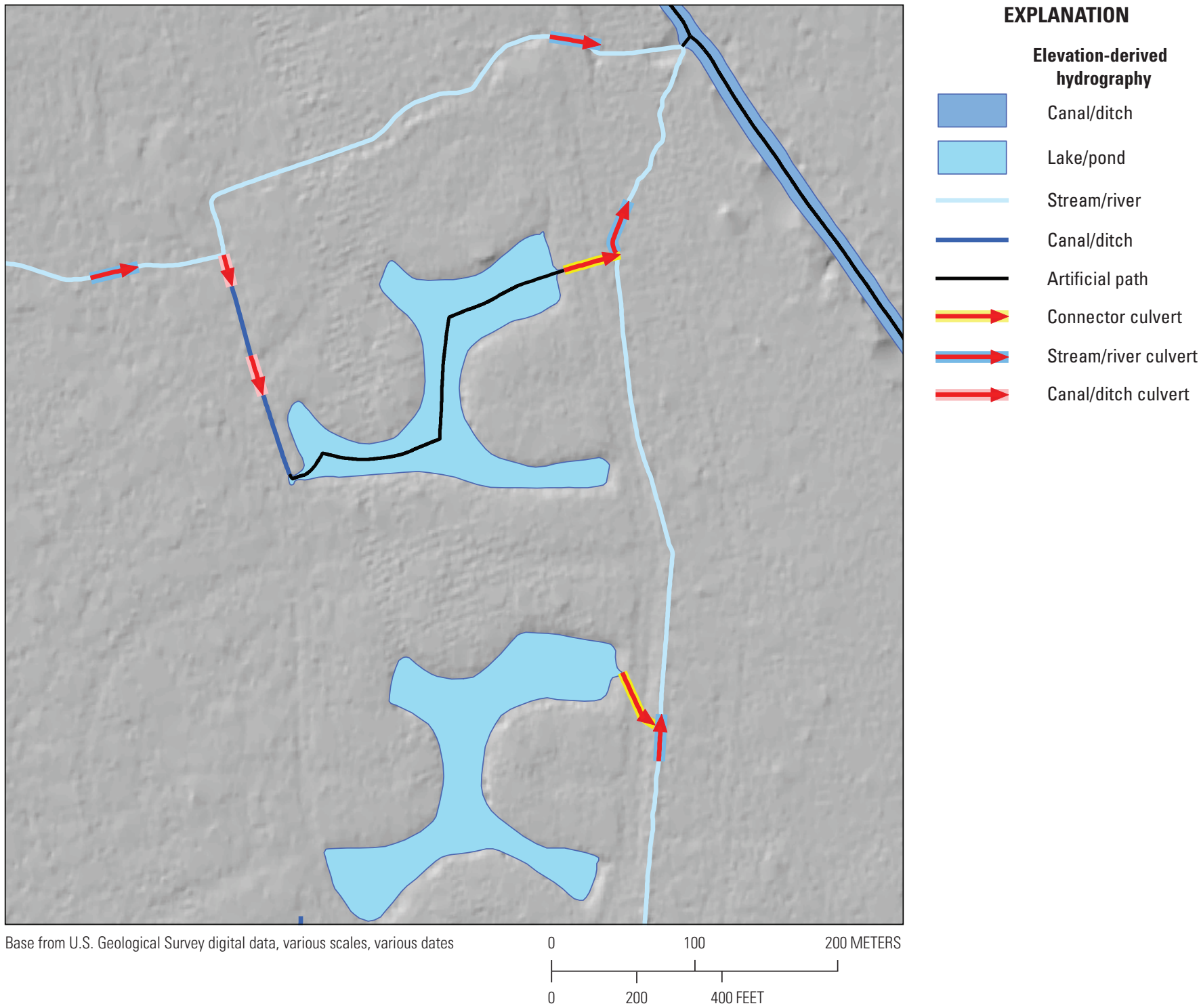

Figure 12. Examples of culverts within a hydrographic network. Lake/pond, stream/river, canal, and connector.

be coded as shown in table 14. The stream/river polygon will be coded as shown in table 15 . When a lake/pond is connected to a downstream feature by a culvert that traverses a transportation feature or levee, the connecting culvert will be coded as FCode 33400, connector, and EClass 3, culvert (fig. 15). The culverts, shown as red lines in figure $15 B$, will be coded as shown in table 16. 


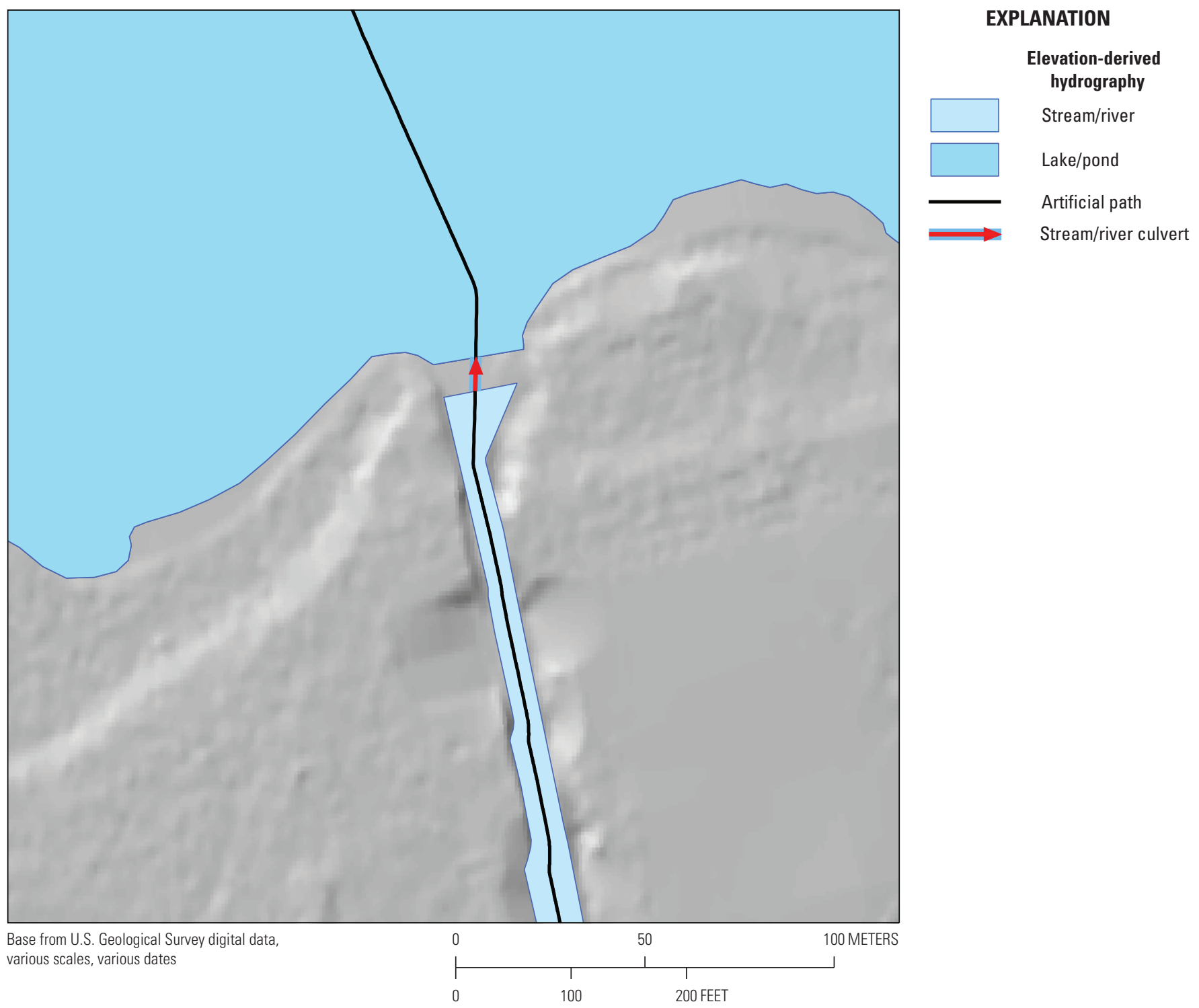

Figure 13. Example of culverts within a hydrographic network. Stream/river line and polygon, artificial path, and lake/pond.

Table 13. Attribute coding used for culvert segments. Artificial path example.

[FClass, feature class; EClass, feature class (elevation); FCode, feature code; Desc, description; NHD, National Hydrography Dataset]

\begin{tabular}{ccccccc}
\hline & FClass & \multicolumn{3}{c}{ EClass } & FCode & Desc \\
\cline { 1 - 4 } $\begin{array}{c}\text { Domain } \\
\text { value }\end{array}$ & Feature attribute & $\begin{array}{c}\text { Domain } \\
\text { value }\end{array}$ & Feature attribute & & Artificial path \\
\hline 1 & $\begin{array}{c}\text { NHD feature (will be } \\
\text { used for conflation) }\end{array}$ & 3 & $\begin{array}{c}\text { Culvert-used for } \\
\text { hydroenforcement }\end{array}$ & 55800 & \\
\hline
\end{tabular}




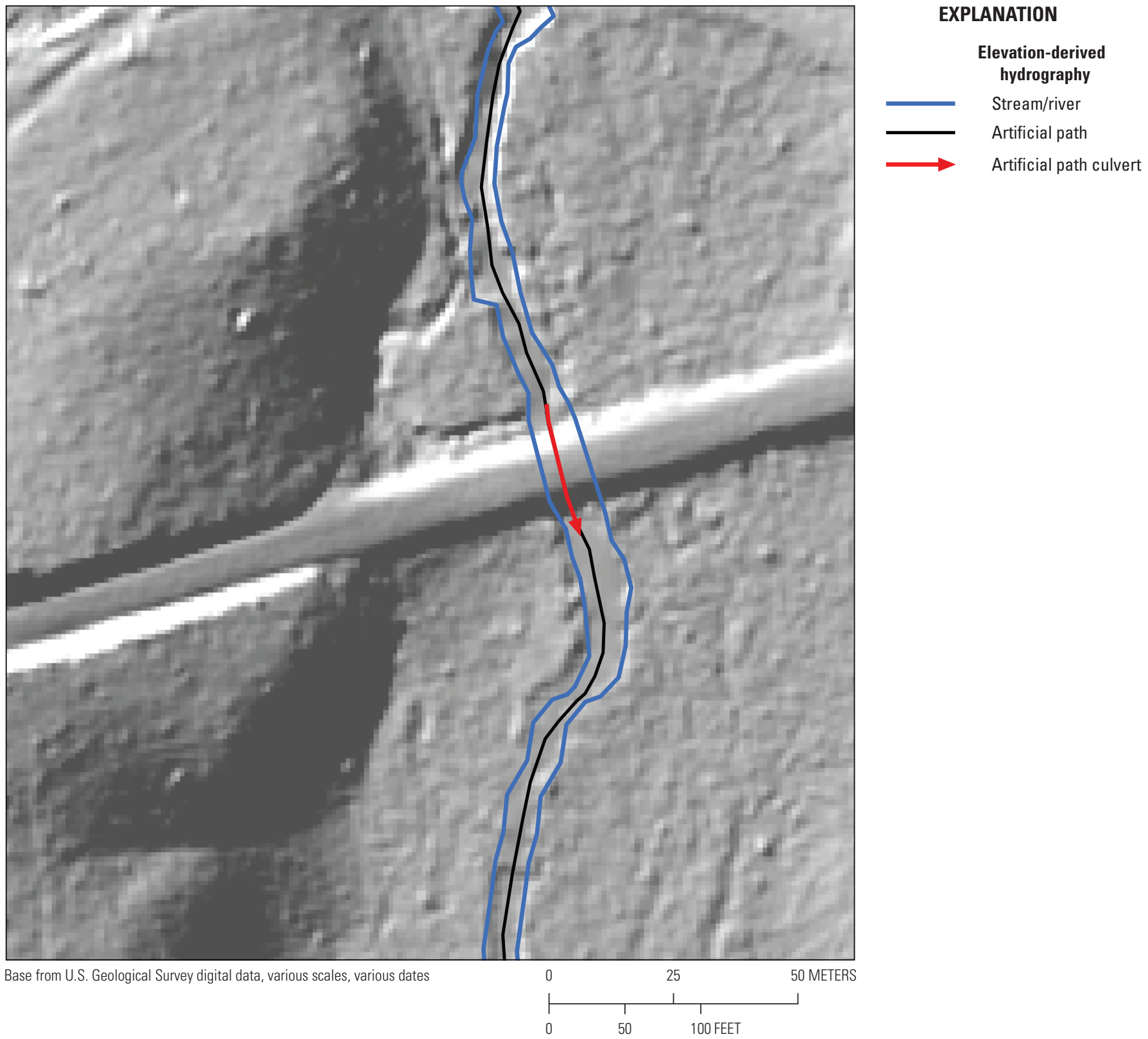

Figure 14. Example of culverts within a hydrographic network. A continuous stream/river polygon with artificial path and culvert location.

Table 14. Attribute coding used for segments adjacent to a culvert segment. Artificial path example.

[FClass, feature class; EClass, feature class (elevation); FCode, feature code; Desc, description; NHD, National Hydrography Dataset]

\begin{tabular}{ccccccc}
\hline & FClass & & EClass & FCode & Desc \\
\cline { 1 - 4 } $\begin{array}{c}\text { Domain } \\
\text { value }\end{array}$ & Feature attribute & & $\begin{array}{c}\text { Domain } \\
\text { value }\end{array}$ & Feature attribute & Artificial path \\
\hline 1 & $\begin{array}{c}\text { NHD feature (will be used } \\
\text { for conflation) }\end{array}$ & 2 & $\begin{array}{c}\text { Hydrographic feature used for elevation } \\
\text { purposes, other than culverts or those } \\
\text { used for hydroflattening }\end{array}$ & 55800 & \\
\hline
\end{tabular}


Table 15. Attribute coding used for polygon feature that contains a culvert. Stream/river example.

[FClass, feature class; EClass, feature class (elevation); FCode, feature code; Desc, description; NHD, National Hydrography Dataset]

\begin{tabular}{cccccc}
\hline & FClass & & EClass & FCode & Desc \\
\cline { 3 - 6 } $\begin{array}{c}\text { Domain } \\
\text { value }\end{array}$ & Feature attribute & $\begin{array}{c}\text { Domain } \\
\text { value }\end{array}$ & Feature attribute & Stream/river \\
\hline 1 & $\begin{array}{c}\text { NHD feature (will be used } \\
\text { for conflation) }\end{array}$ & 2 & $\begin{array}{c}\text { Hydrographic feature used for elevation } \\
\text { purposes, other than culverts or those } \\
\text { used for hydroflattening }\end{array}$ & 46000 & \\
\hline
\end{tabular}

$\boldsymbol{A}$

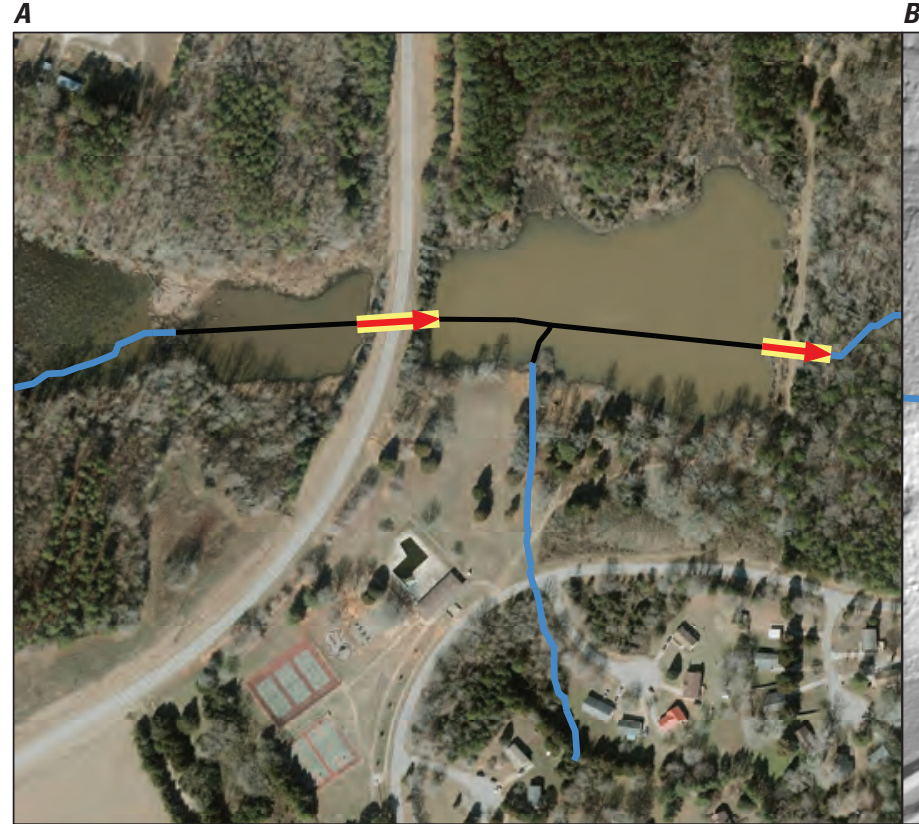

Base modified from U.S. Geological Survey digital data

North Carolina OneMap, North Carolina Center for Geographic Information and Analysis,

North Carolina 911 Board

B

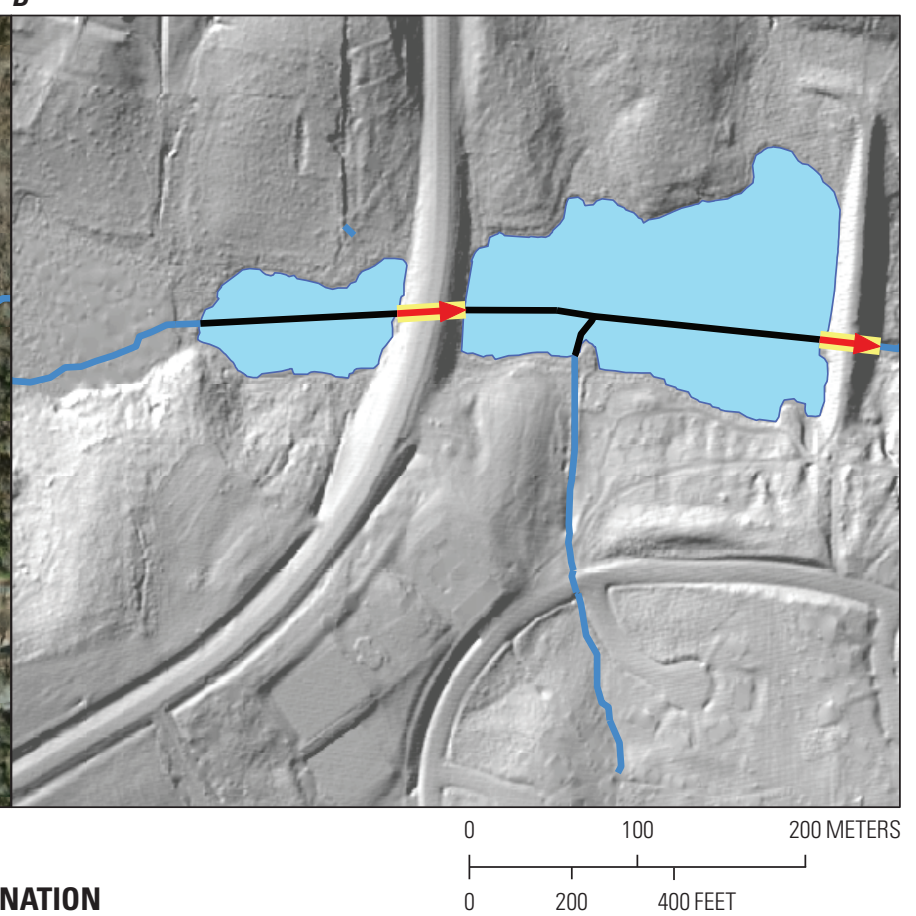

EXPLANATION

Elevation-derived hydrography

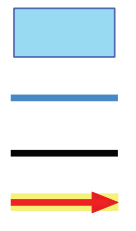

Lake/pond

Stream/river

Artificial path

Connector culvert

Figure 15. Examples of culverts within a hydrographic network. $A$, two lakes/ponds, showing that vegetation and the road clearly separate the two lakes; $B$, the coded connectors at the culvert locations.

Table 16. Attribute coding used for culvert segments. Lake/pond to connector example.

[FClass, feature class; EClass, feature class (elevation); FCode, feature code; Desc, description; NHD, National Hydrography Dataset]

\begin{tabular}{ccccccc}
\hline & FClass & & EClass & FCode & Desc \\
\cline { 1 - 4 } $\begin{array}{c}\text { Domain } \\
\text { value }\end{array}$ & Feature attribute & & $\begin{array}{c}\text { Domain } \\
\text { value }\end{array}$ & Feature attribute & 33400 & Connector \\
\hline 1 & $\begin{array}{c}\text { NHD feature (will be used } \\
\text { for conflation) }\end{array}$ & 3 & Culvert - used for hydroenforcement & \\
\hline
\end{tabular}




\section{Drainageway}

The headwater of a stream is often difficult to determine from a lidar dataset. Many factors determine where a stream begins: geology, weather patterns, soil types, and topography. The extent of headwaters from lidar is not expected to be exact; many of the streams will be approximate representations. Although a channel may be present at a location, it may not be visible in the elevation surface. An example of three field-verified headwater sites in a county on the coast of North Carolina is provided in figure 16. The "ephemeral to intermittent" site and "perennial at this point" site are both difficult to distinguish as channelized features in the lidar surface. The "intermittent to perennial" site has a more obvious channel but not an obvious initiation point. As shown in figure $16 B$, orthoimagery is also not helpful in this area. When mapping hydrography in this area, streams would be underrepresented if only visible channels were delineated. Mapping features that may not be actual streams may be necessary. When a high degree of uncertainty exists, a feature code, FCode 46800, with drainageway as the description, should be used. This code indicates that further investigation is necessary to determine if a hydrographic feature exists on the ground.

$\boldsymbol{A}$

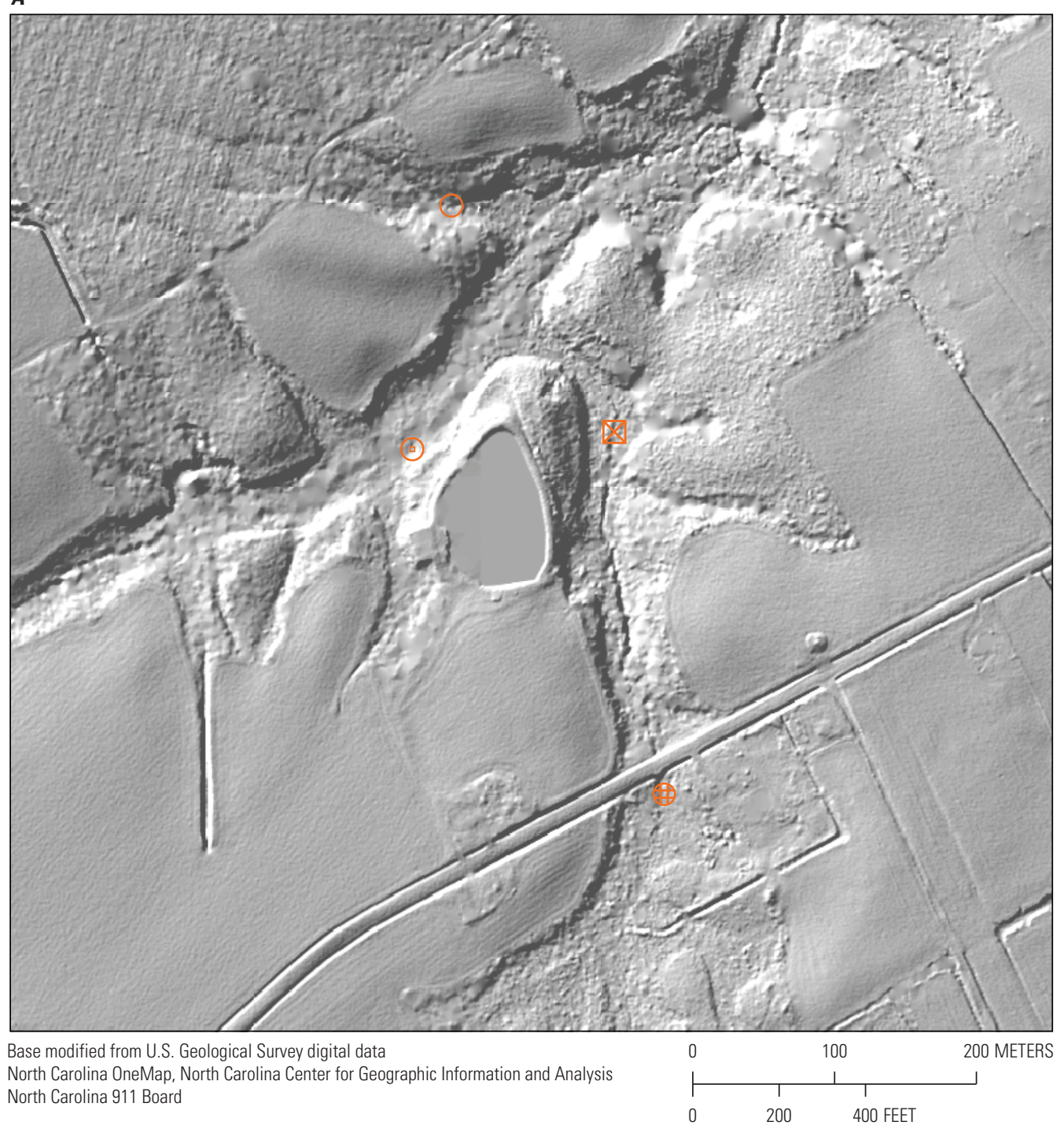

\section{EXPLANATION}

Stream initiation points

Ephemeral to intermittent

$\bigotimes \quad$ Intermittent to perennial

(a) Perennial at this point

$\circledast$ Wetland to intermittent

Figure 16. Field-collected stream initiation points. $A$, points shown on the light detection and ranging-elevation surface; $B$, points shown on orthoimagery of the area. 


\section{B}

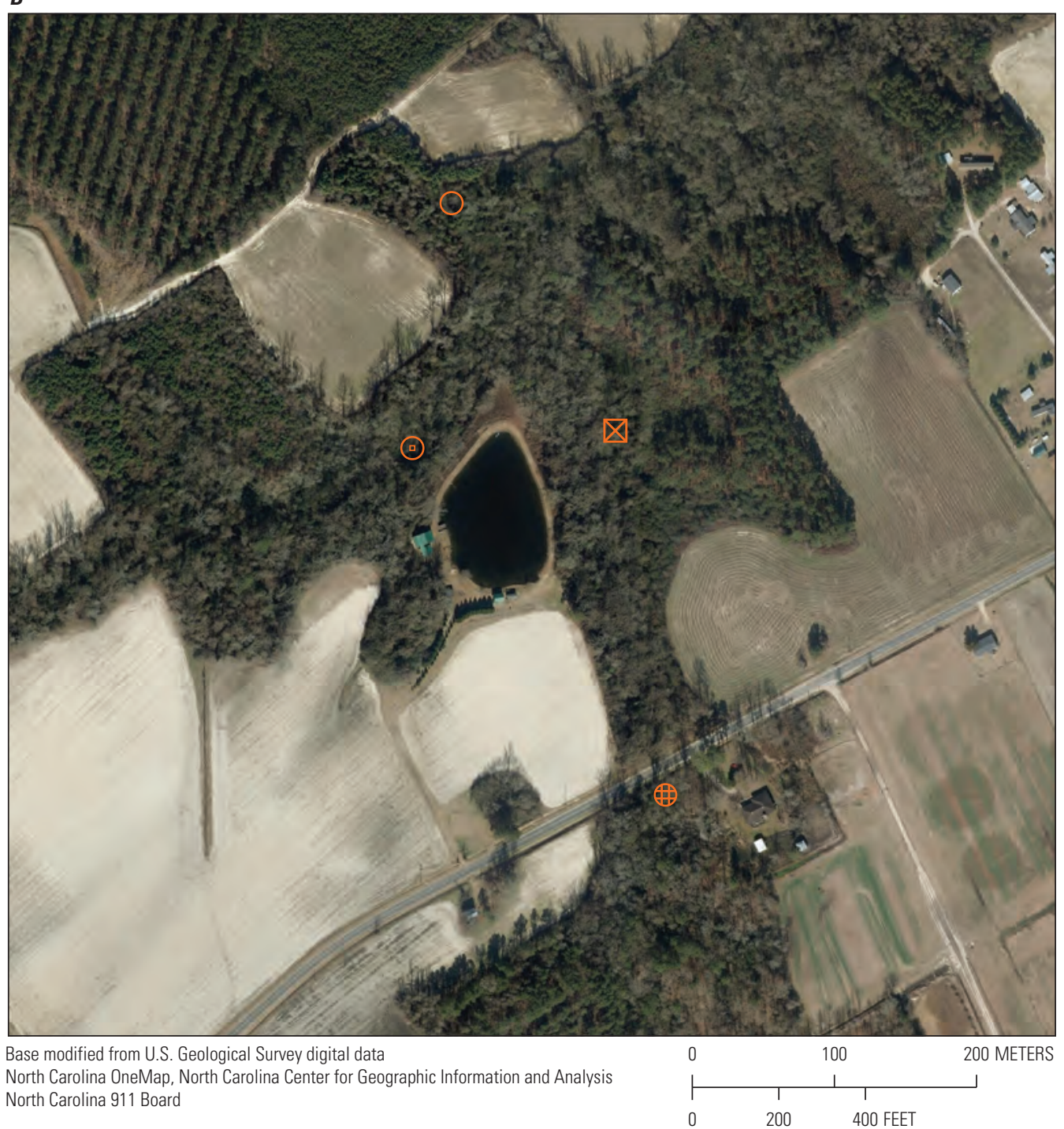

\section{EXPLANATION}

Stream initiation points

Ephemeral to intermittent

$\bigotimes$ Intermittent to perennial

(1) Perennial at this point

Wetland to intermittent

Figure 16. Field-collected stream initiation points. $A$, points shown on the light detection and ranging-elevation surface; $B$, points shown on orthoimagery of the area.-Continued

\section{Headwaters at Roads}

Another important consideration in the delineation of streams is if a road or other impasse has affected the identification of headwaters. A road can become an artificial watershed divide if it impedes the flow at a headwater reach. To avoid cutting off headwater streams at roads, some general rules are recommended:

1. Identify any stream whose initiation point (headwater point) is within 100 feet (ft) or $30 \mathrm{~m}$ of a road.

2. If a stream channel is visible (in imagery or a lidar surface) upstream from the road, extend the stream/river through the road using the rules described for delineation of culverts, and extend the stream/river at least $100 \mathrm{ft}$ or $30 \mathrm{~m}$ upstream from the road intersection.
3. If a stream channel is not visible upstream from the road, but there are other indications that a culvert is at the intersection of the road that allows flow to continue into the stream/river, extend the stream/river to the road and add a culvert through the road feature. Extending the stream/river upstream from the culvert is not necessary if a channel is not visible.

4. If a stream channel is not visible upstream from the road, and no other indications exist of a connection between the upstream area and the headwater, then no action is required.

Three possible ways to address a road at a stream headwater are shown in figure 17. The rules for capturing the minimum content are followed in figure 17 (example A). The blue lines are the existing NHD. The red lines are the geometrically 
corrected segments to match the elevation-derived DEM.

Because the NHD headwater was upstream from the road, the newly delineated stream/river also extends above the road (the culvert segment within the EDH is not shown on this figureit occurs where the EDH crosses the road). An example of a modeled stream that ends $90 \mathrm{ft}$ from a road feature is provided in figure 17 (example B). In this case, the NHD stream was drawn farther downstream. Because the stream headwater is closer than $100 \mathrm{ft}$ from a road, it should be evaluated. A clear channel upstream from the road and culvert is present in the lidar surface. In this case, a culvert feature should be added through the road section of the surface, and the stream/river should be extended for at least $100 \mathrm{ft}$ upstream from the road. A more ambiguous case is shown in figure 17 (example C). The headwater ends $60 \mathrm{ft}$ from a road. The surface features upstream from the road indicate some channelization but not a clear streambed. In this case, a culvert could be added to the end of the stream segment to allow runoff in a hydroenforced surface to reach the stream, but extension of the stream is not necessary past the road intersection.

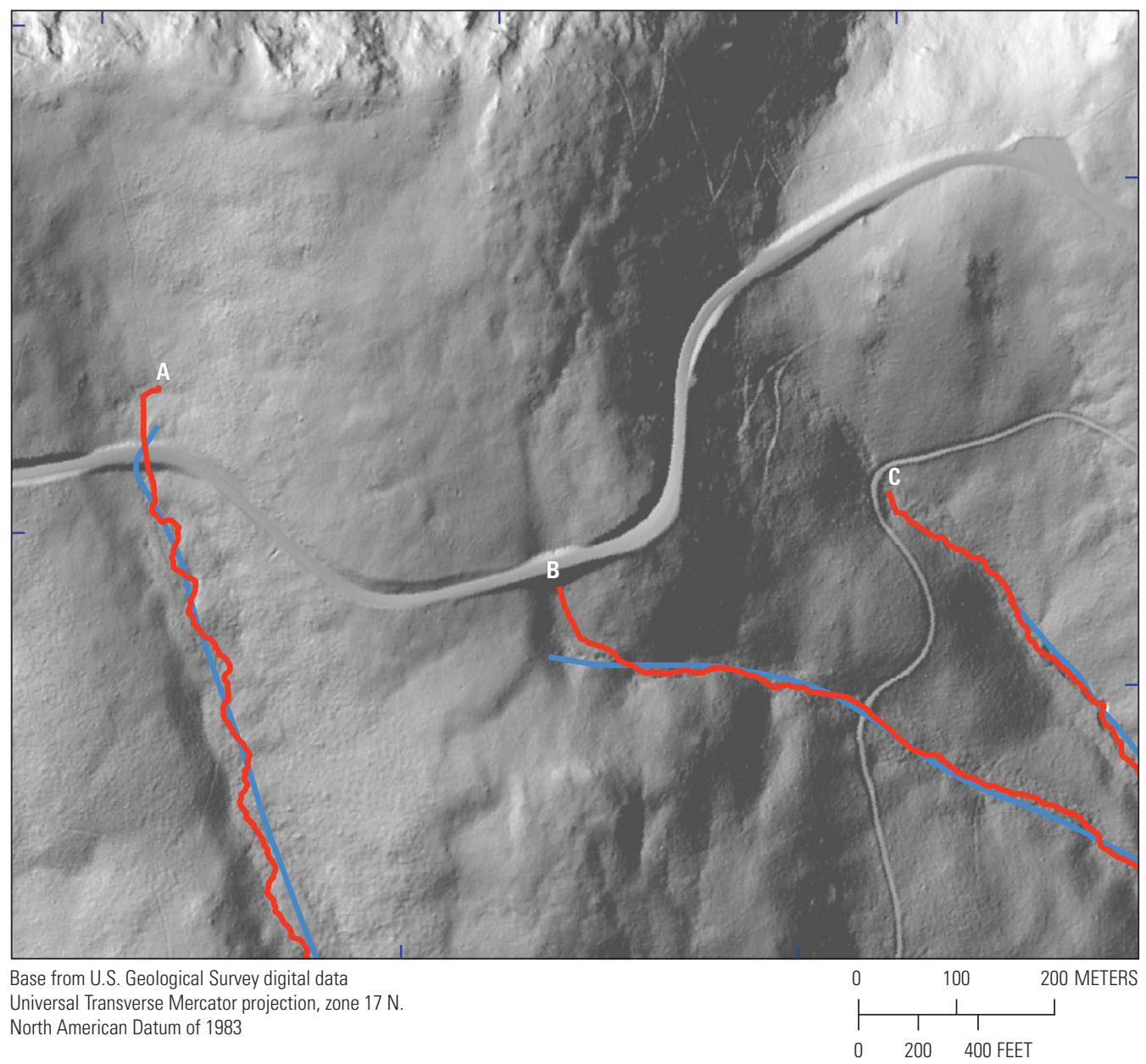

Figure 17. Correcting headwater stream delineation at roads.

\section{EXPLANATION}

[NHD, National Hydrography Dataset; A, shows the National Hydrography Dataset (blue line) exists upstream from the road; therefore, elevation-derived stream/river segments (red line) were also extended upstream from the road; $B$, shows a headwater ends 90 feet from the road. A clear channel is present on the other side of the road; therefore, the elevation-derived stream/river segment should be extended across the road to connect to the channel; $C$, shows a headwater ends 60 feet from the road; a strear channel is not well defined upstream]

\section{Elevation-derived} hydrography

\section{Original NHDFlowline}




\section{Canals and Ditches}

Canals and ditches can be an important aspect of a hydrologic network, particularly in low relief areas. The problem with many interconnected canals as a part of a hydrologic network is that it becomes difficult to navigate the stream network. The direction of flow is not always apparent and may vary based on weather or season. Creating a network that flows in a downstream direction, with z-values descending from upstream to downstream, is a challenge when many segments with low slope are present. Culverts are also difficult to identify for smaller canal systems, leading to isolated networks. An area of the Coastal Plain of North Carolina with many visible canals in the orthoimagery (fig. 18A) and in the lidar surface (fig. 18B) is shown in figure 18.

To avoid overcollection, adhere to the following READ Rules when delineating canal/ditch features (Archuleta and Terziotti, 2020):

1. If a canal/ditch is named, or if a canal/ditch is greater than or equal to $984 \mathrm{ft}(300 \mathrm{~m})$ along the longest axis, then it should be captured.

2. If a canal/ditch is needed to provide network connectivity, it should be captured.

3. If a canal/ditch feature is within agricultural fields, is less than $300 \mathrm{~m}$, and drains to another canal/ditch or other hydrologic feature, it should not be captured.
4. Isolated canal/ditch features or networks should not be collected unless they are of particular importance to the regional hydrology.

5. If a project has a special need for canal/ditch features not covered by these capture conditions, a separate UserCode attribute should be added to allow those features to be removed from an NHD conflation process.

a. Coding should follow the rules for additional userdefined features:

FClass, EClass, and FCode should be coded as 2, 0 , and 0 , respectively. The Desc field may be used to provide a text description. A unique user-defined code should be added to the UserCode field. Codes should not duplicate other defined features or coding needed for NHD conflation.

An example of features that were present in the original NHD (delineated in black lines) and additional canal/ ditch features added to an elevation-derived stream network (represented in purple) are shown in figure 19. Those features tagged as "A" are canals that extend existing canal networks, help guide drainage patterns around a built environment, and are therefore substantial additions to the network. The features tagged as "B" have a length less than $300 \mathrm{~m}$, are within a field that is agricultural, and do not add a substantial amount of information about drainage patterns because the canals/ditches

A

B

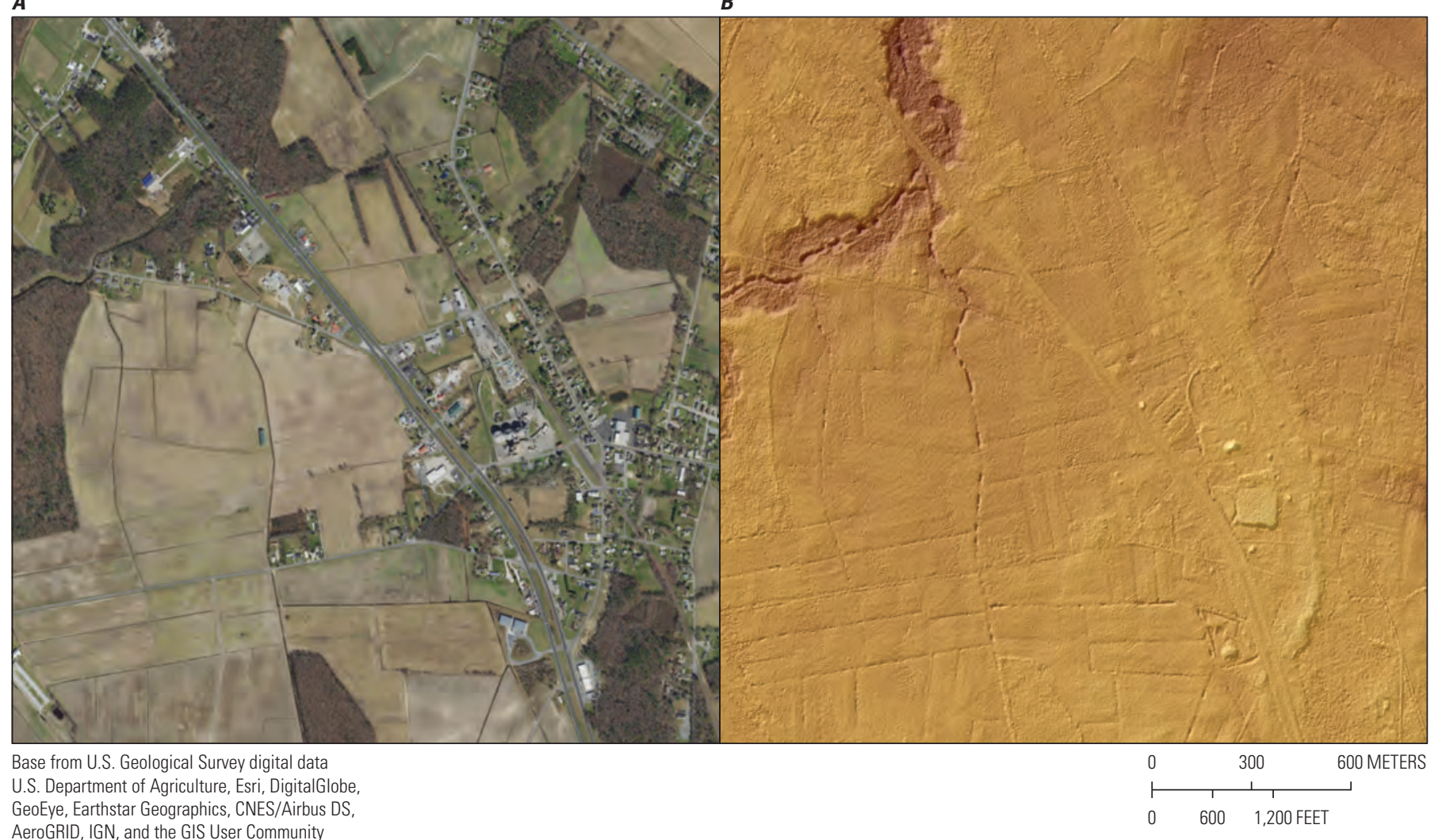

Figure 18. An area with an abundance of canal/ditch features. $A$, orthoimagery; $B$, light detection and ranging-derived terrain model. 


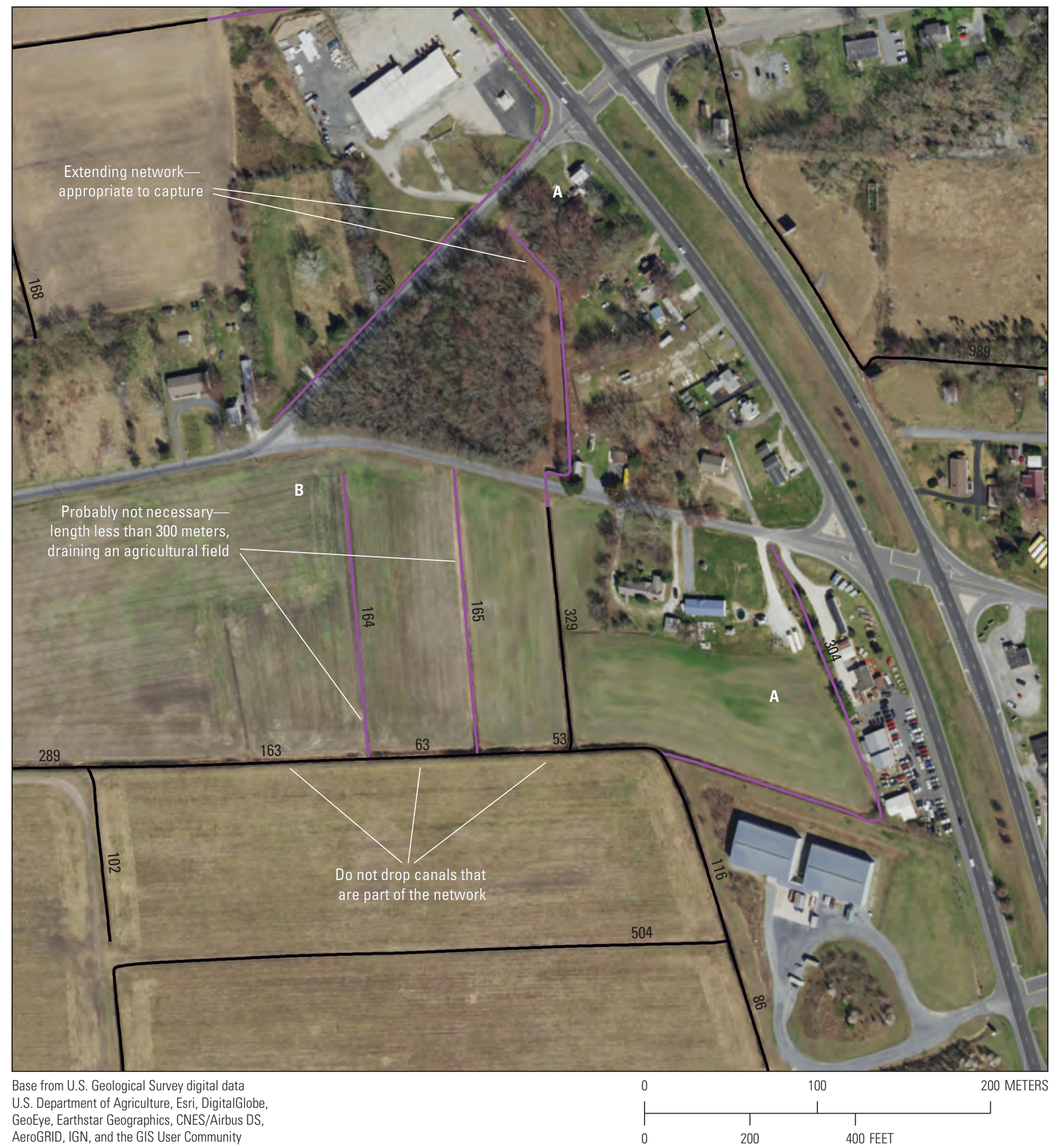

Figure 19. Canal/ditch features as part of a hydrologic network. [A denotes features in purple line color that should be included in the network. $B$ denotes features in purple line color that should be removed from the network] 
are flowing into larger canals/ditches that are part of the hydrologic network. These two canals/ditches (B) do not meet the current criteria for capture as an EDH feature and will not be added to the NHD. If local/project needs require, the features may be collected and identified using the UserCode attribute as described previously.

\section{Summary of Delineation Rules}

In summary, when delineating EDH features, the correct geometry shall be used to capture each feature type. At a minimum, a hydrographic feature collection shall do the following:

- capture all features from table 3 that are present in the most current NHD,

- capture any additional features that meet the capture conditions described in Archuleta and Terziotti (2020), and

- remove features that are not visible in the elevation data or appropriate imagery, or if known to no longer exist by some other method, even if in the original NHD.

Additional features shall be collected for the following reasons:

- if there is clear evidence of the feature in the elevation data source,

- if there is clear evidence of the feature using an appropriate ancillary data source,

- if a method has given good results for delineation of stream channels or other features, and it is quality assured using the elevation data and other high-quality ancillary datasets, and (or)

- if it is necessary to connect a hydrographic network.

All criteria described in this document under the "Special Cases" subsection of the "Delineation of Hydrographic Features" section shall be met.

\section{Topology}

Topology is a set of rules and behaviors that define the spatial relation between the features in the hydrographic network. To prepare for the conflation of hydrographic features into the NHD, topology rules must be followed. The NHD relies on the topology of the features to maintain a continuous network and to support functions such as network navigation.

\section{Topology Rules}

The checks that shall be done to ensure that the dataset meets NHD preconflation standards are as follows:

1. Remove vertices that are less than $1.5 \mathrm{~m}$ apart. a. Caution should be exercised to not compromise positional accuracy by removing more vertices than necessary.

b. All features should have a smooth, nonrasterized appearance and maintain horizontal and vertical accuracy.

2. Split all line features at polygon boundaries.

a. Code flowlines within a waterbody polygon as "artificial paths."

b. Any "artificial path" must be completely within the waterbody polygon, starting and ending at the nodes that are coincident with inflowing features and outflowing features.

3. All line features should be one segment, with no breaks within the feature.

a. The exception to this rule is for "culvert" features. Culverts may split another feature but must use the same FCode as the feature that flows into or out of the culvert. The EClass will be equal to the "culvert-used for hydroenforcement" code of 3.

4. All intersections of features shall have a node (a start/beginning, or end/terminating, vertex) at that intersection.

a. Features that change FCodes within a flowline segment shall be split at that point.

b. Line features that intersect shall be split at that intersection, unless there is evidence that the features do not interact (a pipeline crossing over a stream/river, for example).

c. Lines that meet polygons shall be split at the point where they intersect the polygon. Avoid splitting the polygon feature.

d. Artificial paths within a polygon shall have an end or start node that is snapped to incoming linework. Avoid splitting the polygon feature.

e. No lines shall have self-intersections or cutbacks.

f. Polygon features shall not overlap, but they may share edges. Exceptions are outlined within the READ Rules (Archuleta and Terziotti, 2020).

5. The linear features of the dataset shall create a complete network.

a. Digitized direction shall be from upstream to downstream.

i. Elevation values shall descend monotonically from upstream to downstream. 
b. Isolated pieces of the network may be present along the edges of a DPA, especially where the DPA does not match a drainage divide.

c. Isolated pieces of the network may be present if a sink or other known break in the hydrologic network exists.

i. A sink point shall be used to identify these locations.

6. Features less than $1.5 \mathrm{~m}$ in length or width shall be removed or merged in with a longer feature.

7. All features shall have a complete set of attributes associated with them.

\section{Z-Values}

It is important for every feature within the dataset to have a vertical component that matches the elevation surface. To fulfill this requirement, all features shall meet the following specifications:

1. Features shall be delivered in shapefile, Esri file geodatabase, or Open Geospatial Consortium GeoPackage formats, as pointZ, polylineZ, or polygonZ feature classes.

2. All features shall conform to the defined georeference information defined in the "Spatial Reference System" section of this report.

a. A file with appropriate projection information shall accompany all hydrographic feature deliveries.

3. Lakes/ponds and reservoir waterbody polygons shall be at an elevation at or just below the immediately surrounding terrain.

4. Lakes/ponds and reservoir waterbody polygons shall be flat and level with a single elevation value for every shoreline vertex.

5. Stream/river polygons or downstream flowing lakes/ ponds and reservoirs shall present a level water surface bank to bank.

6. In cases of sharp turns of rapidly moving water, where the natural water surface is notably not level bank to bank, the water surface shall be represented as it exists while maintaining an aesthetic cartographic appearance. Stream/river polygons or downstream flowing lakes/ponds and reservoirs shall have a continuous downstream gradient water surface, at or just below the immediately surrounding terrain.

a. Flat sections are permissible but avoid breaks in downstream gradients that create a stairstep appearance.
7. Stream/river lines shall have a downstream gradient, at or just below the immediately surrounding terrain.

a. Each vertex in a line shall be at the same or a lower elevation value than the preceding vertex in the direction of flow from upstream to downstream.

b. Flat sections are permissible but avoid breaks in downstream gradients that create a stairstep appearance.

8. Nontidal boundary waterbodies shall be flat and level for lakes and reservoirs or maintain a downhill gradient for wide rivers and lakes, with the elevation at or just below the immediately surrounding terrain.

9. Tidal waterbodies will be flat and level with the elevation at or just below the immediately surrounding terrain.

a. Some vertical discontinuities are acceptable if there were tidal variations during the collection process.

10. At all intersections, regardless of feature type, the geometry of all intersection vertices shall match exactly in $\mathrm{x}, \mathrm{y}$, and $\mathrm{z}$, unless there is evidence that there is no interaction between the features (a pipeline crossing a stream/river, for example).

11. Features that are used to traverse surface terrain features (culverts, connectors) or are underground (culverts, connectors, pipelines) shall have the elevation values of the connecting features at the end points. The elevation values of the surface above the culvert, connector, or pipeline will not be used.

12. Pipelines that are above ground and visible on the elevation surface shall use the elevation values for the top of the pipeline from the 3DEP bare-earth surface.

a. A downstream gradient shall be maintained.

\section{Positional Assessment}

In general, existing NHD specifications and 3DEP LBS will be followed to ensure accuracy and completeness. Positional assessment of the EDH is always measured against the bare-earth DEM source. Additional accuracy requirements are detailed in this section.

\section{Elevation-Derived Hydrography Positional Evaluation and Reporting}

The placement of vector hydrographic features will be assessed against their position on the DEM. The goal is to have a hydrography product that is vertically and horizontally integrated with the $3 \mathrm{DEP}$ elevation products. The position 
of the hydrography features shall be measured and assessed against the 3DEP LBS compliant bare-earth DEM from which they were derived.

Ideally all, or as many features as possible, should be inspected to make sure they meet the accuracy standards described in this specification. Automated inspection processes are encouraged. If a complete review is impossible, a stratified random sample may be used to select a subset of features to determine the accuracy of the dataset.

To do a holistic review of the dataset, the features reviewed should be

1. Representative of all features in the dataset, so they should contain at least one feature for each EClass and FCode present in the dataset;

2. Representative of the complete geographic area of the dataset, so they should have features distributed within each 12-digit hydrologic unit that intersects the DPA;

3. Representative of the special cases that make up features, including, but not limited to,
a. Headwaters,
b. Confluences between stream/river reaches,
c. Intersections with polygons and stream features,
d. Canal/ditch features,
e. Isolated networks,
f. Drainageways,
g. Intersections near roads,
h. Culverts,
i. Islands within polygon features,
j. Areas of complex channels;

4. Representative of land cover and geologic types or geophysical regions, including but not limited to
a. Urban areas,
b. Low slope areas.

\section{Positional Assessment and Reporting}

Positional assessment results shall be reported for vertical and horizontal geometry of the hydrographic features relative to the 3DEP bare-earth DEM (see hydroflattening exception below).

Positional assessment is meant to indicate how accurately the vector hydrographic feature is positioned relative to the feature as represented on the DEM, but it is not a measure of how accurate the DEM is, in and of itself, nor is it a measure of how accurate the hydrographic features are in relation to the surface of the Earth. This measure is always represented as (plus or minus) meters.

\section{Hydroflattening Polygon Exception}

An exception to the reporting requirement is for vertices that have been adjusted to maintain monotonicity for hydroflattening (for example, lowering or raising a vertex to maintain a flat bank-to-bank appearance on a lake, lowering or raising a vertex to maintain the downhill flow of a hydroflattened river, or moving the $\mathrm{x}$, y position of a vertex to accommodate the cartographic purposes of hydroflattening). DEMs distributed by the USGS have been hydroflattened to achieve a cartographic effect of smooth waterbodies, and this may affect the position of the vector features relative to the DEM. Vector features used for hydroflattening must follow the requirements of the LBS. Vector features used for hydroflattening purposes shall be integrated into the EDH dataset and shall follow these specifications other than the requirement for positional assessment and reporting.

\section{Vertical Positional Assessment of Hydrographic Features Relative to the Digital Elevation Model}

- All lines and water surface edges shall be at or just below the elevation value of the immediately surrounding terrain, within $1 \mathrm{~m}$ of the location on the bare-earth DEM (fig. 20).

- Exceptions to this requirement are features that are used to traverse surface terrain (culverts, connectors), are underground conduits (culverts, connectors, pipelines), or are overland pipelines (pipelines).

\section{Horizontal Positional Assessment of Elevation-Derived Hydrography}

The horizontal positional assessment evaluates the placement of vector hydrographic features against the bare-earth DEM from which they were derived. Linear, polygonal and point features shall be within the visible channels or other hydrographic features visible on the elevation surface.

\section{Linear Features}

Stream and other linear channel features shall stay within the apparent channels in the elevation data and shall not leave the channel.

Hydrographic feature positional assessment.-Whereby streams and other linear channel features will stay within the apparent channels in the elevation data and will not leave the channel. 


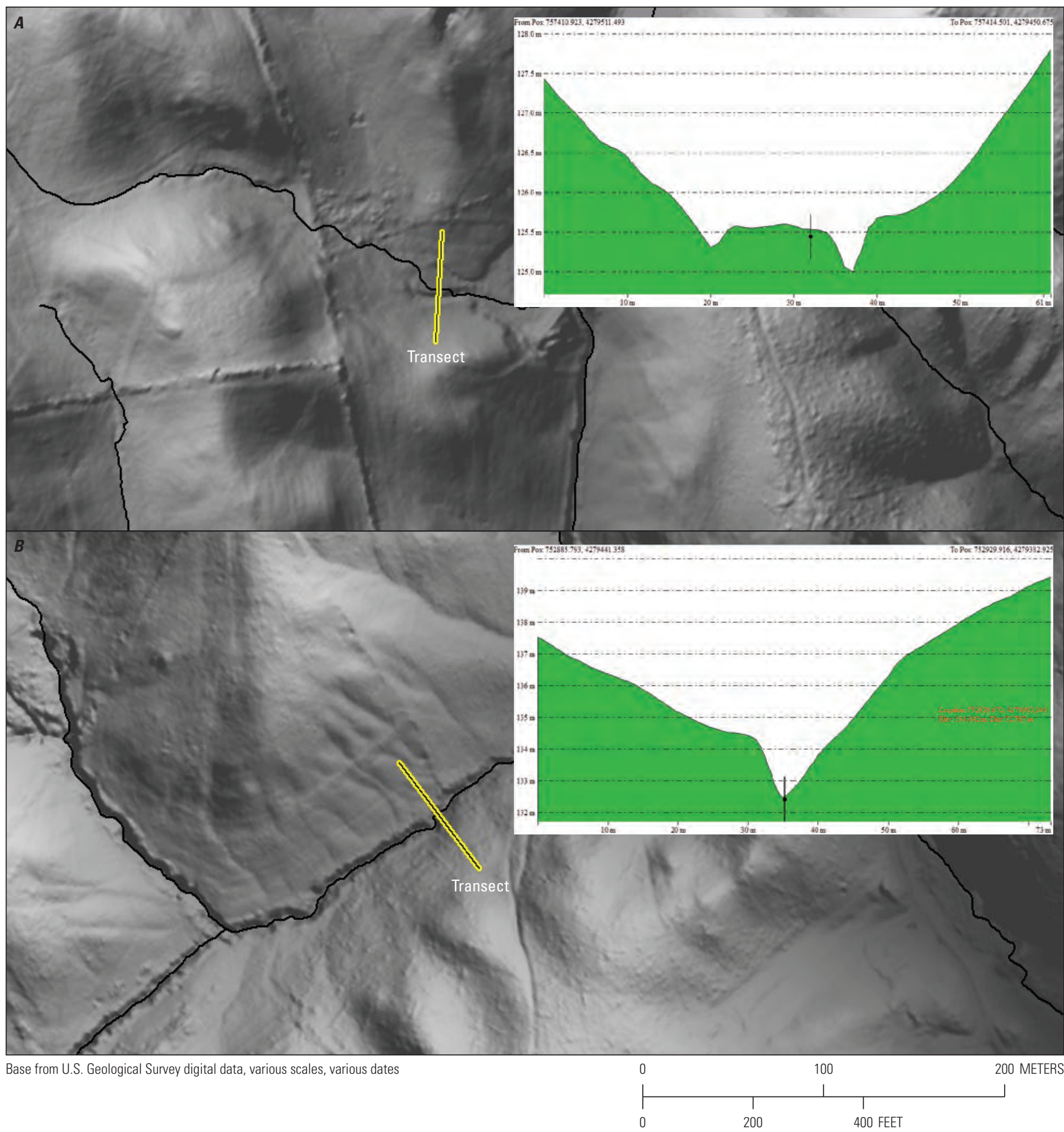

Figure 20. Two cross-sectional views of transects intersecting two stream/river segments. $A$. This stream/river segment has deviated horizontally from the main channel but is still vertically integrated with the elevation surface. $B$. This segment is well integrated vertically and horizontally with the lidar-derived surface. Both segments' elevation values are within 0.1 meter of the elevation values of the surface. 


\section{Polygonal Features}

Lake/pond and other polygonal features shall match the apparent boundary of the feature in the elevation data and shall not vary from the boundary of the feature.

Hydrographic feature positional assessment.-Whereby lake/ pond and other polygonal features will match the apparent boundary of the feature in the elevation data and will not vary from the boundary of the feature.

\section{Point Features}

Point features shall remain within $3 \mathrm{~m}$ of the apparent location of the feature in the elevation data.

Hydrographic feature positional assessment.-Whereby point features will remain within $3 \mathrm{~m}$ of the apparent location of the feature in the elevation data.

\section{Alignment}

Alignment specifications describe the geometry and placement of features. It is important that all features collected shall be logically and spatially consistent with the elevation data horizontally and vertically. Features shall also be spatially consistent with existing NHD features, where appropriate (if an existing feature is spatially correct and will remain unchanged).

\section{Horizontal Alignment}

- New features shall align appropriately with existing NHD features outside of the collection area. For instance, if a stream is added to an existing stream channel, it should "snap" to the stream network nodes. Exceptions include the following:

- New features with horizontal accuracy greater than existing NHD features should not be moved to snap to lower accuracy features.

- New features where no NHD features exist may end at a DPA boundary.

- Features shall be aligned in accordance with topology rules.

- Features shall edge match exactly across tile and project boundaries in the horizontal (x, y) spatial dimensions.

- Delivered data shall be sufficient for the USGS to effectively use as breaklines for hydroflattening or conflation into the NHD without substantial editing.

- Lines shall be oriented from upstream to downstream.

- No lines shall have pseudonodes or breaks within reaches.
- A change in FCode signifies a new feature, so nodes are necessary at those junctions.

- The centerline (artificial path) should begin and end at the inflow and outflow of the two-dimensional (2D) feature.

- Where any other features intersect, the intersection shall be coincident with vertices of each feature.

- At all intersections, regardless of feature type, the geometry of all intersection vertices shall match exactly in $\mathrm{x}$ and $\mathrm{y}$, unless there is no evidence for interaction between the features (a pipeline crossing a stream, for example).

- Features shall align horizontally with the bare-earth DEM they were derived from, within the positional assessment limits described in the "Accuracy" section (fig. 21).

- Horizontal discontinuities along the shoreline of a waterbody resulting from tidal variations during the collection are considered normal and shall be retained in the final hydrography.

\section{Vertical Alignment}

- Features shall edge match exactly across tile and project boundaries in the vertical (z) spatial dimensions.

- Delivered data shall be sufficient for the USGS to effectively use as breaklines for hydroflattening or conflate into the NHD without substantial editing.

- Each vertex in a line shall be at the same or a lower elevation value than the preceding vertex in the direction of flow from upstream to downstream.

- At all intersections, regardless of feature type, the geometry of all intersection vertices shall match exactly in z-value, unless there is evidence of no interaction between features (a pipeline crossing a stream, for example).

- Features shall align vertically with the DEM they were derived from, within the positional assessment limits described in the "Accuracy" section.

- All lines shall be at or just below the elevation of the immediately surrounding terrain, as defined by the bare-earth DEM.

- Flattened waterbodies shall present a flat and level water surface (a single elevation for every bank vertex defining the waterbody's perimeter). 


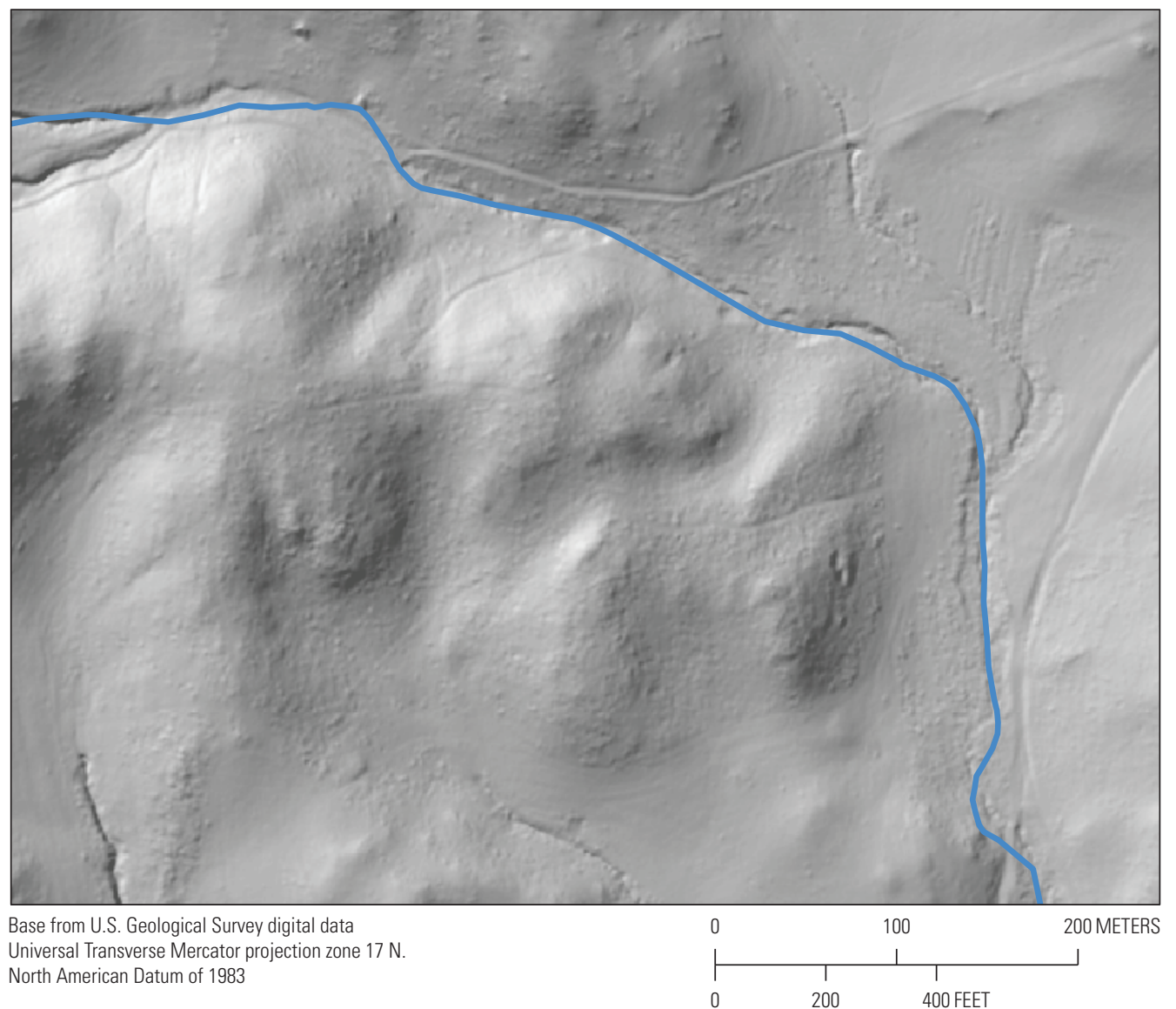

EXPLANATION

[NHD, National Hydrography Dataset] NHDFlowline

Figure 21. An example of poor horizontal alignment. There are many instances in which the streams (in blue) fall outside the apparent channel of the elevation-derived surface.

- Long impoundments that are considered lakes/ponds or reservoirs, whose water surface elevations decrease with downstream travel, shall present a gradient downhill water surface, following the immediately surrounding terrain.

- The entire water surface edge shall be at or below the immediately surrounding terrain (the presence of waterbodies "floating" above the source bare-earth DEM will be cause for rejection of the final product [deliverable]).

- Flattened streams and rivers shall present a flat and level water surface bank to bank (perpendicular to the apparent flow centerline).

- Flattened streams and rivers shall present a gradient downhill water surface, following the immediately surrounding terrain.

- In cases of sharp turns of rapidly moving water, where the natural water surface is notably not level bank to bank, the water surface will be represented as it exists while maintaining an aesthetic cartographic appearance.
- The entire water surface edge shall be at or below the immediately surrounding terrain.

- If a polygon is incomplete because it is on the boundary of the collection area, the water surface shall be flat and level, as appropriate for the type of waterbody (level for lakes, gradient for rivers, and so forth).

- All landward water surface edges shall be at or below the immediately surrounding terrain.

- Unusual changes in the water surface elevation that may take place over the course of the collection (for example, different river stages because of increased or decreased discharge from an upstream dam) shall be documented in the project metadata.

- Vertical discontinuities within a waterbody resulting from tidal variations during the collection are considered normal and shall be retained in the final hydrography. 


\section{Completeness}

All features shall be collected to form a complete stream network without breaks, unless there is evidence a break should occur (for example, isolated waterbodies or subterranean streamflow). All topology rules shall be followed.

All features shall be coded with the appropriate FClass, EClass, FCode, Desc, source, and method. UserCodes shall be used where applicable. Domains shall match those specified within this document and within Archuleta and Terziotti (2020).

\section{Metadata}

Metadata for the EDH shall be provided in Extensible Markup Language (commonly known as XML) formatted files (Bray and others, 2008) compliant with the Federal Geographic Data Committee Content Standard for Digital Geospatial Metadata (Federal Geographic Data Committee, 1998a). The USGS may require additional or alternative metadata formats in the future.

Metadata shall document the following:

- Methods used to delineate features;

- Minimum feature length;

- Format of elevation data (lidar derivatives);

- Source of elevation data (where the data were acquired);

- Date of source elevation data;

- Quality level of source elevation data;

- Ancillary datasets used, including source, date, and resolution;

- Spatial reference system, including horizontal and vertical units, and horizontal and vertical datum used;

- Results of relative accuracy assessment of hydrographic data;

- Method for positional accuracy assessment;

- Field definitions for tables associated with geospatial data (explanation of what type of information the field contains); and

- Contact information for data collector.

\section{Delivered Products and Formats}

Delivered products shall include the following:

- A polygon defining the complete boundary of the DPA,
- Polygons defining any areas within the DPA that were not included in the hydrography collection.

- A hydrography dataset that adheres to all specifications herein,

- Data will be delivered as a current version of shapefile, Esri file geodatabase, or Open Geospatial Consortium GeoPackage.

○ Points, lines, and polygons will have $3 \mathrm{D}$ geometry.

- Metadata describing the final dataset, and

- A summary of any accuracy assessments completed on the data.

\section{Acknowledgments}

The authors would like to acknowledge the expertise and research contributions of Hans Karl Heidemann, Stephen Aichele, Karen Adkins, David Anderson, Robert Wheelwright, Kristina Yamamoto, Lori Phillips, Jason Stoker, Rebecca D. Anderson, and Al Rea of the U.S. Geological Survey.

\section{Selected References}

American Society for Photogrammetry and Remote Sensing, 2015, ASPRS positional accuracy standards for digital geospatial data (edition 1, version 1.0-November 2014): Photogrammetric Engineering \& Remote Sensing, v. 81, no. 3, March 2015, p. A1-A26.

American Society for Photogrammetry and Remote Sensing, 2011, LAS specification version 1.4-R13: Bethesda, Md., American Society for Photogrammetry and Remote Sensing, 27 p. [Also available at http://www.asprs.org/wp-content/uploads/2010/12/LAS_1 4 r13.pdf.]

Archuleta, C.M., and Terziotti, S., 2020, Elevation-Derived Hydrography - Representation, Extraction, Attribution, and Delineation Rules: U.S. Geological Survey Techniques and Methods, book 11, chap. B12, 60 p., https://doi.org/10.3133/ tm11B12.

Arundel, S.T., Archuleta, C.M., Phillips, L.A., Roche, B.L., and Constance, E.W., 2015, 1-meter digital elevation model specification: U.S. Geological Survey Techniques and Methods, book 11, chap. B7, 25 p. with appendixes, https://dx.doi.org/10.3133/tm11B7. 
Bray, T., Paoli, J., Sperberg-McQueen, C.M., Maler, E., and Yergeau, F., eds., 2008, Extensible Markup Language (XML) 1.0 (5th ed.) (W3C Recommendation 26 November 2008): W3C web page, accessed December 2019 at https://www.w3.org/TR/2008/REC-xml-20081126/.

Esri, 1998, Esri shapefile technical description: Redlands, Calif., Environmental Systems Research Institute, Inc., 34 p., accessed July 19, 2019, at http://downloads.esri.com/ support/whitepapers/mo_/shapefile.pdf.

Esri, 2016, What is a file geodatabase?: Esri web page, accessed July 19, 2019, at https://desktop.arcgis.com/ en/arcmap/10.3/manage-data/administer-file-gdbs/filegeodatabases.htm.

Federal Geographic Data Committee, 1998a, Content standard for digital geospatial metadata (revised June 1998): Washington, D.C., Federal Geographic Data Committee FGDC-STD-001-1998, 90 p., accessed April 7, 2017, at https://www.fgdc.gov/standards/projects/FGDC-standardsprojects/metadata/base-metadata/v2_0698.pdf.

Federal Geographic Data Committee, 1998b, Geospatial positioning accuracy standards, Part 3-National standard for spatial data accuracy: Federal Geographic Data Committee, Subcommittee for Base Cartographic Data, FGDC-STD-007.3-1998, 28 p. [Also available at https://www.fgdc.gov/standards/projects/FGDC-standardsprojects/accuracy/part3/chapter3.]

Heidemann, H.K., 2018, 3DEP Lidar Base Specification (ver. 1.3, February 2018): U.S. Geological Survey Techniques and Methods, book 11, chap. B4, 101 p., accessed December 2019 at https://doi.org/10.3133/tm11b4.

National Digital Elevation Program, 2004, Guidelines for digital elevation data, version 1: National Digital Elevation Program, 93 p. [Also available at https:/nationalmap.gov/ standards/pdf/NDEP_Elevation_Guidelines_Ver1_ 10May2004.pdf.]

National Geodetic Survey, 2019, Geoid models: National Geodetic Survey web page, accessed May 2020 at https://geodesy.noaa.gov/GEOID/.

Open Geospatial Consortium, 2018, OGC GeoPackage: Open Geospatial Consortium web page, accessed July 19, 2019, at https://www.geopackage.org/.

U.S. Geological Survey, 2019a, NGP standards and specifications: U.S. Geological Survey web page, accessed May 2020 at https://www.usgs.gov/core-science-systems/ngp/ss/ product-standards.

U.S. Geological Survey, 2019b, National hydrography: U.S. Geological Survey web page, accessed August 1, 2019, at https:/www.usgs.gov/core-science-systems/ngp/nationalhydrography.
U.S. Geological Survey, 2019c, 3D Elevation Program: U.S. Geological Survey web page, accessed August 1, 2019, at https:/www.usgs.gov/core-science-systems/ngp/3dep. 


\section{Glossary}

Note: The following definitions are selected from the 3D Elevation Program Lidar Base Specification because they are also pertinent to elevation-derived hydrography. A complete glossary, containing additional terms specific to lidar characteristics and processing is available in the Lidar Base Specification, version 1.3 (Heidemann, 2018).

A

accuracy The closeness of an estimated value (for example, measured or computed) to a standard or accepted (true) value of a particular quantity. See precision.

- absolute accuracy A measure that accounts for all systematic and random errors in a dataset. Absolute accuracy is stated with respect to a defined datum or reference system.

- accuracy $\boldsymbol{~}_{\mathrm{r}}\left(\boldsymbol{A C C}_{\boldsymbol{r}}\right)$ The National Standards for Spatial Data Accuracy (Federal Geographic Data Committee, 1998b) reporting standard in the horizontal component that equals the radius of a circle of uncertainty, such that the true or theoretical horizontal location of the point falls within that circle 95 percent of the time.

$$
A C C_{r}=1.7308 \times R M S E_{r}
$$

See RMSE

- accuracy $\mathbf{A}_{\mathbf{z}}\left(\boldsymbol{A C C}_{\mathbf{z}}\right)$ The National Standards for Spatial Data Accuracy reporting standard in the vertical component that equals the linear uncertainty value, such that the true or theoretical vertical location of the point falls within that linear uncertainty value 95 percent of the time.

$$
A C C_{z}=1.9600 \times R M S E_{z}
$$

See RMSE

- horizontal accuracy The horizontal (radial) component of the positional accuracy of a dataset with respect to a horizontal datum, at a specified confidence level. See accuracy $_{\mathrm{r}}$.

- local accuracy The uncertainty in the coordinates of points with respect to coordinates of other directly connected, adjacent points at the 95-percent confidence level.

- network accuracy The uncertainty in the coordinates of mapped points with respect to the geodetic datum at the 95-percent confidence level.

- positional accuracy The accuracy at the 95-percent confidence level of the position of features, including horizontal and vertical positions, with respect to horizontal and vertical datums.

- relative accuracy A measure of variation in point-to-point accuracy in a dataset. In lidar, this term may also specifically mean the positional agreement between points within a swath, adjacent swaths within a lift, or adjacent lifts within a project or between adjacent projects.

- vertical accuracy The measure of the positional accuracy of a dataset with respect to a specified vertical datum at a specified confidence level or percentile. See accuracy $_{z}$.

aggregate nominal pulse density (ANPD) A variant of nominal pulse density that expresses the total expected or actual density of pulses located in a specified unit area resulting from multiple passes of the light detection and ranging (lidar) instrument, or a single pass of a 
platform with multiple lidar instruments, over the same target area. In all other respects, ANPD is identical to nominal pulse density (NPD). In single coverage collection, ANPD and NPD will be equal. See aggregate nominal pulse spacing, nominal pulse density, nominal pulse spacing.

aggregate nominal pulse spacing (ANPS) A variant of nominal pulse spacing that expresses the typical or average lateral distance between pulses in a lidar dataset resulting from multiple passes of the lidar instrument, or a single pass of a platform with multiple lidar instruments, over the same target area. In all other respects, ANPS is identical to nominal pulse spacing (NPS). In single coverage collections, ANPS and NPS will be equal. See aggregate nominal pulse density, nominal pulse density, nominal pulse spacing.

artifacts An inaccurate observation, effect, or result, especially one resulting from the technology used in scientific investigation or from experimental error. In bare-earth elevation models, artifacts are detectable surface remnants of buildings, trees, towers, telephone poles, or other elevated features; also, detectable artificial anomalies that are introduced to a surface model by way of system specific collection or processing techniques. For example, corn-row effects of profile collection, star and ramp effects from multidirectional contour interpolation, or detectable triangular facets caused when vegetation canopies are removed from lidar data.

attitude The position of a body defined by the angles between the axes of the coordinate system of the body and the axes of an external coordinate system. In photogrammetry, the attitude is the angular orientation of a camera (roll, pitch, yaw), or of the photograph taken with that camera, with respect to some external reference system. With lidar, the attitude is normally defined as the roll, pitch, and heading of the instrument at the instant an active pulse is emitted from the sensor.

\section{B}

bald earth Nonpreferred term. See bare earth.

bare earth Terrain free from vegetation, buildings, and other man-made structures. Elevations of the ground.

breakline A linear feature that describes a change in the smoothness or continuity of a surface. The two most common forms of breaklines are as follows:

- A soft breakline ensures that known z-values along a linear feature are maintained (for example, elevations along a pipeline, road centerline, or drainage ditch) and ensures that linear features and polygon edges are maintained in a triangulated irregular network (TIN) surface model by enforcing the breaklines as TIN edges. They are generally synonymous with three-dimensional (3D) breaklines because they are depicted with series of $\mathrm{x}, \mathrm{y}, \mathrm{z}$ coordinates. Somewhat rounded ridges or the trough of a drain may be collected using soft breaklines.

- A hard breakline defines interruptions in surface smoothness (for example, to define streams, rivers, shorelines, dams, ridges, building footprints, and other locations) with abrupt surface changes. Although some hard breaklines are 3D breaklines they are typically depicted as two-dimensional (2D) breaklines because features such as shorelines and building footprints are normally depicted with series of $\mathrm{x}, \mathrm{y}$ coordinates only, which are often digitized from digital orthophotographs that include no elevation data. See mass point.

bridge A structure carrying a road, path, railroad, canal, aircraft taxiway, or any other transit between two locations of higher elevation over an area of lower elevation. A bridge may traverse a river, ravine, road, railroad, or other obstacle. "Bridge" also includes but is not limited to aqueduct, drawbridge, flyover, footbridge, overpass, span, trestle, and viaduct. In mapping, the term "bridge" is distinguished from a roadway over a culvert in that a bridge is an elevated deck that is not underlain with earth or soil. See culvert, saddle.

\section{C}

cell (pixel) A single element of a raster dataset. Each cell contains a single numeric value 
of information representative of the area covered by the cell. Although the terms "cell" and "pixel" are synonymous, in this specification, "cell" is used in reference to nonimage rasters such as digital elevation models (DEMs), whereas "pixel" is used in reference to image rasters such as lidar intensity images.

classification (of lidar) The classification of lidar data returns in accordance with a classification scheme to identify the type of target from which each lidar return is reflected. The process allows future differentiation between bare-earth terrain points, water, noise, vegetation, buildings, other man-made features, and objects of interest.

confidence level The percentage of points within a dataset that are estimated to meet the stated accuracy; for example, accuracy reported at the 95-percent confidence level means that 95 percent of the positions in the dataset will have an error with respect to true ground position that is equal to or smaller than the reported accuracy value.

consolidated vertical accuracy (CVA) Replaced by the term vegetated vertical accuracy (VVA) in this specification, CVA is the term used by the National Digital Elevation Program guidelines for vertical accuracy at the 95th percentile in all land cover categories combined (National Digital Elevation Program, 2004). See percentile, vegetated vertical accuracy.

control point (calibration point) A surveyed point used to geometrically adjust a lidar dataset to establish its positional accuracy relative to the real world. Control points are independent of, and may never be used as, check points on the same project.

culvert A tunnel carrying a stream or open drainage under a road or railroad or through another type of obstruction to natural drainage. Typically constructed of formed concrete or corrugated metal and surrounded on all sides, top, and bottom by earth or soil.

\section{D}

data void In lidar, a gap in the point data coverage caused by surface nonreflectance of the lidar pulse, instrument or processing anomalies or failure, obstruction of the lidar pulse, or improper collection flight planning. Any area greater than or equal to four times the aggregate nominal pulse spacing, squared, measured using first returns only, is considered to be a data void.

datum A set of reference points on the Earth's surface against which position measurements are made, and (usually) an associated model of the shape of the Earth (reference ellipsoid) to define a geographic coordinate system. Horizontal datums (for example, the North American Datum of 1983) are used for describing a point on the Earth's surface, in latitude and longitude or another coordinate system. Vertical datums (for example, the North American Vertical Datum of 1988) are used to measure elevations or depths. In engineering and drafting, a datum is a reference point, surface, or axis on an object against which measurements are made.

digital elevation model resolution The linear size of each cell of a raster DEM. Features smaller than the cell size cannot be explicitly represented in a raster model. DEM resolution may also be referred to as cell size, grid spacing, or ground sample distance.

digital elevation model (DEM) See four definitions below:

- A popular acronym used as a generic term for digital topographic and bathymetric data in all its various forms. Unless specifically referenced as a digital surface model (DSM), the generic DEM normally implies $x, y$ coordinates and z-values of the bareearth terrain void of vegetation and man-made features.

- As used by the U.S. Geological Survey (USGS), a DEM is the digital cartographic representation of the elevation of the land at regularly spaced intervals in $\mathrm{x}$ and $\mathrm{y}$ directions, using $\mathrm{z}$-values referenced to a common vertical datum.

- As typically used in the United States and elsewhere, a DEM has bare-earth z-values at regularly spaced intervals in $\mathrm{x}$ and $\mathrm{y}$ directions; however, grid spacing, datum, coordinate systems, data formats, and other characteristics may vary widely.

- A "D-E-M" is a specific raster data format once widely used by the USGS. DEMs are a sampled array of elevations for ground positions at regularly spaced intervals. 
digital surface model (DSM) Similar to DEMs except that they may depict the elevations of the top surfaces of buildings, trees, towers, and other features elevated above the bare-earth. DSMs are especially relevant for telecommunications management, air safety, forest management, and 3D modeling and simulation.

digital terrain model (DTM) See two definitions below:

- In some countries, DTMs are synonymous with DEMs, representing the bare-earth terrain with uniformly spaced z-values, as in a raster.

- As used in the United States, a DTM is a vector dataset composed of 3D breaklines and irregularly spaced 3D mass points, typically created through stereo photogrammetry, that characterize the shape of the bare-earth terrain. Breaklines more precisely delineate linear features whose shape and location would otherwise be lost. A DTM is not a surface model and its component elements are discrete and not continuous; a TIN or DEM surface must be derived from the DTM. Surfaces derived from DTMs can represent distinctive terrain features much better than those generated solely from gridded elevation measurements. A lidar dataset combined with ancillary breaklines is also considered a DTM.

discrete-return lidar Lidar system or data in which important peaks in the waveform are captured and stored. Each peak represents a return from a different target, discernible in vertical or horizontal domains. Most modern lidar systems are capable of capturing multiple discrete returns from each emitted laser pulse. See waveform lidar.

\section{E}

elevation The distance measured upward along a plumb line between a point and the geoid. The elevation of a point is normally the same as its orthometric height, defined as $H$ in the equation:

where

$$
H=h-N
$$

$h \quad$ is equal to the ellipsoid height and

$N \quad$ is equal to the geoid height.

\section{F}

first return The first important measurable part of a return lidar pulse.

flightline A single pass of the collection aircraft over the target area. Commonly used incorrectly to refer to the data resulting from a flightline of collection. See swath.

fundamental vertical accuracy (FVA) Replaced by the term nonvegetated vertical accuracy (NVA), in this specification, FVA is the term used by the National Digital Elevation Program (NDEP) guidelines for vertical accuracy at the 95-percent confidence level in open terrain only where errors should approximate a normal error distribution. See nonvegetated vertical accuracy, accuracy, confidence level.

\section{G}

geographic information system (GIS) A system of spatially referenced information, including computer programs that acquire, store, manipulate, analyze, and show spatial data.

geospatial data Information that identifies the geographic location and characteristics of natural or constructed features and boundaries of Earth. This information may be derived from - among other things - remote-sensing, mapping, and surveying technologies. Geospatial data generally are considered to be synonymous with spatial data; however, the former is always associated with geographic or Cartesian coordinates linked to a horizontal or vertical datum, whereas the latter (for example, generic architectural house plans) may include dimensions and other spatial data not linked to any physical location. 
ground truth Verification of a situation without errors introduced by sensors or human perception and judgment.

\section{H}

hillshade A function used to create an illuminated representation of the surface, using a hypothetical light source, to enhance terrain visualization effects.

horizontal accuracy Positional accuracy of a dataset with respect to a horizontal datum. According to the "National Standards for Spatial Data Accuracy" (Federal Geographic Data Committee, 1998b), horizontal (radial) accuracy at the 95-percent confidence level is defined as $A C C_{r}$.

hydraulic modeling The use of digital elevation data, rainfall-runoff data from hydrologic models, surface roughness data, and information on hydraulic structures (for example, bridges, culverts, dams, weirs, and sewers) to predict flood levels and manage water resources. Hydraulic models are based on computations involving liquids under pressure, and many other definitions of hydraulic modeling exist that are not associated with terrain elevations (for example, modeling of hydraulic lines in aircraft and automobiles).

hydrologic modeling The computer modeling of rainfall and the effects of land cover, soil conditions, and terrain slope to estimate rainfall runoff into streams, rivers, and lakes. Digital elevation data are used as part of hydrologic modeling.

hydrologically conditioned (hydroconditioned) Processing of a DEM or TIN so that the flow of water is continuous across the entire terrain surface, including the removal of all isolated sinks or pits. The only sinks that are retained are the real ones on the landscape. Although hydrologic enforcement is relevant to drainage features that generally are mapped, hydrologic conditioning is relevant to the entire land surface and is done so that water flow is continuous across the surface, whether that flow is in a stream channel or not. The purpose for continuous flow is so that relations and (or) links among basins and (or) catchments can be known for large areas.

hydrologically flattened (hydroflattened) Processing of a lidar-derived surface (DEM or TIN) so that mapped waterbodies, streams, rivers, reservoirs, and other cartographically polygonal water surfaces are flat and, where appropriate, level from bank to bank. Additionally, surfaces of streams, rivers, and long reservoirs demonstrate a gradient change in elevation along their length, which is consistent with their natural behavior and the surrounding topography. In traditional maps that are compiled photogrammetrically, this process is completed automatically through the inclusion of measured breaklines in the DTM; however, because lidar does not inherently include breaklines, a DEM or TIN derived solely from lidar points will depict water surfaces with unsightly and unnatural artifacts of triangulation. The process of hydroflattening typically involves the addition of breaklines along the banks of specified waterbodies, streams, rivers, and ponds. These breaklines establish elevations for the water surfaces that are consistent with the surrounding topography and produce aesthetically acceptable water surfaces in the final DEM or TIN. Unlike hydroconditioning and hydroenforcement, hydroflattening is not driven by any hydrologic and hydraulic modeling requirements but solely by cartographic mapping needs.

hydrologically enforced (hydroenforced) Processing of mapped waterbodies so that lakes and reservoirs are level and so that streams and rivers flow downhill; for example, a DEM, TIN, or topographic contour dataset with elevations removed from the tops of selected drainage structures (bridges and culverts) so as to depict the terrain under those structures. Hydroenforcement enables hydrologic and hydraulic models to depict water flowing under these structures, rather than appearing in the computer model to be dammed by them because of road deck elevations higher than the water levels. Hydroenforced TINs also use breaklines along shorelines and stream centerlines (for example, where these breaklines form the edges of TIN triangles along the alignment of drainage features). Shore breaklines for streams and rivers would be $3 \mathrm{D}$ breaklines with elevations that decrease as the stream flows downstream; however, shore breaklines for lakes or reservoirs would have the same elevation for the entire shoreline if the water surface is known or assumed to be level throughout. 
intensity (lidar) For discrete-return lidar instruments, intensity is the recorded amplitude of the reflected lidar pulse at the moment the reflection is captured as a return by the lidar instrument. Lidar intensity values can be affected by many factors such as the instantaneous setting of the instrument's automatic gain control and angle of incidence and thus cannot be equated to a true measure of energy for discrete-return systems. In full-waveform systems, the entire reflection is sampled and recorded, and true energy measurements can be made for each return or overall reflection. Intensity values for discrete returns derived from a full-waveform system may or may not be calibrated to represent true energy.

Lidar intensity data make it possible to map variable textures in the form of a grayscale image. Intensity return data enable automatic identification and extraction of objects such as buildings and impervious surfaces and can aid in lidar point classification. In spite of their similar appearance, lidar intensity images differ from traditional panchromatic images in several important ways:

- Lidar intensity is a measure of the reflection of an active laser energy source, not natural solar energy.

- Lidar intensity images are aggregations of values at point samples. The value of a pixel does not represent the composite value for the area of that pixel.

- Lidar intensity images depict the surface reflectivity within an extremely narrow band of the electromagnetic spectrum, not the entire visible spectrum as in panchromatic images.

- Lidar intensity images are strongly affected by the angle of incidence of the laser to the target and are subject to unnatural shadowing artifacts.

- The values on which lidar intensity images are based may or may not be calibrated to any standard reference. Intensity images usually contain wide variation of values within swaths, between swaths, and between lifts.

For these reasons, lidar intensity images must be interpreted and analyzed with unusually high care and skill.

$\mathbf{L}$

LAS A public file format for the interchange of 3D point data between data users. The file extension is .las (American Society for Photogrammetry and Remote Sensing, 2011).

last return The last important measurable part of a return lidar pulse.

lift A lift is a single takeoff and landing cycle for a collection platform (fixed or rotary wing) within an aerial data collection project, often lidar.

light detection and ranging (lidar) An instrument that measures distance to a reflecting object by emitting timed pulses of light and measuring the time difference between the emission of a laser pulse and the reception of the pulse's reflection(s). The measured time interval for each reflection is converted to distance, which when combined with position and attitude information from a global positioning system (GPS), inertial measurement unit (IMU), and the instrument itself, allows the derivation of the 3D point location of the reflecting target's location.

local accuracy See accuracy.

\section{M}

mass point(s) Irregularly spaced points, each with $\mathrm{x}, \mathrm{y}, \mathrm{z}$ coordinates, typically (but not always) used to form a TIN. When generated manually, mass points are ideally chosen to depict the most substantial variations in the slope or aspect of TIN triangles; however, when generated automatically (for example, by lidar), mass point spacing and pattern depend upon the characteristics of the technologies used to acquire the data. Mass points are usually used in conjunction with breaklines. See breakline.

metadata Any information that is descriptive or supportive of a geospatial dataset, including 
formally structured and formatted metadata files (for example, Extensible Markup Language [commonly known as XML] formatted Federal Geographic Data Committee metadata), reports (collection, processing, quality assurance/quality control), and other supporting data (for example, survey points, shapefiles).

monotonic In mathematics, a function that varies such that it either increases or decreases, but never both. As used in this specification, it describes a hydrographic breakline that continuously flows either level or downhill, but never uphill.

\section{N}

node Nodes represent the beginning and ending vertices of each arc, topologically linked to all the arcs that meet there.

nominal pulse density (NPD) A common measure of the density of a lidar dataset; NPD is the typical or average number of pulses within a specified areal unit. NPD is typically expressed as pulses per square meter. This value is predicted in mission planning and empirically calculated from the collected data, using only the first (or last) return points as surrogates for pulses. As used in this specification, NPD refers to single swath, single instrument data, whereas aggregate nominal pulse density describes the overall pulse density resulting from multiple passes of the lidar instrument, or a single pass of a platform with multiple lidar instruments, over the same target area. NPD is more commonly used in high-density collections (greater than or equal to 1 pulse per square meter [pls $\left./ \mathrm{m}^{2}\right]$ ), with its inverse, NPS, being used in low-density collections (less than or equal to $1 \mathrm{pls} / \mathrm{m}^{2}$ ). Assuming meters are being used in both expressions, NPD can be calculated from NPS using the formula $N P D=1 / N P S^{2}$. See aggregate nominal pulse density, aggregate nominal pulse spacing, nominal pulse spacing.

nominal pulse spacing (NPS) A common measure of the density of a lidar dataset, NPS is the typical or average lateral distance between pulses in a lidar dataset, typically expressed in meters and most simply calculated as the square root of the average area per first return point. This value is predicted in mission planning and empirically calculated from the collected data, using only the first (or last) return points as surrogates for pulses. As used in this specification, NPS refers to single swath, single instrument data, whereas aggregate nominal pulse spacing (ANPS) describes the overall pulse spacing resulting from multiple passes of the lidar instrument, or a single pass of a platform with multiple lidar instruments, over the same target area. NPS is more commonly used in low-density collections (greater than or equal to 1 meter [m] NPS), with its inverse, NPD, being used in high-density collections (less than $1 \mathrm{~m}$ NPS). Assuming meters are being used in both expressions, NPS can be calculated from NPD using the formula $N P S=1 / \sqrt{ } N P D$. See aggregate nominal pulse density, aggregate nominal pulse spacing, nominal pulse density.

nonvegetated vertical accuracy (NVA) Replaces fundamental vertical accuracy (FVA). The vertical accuracy at the 95-percent confidence level in nonvegetated open terrain, where errors should approximate a normal distribution. See fundamental vertical accuracy.

$\mathbf{P}$

percentile A measure used in statistics indicating the value below which a given percentage of observations (absolute values of errors) in a group of observations fall; for example, the 95th percentile is the value (or score) below which 95 percent of the observations may be detected. There are different approaches to determining percentile ranks and associated values. This specification recommends the use of the following equations for computing percentile rank and percentile as the most appropriate for estimating the vegetated vertical accuracy. Note that percentile calculations are based on the absolute values of the errors because the magnitude of the errors, not the sign, is of concern. The percentile rank $(n)$ is first calculated for the desired percentile using the following equation:

$$
n=\left(\left(\frac{P}{100}\right) \times(N-1)\right)+1
$$

where 
$n \quad$ is the rank of the observation that contains the $P$ th percentile,

$P \quad$ is the proportion (of 100) at which the percentile is desired

(for example, 95 for 95 th percentile), and

$N \quad$ is the number of observations in the sample dataset.

Once the rank of the observation is determined, the percentile $\left(\mathrm{Q}_{\mathrm{p}}\right)$ can then be interpolated from the upper and lower observations using the following equation:

$$
Q_{p}=\left(A\left[n_{w}\right]+\left(n_{d} \times\left(A\left[n_{w}+1\right]-A\left[n_{w}\right]\right)\right)\right)
$$

where

$Q_{p} \quad$ is the $P$ th percentile; the value at rank $n$;

$A \quad$ is an array of the absolute values of the samples, indexed in ascending order from 1 to $N$;

$A[i]$ is the sample value of array $A$ at index $i$ (for example, $n_{w}$ or $n_{d}$ ) and $i$ must be an integer between 1 and $N$;

$n \quad$ is the rank of the observation that contains the $P$ th percentile;

$n_{w} \quad$ is the whole number component of $n$ (for example, 3 of 3.14); and

$n_{d} \quad$ is the decimal component of $n$ (for example, 0.14 of 3.14).

pixel See cell.

playa An undrained desert basin that periodically fills with water to form a temporary lake. Playas drain directly into the ground. They can often be identified by having apparent inlet channels but no outlets and having flat and level floors.

point classification The assignment of a target identity classification to a particular lidar point or group of points.

point cloud One of the fundamental types of geospatial data (others being vector and raster), a point cloud is a large set of 3D points, typically from a lidar collection. As a basic geographic information system data type, a point cloud is differentiated from a typical point dataset in several key ways:

- point clouds are almost always 3D,

- point clouds are orders of magnitude denser than point datasets, and

- individual point features in point clouds do not typically possess individually meaningful attributes; the informational value in a point cloud is derived from the relations among large numbers of features. See raster, vector.

precision (repeatability) The closeness with which measurements agree with each other, even though they may all contain a systematic bias. See accuracy.

point family The complete set of multiple returns reflected from a single lidar pulse.

preprocessing In lidar, the preprocessing of data most commonly refers to those steps used in converting the collected GPS, IMU, instrument, and ranging information into interpretable $\mathrm{X}-\mathrm{Y}-\mathrm{Z}$ point data, including generating trajectory information, calibrating the dataset, and controlling the dataset to known ground references.

postprocessing In lidar, postprocessing refers to the processing steps applied to lidar data, including point classification, feature extraction (for example, building footprints, hydrographic features, and others), tiling, and generation of derivative products (DEMs, DSMs, intensity images, and others).

\section{$\mathbf{R}$}

raster One of the fundamental types of geospatial data (others being vector and point cloud), a raster is an array of cells (or pixels) that each contain a single piece of numeric information 
representative of the area covered by the cell. Raster datasets are spatially continuous; with respect to DEMs, this quality creates a surface from which information can be extracted from any location. As spatial arrays, rasters are always rectangular; cells are most often square. Colocated rasters can be stored in a single file as layers, as with color digital images. See raster, vector.

resolution The smallest unit a sensor can detect or the smallest unit a raster DEM depicts. The degree of fineness to which a measurement can be made. "Resolution" is also used to describe the linear size of an image pixel or raster cell.

root mean square difference (RMSD) The square root of the average of the set of squared differences between two dataset coordinate values taken at identical locations. RMSD differentiates from root mean square error (RMSE) because neither dataset is known to be more or less accurate than the other, and the differences cannot be regarded as errors. RMSD is used in lidar when assessing relative accuracy, both intraswath and interswath. See root mean square error.

root mean square error (RMSE) The square root of the average of the set of squared differences between dataset coordinate values and coordinate values from an independent source of higher accuracy for identical points. The RMSE is used to estimate the absolute accuracy of horizontal and vertical coordinates when standard or accepted values are known, as with GPS-surveyed check points of higher accuracy than the data being tested. In the United States, the independent source of higher accuracy is expected to be at least three times more accurate than the dataset being tested.

- $\boldsymbol{R M S E}_{\boldsymbol{r}}$ The horizontal root mean square error in the radial direction that includes $\mathrm{x}$ and y coordinate errors.

$$
\sqrt{\left(R M S E_{x}^{2}+R M S E_{y}^{2}\right.}
$$

where

$R M S E_{x} \quad$ is the RMSE in the $\mathrm{x}$ direction, and

$R M S E_{y} \quad$ is the RMSE in the y direction.

- $\boldsymbol{R M S E}_{\boldsymbol{x}}$ The horizontal root mean square error in the $\mathrm{x}$ direction (easting).

$$
\sqrt{\Sigma \frac{\left(x_{n}-x_{n}^{\prime}\right)^{2}}{N}}
$$

where

$x_{n} \quad$ is the is the set of $N \mathrm{x}$ coordinates being evaluated,

$x_{n}^{\prime} \quad$ is the corresponding set of check point $\mathrm{x}$ coordinates for the points being evaluated,

$N \quad$ is the number of $\mathrm{x}$ coordinate check points, and

$n \quad$ is the identification number of each checkpoint from 1 through $N$.

- $\boldsymbol{R M S E}_{\boldsymbol{y}}$ The horizontal root mean square error in the y direction (northing).

$$
\sqrt{\sum \frac{\left(y_{n}-y_{n}^{\prime}\right)^{2}}{N}}
$$

where

$y_{n} \quad$ is the is the set of $N \mathrm{y}$ coordinates being evaluated,

$y_{n}^{\prime} \quad$ is the corresponding set of check point $\mathrm{x}$ coordinates for the points being 
evaluated,

$N \quad$ is the number of $\mathrm{x}$ coordinate check points, and

$n \quad$ is the identification number of each checkpoint from 1 through $N$.

- $\boldsymbol{R M S E}_{\mathbf{z}}$ The vertical root mean square error in the $\mathrm{z}$ direction (elevation).

$$
\sqrt{\sum \frac{\left(z_{n}-z^{\prime} n\right)^{2}}{N}}
$$

where
$z_{n} \quad$ is the is the set of $N \mathrm{x}$ coordinates being evaluated,
$z_{n}^{\prime} \quad$ is the corresponding set of check point $\mathrm{x}$ coordinates for the points being evaluated,
$N \quad$ is the number of $\mathrm{x}$ coordinate check points, and
$n \quad$ is the identification number of each checkpoint from 1 through $N$.

\section{S}

saddle The lowest area between two opposing higher terrain features, usually connecting two areas of lower terrain, as in a mountain pass. Used in this specification to reference the area exposed by the removal or exclusion of a bridge deck from a DEM. See bridge.

siphon A structure designed to convey water by gravitational force over, or under, an obstruction. Often seen as vertical pipes in smaller ponds with earthen dams that convey overflow water under the dam.

spatial distribution In lidar, the regularity or consistency of the point density within the collection. The theoretical ideal spatial distribution for a lidar collection is a perfect regular lattice of points with equal spacing on $\mathrm{x}$ - and $\mathrm{y}$-axes. Various factors prevent this ideal from being achieved, including the following factors:

- instrument design (oscillating mirrors),

- mission planning (difference between along-track and cross-track pulse spacing), and

- in-flight attitude variations (roll, pitch, and yaw).

standard deviation A measure of spread or dispersion of a sample of errors around the sample mean error. It is a measure of precision, rather than accuracy; the standard deviation does not account for uncorrected systematic errors.

systematic error An error whose algebraic sign, and to some extent magnitude, bears a fixed relation to some condition or set of conditions. Systematic errors follow some fixed pattern and are introduced by data collection procedures, processing, or given datum.

\section{T}

topology The spatial relation between geographic features in a common space. Examples particularly relevant to this specification include precise coincidence of ending and beginning vertices of lines in a continuous network (stream connectivity) and consistent line direction (from high to low) corresponding to streamflow direction.

triangulated irregular network (TIN) A vector data structure that partitions geographic space into contiguous, nonoverlapping triangles. In lidar, the vertices of each triangle are lidar points with $\mathrm{x}-, \mathrm{y}-$, and z-values. In most geographic applications, TINs are based on Delaunay triangulation algorithms in which no point in any given triangle lies within the circumcircle of any other triangle.

\section{U}

uncertainty (of measurement) A parameter that characterizes the dispersion of measured 
values, or the range in which the "true" value most likely lies. It can also be defined as an estimate of the limits of the error in a measurement (where "error" is defined as the difference between the theoretically unknowable "true" value of a parameter and its measured value). Standard uncertainty refers to uncertainty expressed as a standard deviation.

\section{V}

vector One of the fundamental types of geospatial data (others being raster and point cloud), vectors include a variety of data structures that are geometrically described by $\mathrm{x}, \mathrm{y}$, and potentially z coordinates. Vector data subtypes include points, lines, and polygons. A DTM consisting of mass points and breaklines is an example of a vector dataset; a TIN is a vector surface. See point cloud, raster.

vegetated vertical accuracy (VVA) Replaces supplemental vertical accuracy (SVA) and consolidated vertical accuracy (CVA). An estimate of the vertical accuracy, based on the 95th percentile, in vegetated terrain where errors do not necessarily approximate a normal distribution. See percentile, nonvegetated vertical accuracy.

\section{W}

well distributed For a dataset covering a rectangular area that has uniform positional accuracy, check points should be distributed so that points are spaced at intervals of at least 10 percent of the diagonal distance across the dataset and at least 20 percent of the points are in each quadrant of the dataset (adapted from the "National Standards for Spatial Data Accuracy" [Federal Geographic Data Committee, 1998b]). As related to this specification, these guidelines are applicable to each land cover class for which checkpoints are being collected.

withheld Within the LAS file specification, a single bit flag indicating that the associated lidar point is geometrically anomalous or unreliable and should be ignored for all normal processes. These points are retained because of their value in specialized analysis. Withheld points typically are identified and tagged during preprocessing or through the use of automatic classification routines. Examples of points typically tagged as withheld are listed below:

- spatial outliers in either the horizontal or vertical domains, and

- geometrically unreliable points near the edge of the swath. 


\section{Appendix 1 Elevation Hydrography Features in 3D Elevation Program Light Detection and Ranging Base Specification Version 1.3}

This appendix describes how this specification differs from the 3D Elevation Program Light Detection and Ranging (Lidar) Base Specification version 1.3 (LBS 1.3) regarding the optional Elevation Hydrography (EleHydro) breakline capture (Heidemann, 2018). This appendix is included as a reference to changes in attribution of elevation-derived hydrography $(\mathrm{EDH})$.

The LBS 1.3 is an informative document that describes the background, justification, and goals of an integrated elevation and hydrography product. The "EleHydro Breakline GIS Data Dictionary" section in LBS 1.3 (Heidemann, 2018) was written before a pilot project testing the data structure and requirements was completed. In this specification, the hydrographic features needed for capture have been reduced because of the difficulty in identifying and coding hydrographic features from a lidar-elevation product.

Images of the tables from LBS 1.3 describing EleHydro breakline features are included here as a reference to the original set of required features that were published. Those tables have been superseded by the specifications contained in this document.

\section{Attribute Table Structure}

The attribute table structure for the EDH Acquisition Specifications has been simplified from the LBS 1.3 attribute table structure. The fields from the LBS 1.3 EleHydro GIS data dictionary, Feature type, elevation (EType), surface feature type (SFType), exclude distance 1 (Exclude1), exclude distance 2 (Exclude2), and obscurity are no longer required attributes in this EDH specification (fig. 1.1).

\section{Domain Values}

The greatest difference between LBS 1.3 and this specification is the type of features expected to be included within the hydrography layer. Many of the features were determined to be too difficult to interpret and collect from a lidar dataset and would cause considerable research to determine the precise feature type. Elevation features that are not necessary for the creation of hydrography-conditioned or enforced elevation surfaces were also removed from the domain list. Features were renamed to the feature code (FCode) description if the elevation and hydrography features were the same. The feature type for elevation (EType) and FCode values were retained, where applicable, from the LBS 1.3 domain values. Two new codes were added, drainageway and pipeline, to remain consistent with new National Hydrography Dataset coding schemas (fig. 1.2).

\section{Codes for Point, Line, and Polygon Features}

The codes and cross-reference between elevation and hydrography are fully described in the EDH Acquisition Specifications and READ Rules (this report and Archuleta and Terziotti, 2020). The following images of tables from the LBS 1.3 are no longer valid (figs. 1.3-1.5). 


\begin{tabular}{|c|c|c|c|c|}
\hline \multicolumn{5}{|c|}{ Point features } \\
\hline Attribute & Item name & Item type & Item precision & Item scale \\
\hline Feature ID & $F I D$ & Object ID & \multicolumn{2}{|c|}{ system } \\
\hline Shape & Shape & Geometry, PointZ & \multicolumn{2}{|c|}{ system } \\
\hline Feature Group (NHD) & FGroup & Short & 4 & 0 \\
\hline Feature Code (NHD) & FCode & Long & 5 & 0 \\
\hline Feature Class (Elevation) & EClass & Short & 4 & 0 \\
\hline Feature Type (Elevation) & EType & Short & 4 & 0 \\
\hline Surface Feature Type & SFType & Short & 4 & 0 \\
\hline Exclude Distance 1 & Exclude1 & Float & 8 & 2 \\
\hline Exclude Distance 2 & Exclude2 & Float & 8 & 2 \\
\hline Description & Desc & Text & 128 & $\mathrm{n} / \mathrm{a}$ \\
\hline Obscurity & Obscurity & Short & 2 & 0 \\
\hline \multicolumn{5}{|c|}{ Line features } \\
\hline Attribute & Item name & Item type & em precision & Item scale \\
\hline Feature ID & $F I D$ & Object ID & \multicolumn{2}{|c|}{ system } \\
\hline Shape & Shape & Geometry, Polyl & \multicolumn{2}{|c|}{ system } \\
\hline Feature Group (NHD) & FGroup & Short & 4 & 0 \\
\hline Feature Code (NHD) & FCode & & 5 & 0 \\
\hline Feature Class (Elevation) & EClass & Short & 4 & 0 \\
\hline Feature Type (Elevation) & EType & Short & 4 & 0 \\
\hline Surface Feature Type & रा 1уре & Short & 4 & 0 \\
\hline Exclude Distance 1 & Exclude1 & Float & 8 & 2 \\
\hline Exclude Distance 2 & & Float & 8 & 2 \\
\hline Description & Desc & Text & 128 & $\mathrm{n} / \mathrm{a}$ \\
\hline Obscurity & Obseurity & Short & 2 & 0 \\
\hline \multicolumn{5}{|c|}{ Polygon features } \\
\hline Attribute & Item name & Item type & Item precision & Item scale \\
\hline Feature ID & $F I D$ & Object ID & \multicolumn{2}{|c|}{ system } \\
\hline Shape & Shape & Geometry, PolygonZ & \multicolumn{2}{|c|}{ system } \\
\hline Feature Group (NHD) & FGroup & Short & 4 & 0 \\
\hline Feature Code (NHD) & FCode & Long & 5 & 0 \\
\hline Feature Class (Elevation) & EClass & Short & 4 & 0 \\
\hline Feature Type (Elevation) & EType & Short & 4 & 0 \\
\hline Surface Feature Type & SFType & Short & 4 & 0 \\
\hline Exclude Distance 1 & Exclude1 & Float & 8 & 2 \\
\hline Exclude Distance 2 & Exclude2 & Float & 8 & 2 \\
\hline Description & Desc & Text & 128 & $\mathrm{n} / \mathrm{a}$ \\
\hline Obscurity & Obscurity & Short & 2 & 0 \\
\hline
\end{tabular}

Figure 1.1. Attribute table structure for Elevation Hydrography breakline features from the 3D Elevation Program Light Detection and Ranging Base Specification, version 1.3 (modified from Heidemann, 2018). The data are invalid and superseded by this report. [ID, identifier; FID, feature identifier; NHD, National Hydrography Dataset; n/a, not applicable or not available] 


\begin{tabular}{|c|c|c|c|c|c|c|c|c|c|c|c|}
\hline \multicolumn{4}{|c|}{ NHD related codes } & \multicolumn{4}{|c|}{ Elevation related codes } & \multicolumn{4}{|c|}{ General codes } \\
\hline \multicolumn{2}{|r|}{ FGroup } & \multicolumn{2}{|c|}{ FCode } & \multicolumn{2}{|r|}{ EClass } & \multicolumn{2}{|r|}{ EType } & \multicolumn{2}{|r|}{ SFType } & \multicolumn{2}{|c|}{ Obscurity $^{1}$} \\
\hline 0 & Non-NHD & 00000 & Non-NHD & 0 & Non-Elevation & 0000 & Non-Elevation & 0 & Ignore & 0 & $<$ blank $>$ \\
\hline 2 & NHD Line & 33400 & Connector & 2 & Topographic & 1003 & Gate & 2 & Soft Line & & \\
\hline 3 & NHD Flowline & 33600 & Canal/Ditch & 3 & Manmade & 1004 & Dam/Weir & 3 & Hard Line & & \\
\hline \multirow[t]{24}{*}{5} & $\begin{array}{l}\text { NHD Water- } \\
\text { body }\end{array}$ & 36100 & Playa & & & 1102 & Canal/Ditch & \multicolumn{2}{|c|}{5 Hard Replace } & & \\
\hline & & 36900 & Gate & & & 1103 & Culvert & 6 & Soft Clip & & \\
\hline & & 39000 & Lake/Pond & & & 1104 & Spillway & 7 & Hard Clip & & \\
\hline & & 42813 & Pipeline-Siphon & & & 1105 & Stream Braid & 8 & Soft Erase & & \\
\hline & & 42816 & Pipeline-Aqueduct & & & 1116 & Playa & 10 & Soft Fill & & \\
\hline & & 43600 & Reservoir & & & 1107 & River & 11 & Hard Fill & & \\
\hline & & 43612 & $\begin{array}{l}\text { Sewage Treatment- } \\
\text { Settling Pond }\end{array}$ & & & 1108 & Reservoir & 12 & Barrier & & \\
\hline & & 44500 & Sea/Ocean & & & 1109 & Fjord & & & & \\
\hline & & 45000 & Sink/Rise & & & 1110 & Bay/Inlet/Sound & & & & \\
\hline & & 45500 & Spillway & & & 1111 & $\begin{array}{l}\text { Boundary Water- } \\
\text { body }\end{array}$ & & & & \\
\hline & & 46000 & Stream/River & & & 1201 & Centerline & & & & \\
\hline & & 46600 & Swamp/Marsh & & & 1202 & Link & & & & \\
\hline & & 53700 & Complex Channel & & & 1203 & Elevation Terminus & & & & \\
\hline & & 55800 & Artificial Path & & & 1204 & Flattener & & & & \\
\hline & & 56600 & Coastline & & & 1205 & Pipeline & & & & \\
\hline & & & & & & 1301 & Bridge Deck & & & & \\
\hline & & & & & & 1303 & Topographic Feature & & & & \\
\hline & & & & & & 1401 & Swamp/Marsh Area & & & & \\
\hline & & & & & & 1402 & $\begin{array}{l}\text { Braided Stream } \\
\text { Area }\end{array}$ & & & & \\
\hline & & & & & & 1403 & $\begin{array}{l}\text { Unusually Inundat- } \\
\text { ed Area }\end{array}$ & & & & \\
\hline & & & & & & 1404 & $\begin{array}{c}\text { Island/Sandbar-In- } \\
\text { termittently/Par- } \\
\text { tially Submerged } \\
\end{array}$ & & & & \\
\hline & & & & & & 1501 & $\begin{array}{l}\text { Low Confidence } \\
\text { Area } \\
\text { (pre-determined) }\end{array}$ & & & & \\
\hline & & & & & & 1502 & $\begin{array}{l}\text { Low Confidence } \\
\text { Area (sparse bare } \\
\text { earth) }\end{array}$ & & & & \\
\hline & & & & & & 1503 & $\begin{array}{l}\text { Low Confidence } \\
\text { Area (snow-cov- } \\
\text { ered) }\end{array}$ & & & & \\
\hline
\end{tabular}

${ }^{1}$ In the EleHydro database, "obscurity" is used to identify feature segments that lie beneath bridge decks, not those obscured by vegetation or other structures. Usually these are sections of rivers, lakes, centerlines, single-line streams, or other features where they pass under bridges (EType 1301).

Figure 1.2. Domain values and descriptions for feature attributes from the 3D Elevation Program Light Detection and Ranging Base Specification, version 1.3 (modified from Heidemann, 2018). The data are invalid and are superseded by this report. [NHD, National Hydrography Dataset; EClass, EType, SFType, FGroup, and FCode are user field names, specified in figure 1.1. They represent elevation class, elevation type, surface feature type, feature group, and feature code, respectively] 


\begin{tabular}{|c|c|c|c|c|c|c|}
\hline Elevation description & EClass & EType & SFType & $\begin{array}{l}\text { NHD } \\
\text { description }\end{array}$ & FGroup & FCode \\
\hline \multicolumn{7}{|c|}{ Features as points } \\
\hline $\begin{array}{l}\text { Gate (connecting two single-line flows; } \\
\text { marks a potential change in flow direction) }\end{array}$ & 3 & & tbd & Gate & 1 & 36900 \\
\hline $\begin{array}{l}\text { Dam/Weir (connecting two single-line flows; } \\
\text { marks a change in water surface elevation) }\end{array}$ & & 1004 & tbd & Dam/Weir & 1 & 34300 \\
\hline Other topographic element & 2 & 1303 & tbd & $\mathrm{n} / \mathrm{a}$ & 0 & 00000 \\
\hline
\end{tabular}

Figure 1.3. Codes for Elevation Hydrography breakline point features from the 3D Elevation Program Light Detection and Ranging Base Specification, version 1.3 (modified from Heidemann, 2018). The data are invalid and are superseded by this report. [EClass, EType, SFType, FGroup, and FCode are user field names, specified in figure 1.1. They represent elevation class, elevation type, surface feature type, feature group, and feature code, respectively. Gray shading indicates codes that are not relevant for the data type in that column. NHD, National Hydrography Dataset; tbd, to be determined; n/a, not applicable or not available] 


\begin{tabular}{|c|c|c|c|c|c|c|}
\hline Elevation description & EClass & EType & SFType & NHD description & FGroup & FCode \\
\hline \multicolumn{7}{|c|}{ Features as lines } \\
\hline \multicolumn{7}{|l|}{ Gate } \\
\hline $\begin{array}{l}\text { (crossing polygonal water features; marks } \\
\text { a potential change in flow direction) }\end{array}$ & 3 & 1003 & tbd & Gate & 2 & 36900 \\
\hline $\begin{array}{l}\text { Dam/Weir } \\
\text { (crossing polygonal water features; marks } \\
\text { a change in water surface elevation) }\end{array}$ & 3 & 1004 & tbd & Dam/Weir & 2 & 34300 \\
\hline Canal/Ditch (narrow; depicted as single line) & 1 & 1102 & & Canal/Ditch & 3 & 33600 \\
\hline \multirow{2}{*}{$\begin{array}{l}\text { Culvert } \\
\text { (single line, or centerline of polygonal } \\
\text { culvert) }\end{array}$} & & 1103 & & if in Stream/River & 3 & 46000 \\
\hline & 1 & & & if in Canal/Ditch & 3 & 33600 \\
\hline $\begin{array}{l}\text { Spillway } \\
\text { (single line, or centerline of polygonal } \\
\text { spillway) }\end{array}$ & & & tbd & $\rightarrow$ if in Artificial Path & 3 & 55800 \\
\hline $\begin{array}{l}\text { Stream braid (narrow single-line streams; } \\
\text { not the apparent main channel) }\end{array}$ & & & tbd & Stream/River & 3 & 46000 \\
\hline Centerline (any waterbody) & & 1201 & tbd & Artificial Path & 3 & 55800 \\
\hline Link (single line to centerline) & 1 & 1202 & tbd & Artificial Path & 3 & 55800 \\
\hline \multirow{3}{*}{$\begin{array}{l}\text { Pipeline } \\
\text { (siphon, penstock, or aqueduct - possibly } \\
\text { buried) }\end{array}$} & \multirow{3}{*}{1} & \multirow{3}{*}{1205} & \multirow{3}{*}{$\begin{array}{l}\text { tbd } \\
\text { tbd }\end{array}$} & $\rightarrow$ if Siphon & 3 & 42813 \\
\hline & & & & $\rightarrow$ if Penstock & 3 & 42815 \\
\hline & & & & $\rightarrow$ if Aqueduct & 3 & 42816 \\
\hline $\mathrm{n} / \mathrm{a}$ & 0 & 0000 & tbd & $\begin{array}{l}\text { Connector (see NHD } \\
\text { definition) }\end{array}$ & 3 & 33400 \\
\hline
\end{tabular}

Figure 1.4. Codes for Elevation Hydrography breakline line features from the 3D Elevation Program Light Detection and Ranging Base Specification, version 1.3 (modified from Heidemann, 2018). The data are invalid and are superseded by this report. [EClass, EType, SFType, FGroup, and FCode are user field names specified in figure 1.1. They represent elevation class, elevation type, surface feature type, feature group, and feature code, respectively. Gray shading indicates codes that are not relevant for the data type in that column. NHD, National Hydrography Dataset; tbd, to be determined; n/a, not applicable or not available] 


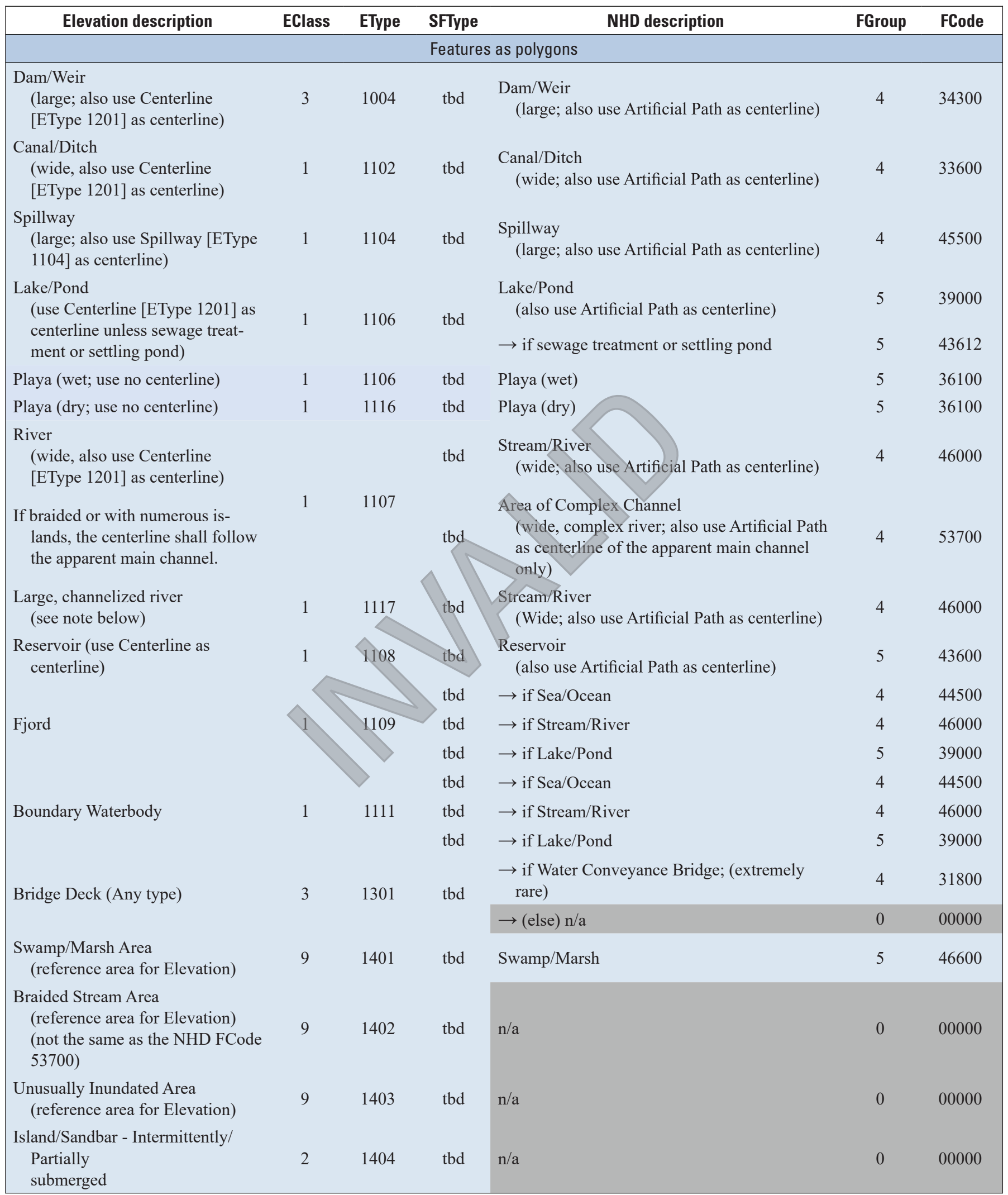

Figure 1.5. Codes for Elevation Hydrography breakline polygon features from the 3D Elevation Program Light Detection and Ranging Base Specification, version 1.3 (modified from Heidemann, 2018). The data are invalid and are superseded by this report. [EClass, EType, SFType, FGroup, and FCode are user field names, specified in figure 1.1. They represent elevation class, elevation type, surface feature type, feature group, and feature code, respectively. Gray shading indicates codes that are not relevant for the data type in that column. NHD, National Hydrography Dataset; tbd, to be determined; n/a, not applicable or not available] 


\begin{tabular}{|c|c|c|c|c|c|c|}
\hline Elevation description & EClass & EType & SFType & NHD description & FGroup & FCode \\
\hline \multicolumn{7}{|c|}{ Features as polygons (continued) } \\
\hline $\begin{array}{l}\text { Low Confidence Area } \\
\text { (pre-determined) } \\
\text { (reference area for Elevation) }\end{array}$ & 9 & 1501 & tbd & & 0 & 00000 \\
\hline $\begin{array}{l}\text { Low Confidence Area } \\
\text { (sparse bare earth) } \\
\text { (reference area for Elevation) }\end{array}$ & 9 & 1502 & & & 0 & 00000 \\
\hline $\begin{array}{l}\text { Low Confidence Area } \\
\text { (snow-cover) } \\
\text { (reference area for Elevation) }\end{array}$ & 9 & & & & 0 & 00000 \\
\hline $\begin{array}{l}\text { Culvert (large) } \\
\text { also use Culvert Line as centerline } \\
\quad \text { (uncommon) }\end{array}$ & 1 & & & & 0 & 00000 \\
\hline
\end{tabular}

Figure 1.5. Codes for Elevation Hydrography breakline polygon features from the 3D Elevation Program Light Detection and Ranging Base Specification, version 1.3 (modified from Heidemann, 2018). The data are invalid and are superseded by this report. [EClass, EType, SFType, FGroup, and FCode are user field names, specified in figure 1.1. They represent elevation class, elevation type, surface feature type, feature group, and feature code, respectively. Gray shading indicates codes that are not relevant for the data type in that column. NHD, National Hydrography Dataset; tbd, to be determined; n/a, not applicable or not available]—Continued

\section{References Cited}

Archuleta, C.M., and Terziotti, S., 2020, Elevation-Derived Hydrography-Representation, Extraction, Attribution, and Delineation Rules: U.S. Geological Survey Techniques and Methods, book 11, chap. B12, 60 p., https://doi.org/10.3133/ tm11B12.

Heidemann, H.K., 2018, Lidar Base Specification (ver. 1.3, February 2018): U.S. Geological Survey Techniques and Methods, book 11, chap. B4, 101 p., accessed December 2019 at https://doi.org/10.3133/tm11b4. 


\section{Appendix 2 Specification Chapter Summary}

Chapter summaries are provided as a quick reference to the Elevation-Derived Hydrography Acquisition Specification. No explanatory figures are included in the summary. Please refer to the main report for more details. Primary headings in the summary appendix are preceded with "A-2" to differentiate from the body of the report.

\section{A-2 Collection Area}

The collection area refers to the geographic extent where the elevation source exists and from which hydrography will be derived. Hydrographic features can be collected at the same time elevation source data are being processed or taken from an existing 3D Elevation Program (3DEP) collection, when available. Collection areas from multiple sources of elevation data should be inspected and tile and collection area boundaries shall edge-match seamlessly and without gap prior to deriving hydrography.

\section{Collection Concurrent with Elevation}

Features shall be collected within the same defined project area (DPA) as the source elevation data.

1. Hydrography should be delineated for the entire DPA.

2. Parts of the DPA within a complete 10-digit hydrologic unit should have complete network connectivity.

3. Areas outside a 10-digit hydrologic unit, but within the DPA, should be connected and network connectivity created where possible.

a. Linework should not be snapped to less accurate features outside of the DPA.

b. A complete set of features shall be captured up to the boundary, but topology and network connectivity may need to be corrected at a later date.

4. If elevation-derived hydrography exists adjacent to the DPA, linework should be snapped and merged to create continuous features that do not stop at the DPA boundary (unless it is also a hydrologic unit boundary).

\section{Collection from Existing Elevation Data}

1. Features shall be collected within a minimum 10-digit hydrologic unit area.

2. Features that flow from one 10-digit hydrologic unit area to another that contains light detection and ranging (lidar) derived hydrography shall be snapped and topology corrected between hydrologic units.

a. Linear features shall be merged based on the feature code (FCode).

b. Polygons shall be merged with the same FCode.

3. If less accurate hydrologic features are the only ones that exist outside of a hydrologic unit, features should not be snapped or adjusted to match those adjacent features.

\section{A-2 Spatial Reference System}

Final products shall be in the spatial reference system that matches the source data as defined in the LBS (U.S. Geological Survey, 2019). If a collection area is composed of multiple sources of elevation data, all elevation data shall be processed to one common coordinate reference system prior to EDH compilation.

\section{Datums}

1. For the conterminous United States, unless otherwise specified by the user and agreed to in advance by the U.S. Geological Survey (USGS) National Geospatial Program, the following guidelines apply:

- The horizontal datum for latitude and longitude and ellipsoid heights will be the North American Datum of 1983 (NAD 83) using the most recent National Geodetic Survey published adjustment (currently NAD 83, epoch 2010.00, realization of 2011).

- The vertical datum for orthometric heights will be the North American Vertical Datum of 1988.

- The geoid model used to convert between ellipsoid heights and orthometric heights will be the latest hybrid geoid model of the National Geodetic Survey, supporting the latest realization of NAD 83 (for example, [2017] GEOID12b model, GEOID18, or most current). 
2. For Alaska, American Samoa, Commonwealth of the Northern Mariana Islands, Guam, Hawaii, Puerto Rico, U.S. Virgin Islands, and other U.S. territories, the following guideline applies:

- USGS National Geospatial Program and all collection partners shall agree to and specify horizontal and vertical datums, ellipsoids, and geoids in advance of data collection.

\section{A-2 Attribute Table Structure}

The structure of the attribute tables is described in tables 2.1 and 2.2. An important component of the EDH features is that they have three-dimensional (3D) geometry. Each feature type must be z-enabled, with z-values assigned to each point, vertex, and node. The feature classes (pointZ, polylineZ, and polygonZ) are 3D geometry.

- Feature class (FClass) - A short integer one-digit code defining whether a feature is intended for use as a National Hydrography Dataset (NHD) feature (will be used for conflation), a non-NHD feature (outside of the collection criteria and not intended to be used

Table 2.1. Geometry of elevation-derived hydrography feature types.

$[3 \mathrm{D}$, three dimensional $]$

\begin{tabular}{lcc}
\hline \multicolumn{3}{c}{ Geometry of each feature type } \\
\hline \multicolumn{1}{c}{ Feature type } & \multicolumn{1}{c}{ Format } & \multicolumn{1}{c}{ Geometry } \\
\hline Point & Vector shape & 3D point, pointZ \\
Line & Vector shape & 3D line, polylineZ \\
Polygon & Vector shape & 3D polygon, polygonZ \\
\hline
\end{tabular}

for conflation), or a nonhydrography feature (elevation dataset limitation). An example of a point feature is a sink. An example of a line feature is a stream that is too narrow to be represented (less than 15 meters [m] wide) as a polygon, so is represented with a line. An example of a polygon feature is a wide river, or a lake/pond. If a feature is not an NHD feature, and is necessary for elevation processing, a 9 is used as the FClass. A polygon representing a low-confidence area is an example of a feature that would not be used in the NHD but may be useful for elevation processing.

- Feature class for elevation (EClass) - A short integer one-digit code indicating whether a feature is used for elevation derivatives; used for other nonspecified elevation purposes; used for hydroflattening; or an elevation dataset limitation feature. For instance, a low-confidence area is coded as a 9. A culvert is a special case with no associated NHD coding but is necessary for some elevation treatments. Culverts shall be coded as an EClass of 3 .

- FCode-A long integer field containing a coded value. Most of the FCodes are equivalent to the NHD FCode value, which is a five-digit integer code representing various hydrologic feature types. For instance, a lake/pond has an FCode of 39000, and a stream/river has an FCode of 46000. The codes that do not have a corresponding NHD code are included to differentiate features that may be useful in describing limitations in the elevation dataset, potentially affecting hydrography and elevation derivatives.

Table 2.2. Attribute table structure for hydrographic feature.

[NHD, National Hydrography Dataset]

\begin{tabular}{lllcc}
\hline \multicolumn{1}{c}{ Attributes for each feature type } \\
\hline \multirow{2}{*}{ Attribute description } & \multicolumn{3}{c}{ Table items } \\
\cline { 2 - 5 } & \multicolumn{1}{c}{ Item name } & Item & Item type & Item precision \\
\hline Feature class (NHD) & FClass & Integer & Short & 4 \\
Feature class (elevation) & EClass & Integer & Short & 4 \\
Feature code (NHD) & FCode & Integer & Long & 5 \\
Description & Desc & Text & Text & 250 \\
Elevation source data & Source & Text & Text & 128 \\
Hydrography delineation method & Method & Text & Text & 250 \\
User-defined code & UserCode & Text & Text & 25 \\
Free-text space for user comments & Comments & Text & Text & 250 \\
\hline
\end{tabular}


- Desc-A 250-character free-text field with a text description of FCode, or it can be used for user-defined features not included in the domain list. Not required.

- Source-A 128-character free-text field with a text description of the elevation source data used for deriving the hydrography. Lidar-source data should include collection name, date, and quality level.

- Method-A 250-character free-text field with a text description of the method used for deriving the hydrography. For instance, software or models could be listed, or digitizing techniques, if used. Ancillary datasets could be noted here.

- User-defined code (UserCode) - A 25-character freetext field with a code designated by the acquisition entity to identify features collected outside the scope of features described in this specification document. It is intended to be used as a key to join tables with attributes outside of this specification. Not required.

- Comments-A 250-character free-text field for user comments. Not required.

\section{A-2 Feature Codes and Values}

Hydrographic features collected under the scope of this specification document represent a subset of the features included within the NHD. Where appropriate, the FCode values and descriptions match the NHD specifications. Elevation features used as breaklines for hydroflattening, or for other elevation surface treatments, are identified with an elevation class as well as a hydrography FCode. The complete set of domain values required with this specification is provided in table 2.3. The companion document "Elevation-Derived Hydrography-Representation, Extraction, Attribution, and Delineation rules" (READ Rules) further defines the fields, domains, and minimum feature collection requirements for each required feature (Archuleta and Terziotti, 2020).

\section{D Elevation Program Light Detection and Ranging Base Specification Required Hydroflattening Features}

A subset of the features collected can be used for the LBS hydroflattening requirement (table 2.4). The EDH FCodes that correspond to hydroflattening features are cross-referenced so the appropriate code can be used to adhere to the hydroflattening requirements of the LBS (U.S. Geological Survey, 2019). EClass $=1$, which is used for hydroflattening (3D polygon), shall be used to identify the polygons in the EDH data (table 2.5).
Table 2.3A. Domain values for feature attributes.

[FClass, feature class; NHD, National Hydrography Dataset; EClass, feature class (elevation); 3D, three dimensional]

\begin{tabular}{cc}
$\begin{array}{c}\text { Domain } \\
\text { value }\end{array}$ & \multicolumn{1}{c}{$\begin{array}{c}\text { Feature } \\
\text { description }\end{array}$} \\
\hline 1 & FClass \\
2 & Non-NHD feature (outside of collection criteria). \\
9 & $\begin{array}{c}\text { Nonhydrography feature (elevation dataset } \\
\text { limitation). }\end{array}$ \\
\hline 0 & EClass \\
\hline 1 & Not used for elevation derivatives. \\
2 & Hsed for hydroflattening (3D polygon). \\
& other than culverts or those used for \\
& hydroflattening. \\
\hline & Culvert - used for hydroenforcement. \\
\hline
\end{tabular}

Table 2.3B. FCode domain values and descriptions.

[FCode, feature code; Desc, description]

\begin{tabular}{cl}
\hline FCode & \\
\hline 0 & User-defined feature ${ }^{1}$ \\
33400 & Connector \\
33600 & Canal/ditch \\
34300 & Dam/weir \\
36100 & Playa \\
37800 & Ice mass \\
39000 & Lake/pond \\
42800 & Pipeline \\
43600 & Reservoir \\
44500 & Sea/ocean \\
45000 & Sink/rise \\
46000 & Stream/river \\
46800 & Drainageway ${ }^{1}$ \\
53700 & Area of complex channels \\
55800 & Artificial path \\
Assigned based on & Culvert ${ }^{1}$-adjacent feature description \\
adjacent features ${ }^{2}$ & \\
991 & Low-confidence area (predetermined) \\
992 & Low-confidence area (sparse bare earth) \\
993 & Low-confidence area (snow covered) \\
\hline
\end{tabular}

1 New feature

2FCodes include 33400, 42800, 33600, 46000, 46800, and 55800. See figure 11 and table 12. 


\section{Additional User-Defined Features}

There are two primary uses for the UserCode field: to identify features that are outside the scope of this specification but are required by the user and to refine the FCode classification with additional NHD FCode values.

Table 2.4. Polygon features used for hydroflattening an elevation surface.

[Desc, description; FCode, feature code]

\begin{tabular}{lc}
\hline & Features required for hydroflattening \\
\hline \multicolumn{1}{c}{ Desc } & FCode \\
\hline Lake/pond & 39000 \\
Reservoir & 43600 \\
Sea/ocean & 44500 \\
Stream/river & 46000 \\
\hline
\end{tabular}

1. Additional features (not defined within table 2.3) may be collected but should be given unique codes in UserCode.

2. If the feature is outside the scope of this specification, the following guidelines apply:

a. FClass, EClass, and FCode should be coded as 2, 0 (unless collected to produce an elevation derivative, then 2 ), and 0 , respectively.

b. The Desc field may be used to describe the additional feature.

c. A unique code per feature type should be added to the UserCode field.

d. Codes should not duplicate other defined features or coding used for NHD conflation.

3. Refinement of FCode with NHD FCodes should be done as follows:

Table 2.5. Hydroflattening feature and updated code.

[3DEP, 3D Elevation Program; 2D, two dimensional; ha, hectare; m, meter; DPA, defined project area]

\begin{tabular}{|c|c|c|c|c|}
\hline \multicolumn{2}{|c|}{$\begin{array}{l}\text { Hydroflattening requirements from 3DEP } \\
\text { Lidar Base Specification }\end{array}$} & \multicolumn{3}{|c|}{$\begin{array}{l}\text { Elevation-Derived Hydrography Acquisition } \\
\text { Specification codes for hydroflattening }\end{array}$} \\
\hline $\begin{array}{l}\text { Hydroflattening } \\
\text { feature }\end{array}$ & $\begin{array}{l}\text { Hydroflattening short description (see } \\
\text { Lidar Base Specification for all cases) }\end{array}$ & $\begin{array}{l}\text { Elevation-derived } \\
\text { hydrographic feature }\end{array}$ & FCode & $\begin{array}{l}\text { Elevation-derived hydrographic } \\
\text { feature 2D (polygon) description }\end{array}$ \\
\hline $\begin{array}{l}\text { Inland ponds and } \\
\text { lakes }\end{array}$ & $\begin{array}{l}\text { Waterbodies with a surface area of } \\
0.8 \text { ha ( } 2 \text { acres) or greater (approxi- } \\
\text { mately equal to a round pond } 100 \mathrm{~m} \\
\text { in diameter) at the time of collec- } \\
\text { tion shall be flattened. }\end{array}$ & Lake/pond & 39000 & $\begin{array}{l}\text { A standing body of water with a } \\
\text { predominantly natural shoreline } \\
\text { surrounded by land. }\end{array}$ \\
\hline $\begin{array}{l}\text { Inland streams and } \\
\text { rivers }\end{array}$ & $\begin{array}{l}\text { Streams and rivers of a } 30 \mathrm{~m} \text { or } \\
\text { greater nominal width shall be } \\
\text { flattened. }\end{array}$ & Stream/river & 46000 & A body of flowing water. \\
\hline Tidal waterbodies & $\begin{array}{l}\text { Tidal waterbodies are defined as any } \\
\text { waterbody that is affected by tidal } \\
\text { variations, including oceans, seas, } \\
\text { gulfs, bays, inlets, salt marshes, and } \\
\text { large lakes. }\end{array}$ & Sea/ocean & 44500 & $\begin{array}{l}\text { The great body of saltwater that } \\
\text { covers much of the Earth. }\end{array}$ \\
\hline $\begin{array}{l}\text { Nontidal boundary } \\
\text { waterbodies }\end{array}$ & $\begin{array}{l}\text { Boundary waterbodies are waterbod- } \\
\text { ies that contain some or all of the } \\
\text { DPA. } \\
\text { - Boundary waterbodies may be any } \\
\text { type of waterbody but are virtually } \\
\text { always large in area or width. } \\
\text { - A boundary waterbody shall } \\
\text { be represented as a polygon that } \\
\text { follows the shore throughout the } \\
\text { project and is then closed using } \\
\text { arbitrary line segments as needed } \\
\text { across the waterbody. Boundary } \\
\text { waterbodies do not include the } \\
\text { natural far shoreline. }\end{array}$ & $\begin{array}{l}\text { Any large } 2 \mathrm{D} \text { features at } \\
\text { the edge of the DPA. } \\
\text { Exceptions are tidal wa- } \\
\text { terbodies: sea/ocean. }\end{array}$ & $\begin{array}{l}39000, \\
43600, \\
46000\end{array}$ & $\begin{array}{l}\text { A } 2 \mathrm{D} \text { feature that is not wholly } \\
\text { contained within the DPA } \\
\text { and is therefore only partially } \\
\text { delineated. }\end{array}$ \\
\hline
\end{tabular}


a. FClass and EClass should be coded as 1 and 2, respectively.

b. FCode should be a valid code from table 2.3 .

c. The Desc field may be used to describe the additional feature.

d. The UserCode field should have a valid NHD FCode per feature (https://nhd.usgs.gov/userGuide/ Robohelpfiles/index.htm\#NHD_User_Guide/ Feature_Catalog/Hydrography_Dataset/Complete FCode_List.htm).

e. Codes should be appropriate for NHD conflation.

\section{A-2 Delineation of Hydrographic Features}

Hydrographic features will be captured as either threedimensional (3D) point, line, or polygon geometry (table 2.6). Some features may be collected either as 3D lines or 3D polygons, determined by minimum area or length of shortest access (Archuleta and Terziotti, 2020). EClass indicates how the features are used in elevation surface treatments. FClass indicates how the features are used in a hydrography product.

\section{D Elevation Program Light Detection and Ranging Base Specification Required Hydroflattening Features}

1. The features required to meet the hydroflattening requirement may be collected using the specifications outlined within this document (EClass=1).

2. The subset of features identified in table 2.5 can be used to fulfill the hydroflattening requirement.

3. Either all EClass $=1$ features, as defined within this document, can be used to create a hydroflattened surface, or a subset that meets the minimum size for hydroflattening requirements can be used to create a hydroflattened digital elevation model (DEM) to meet the Lidar Base Specification requirements.

\section{Elevation-Derived Hydrography Feature Collection}

1. The correct geometry shall be used to capture each feature type.
2. At a minimum, a hydrographic feature collection shall do the following:

a. capture all features from table 2.3 that are present in the high-resolution NHD,

b. capture any additional features that meet the capture conditions described in Archuleta and Terziotti (2020), and

c. remove features that are not visible in the lidar data, or appropriate imagery, even if they were in the original NHD.

3. Additional features shall be collected for the following reasons:

a. if there is clear evidence of the feature in the lidar data source,

b. if there is clear evidence of the feature using an appropriate ancillary data source (see table 2.7 for examples),

c. if a method has given good results for delineation of stream channels or other features and it is quality assured using the lidar data and other high-quality ancillary datasets,

d. if it is necessary to connect a hydrographic network.

4. All criteria described in the following special cases shall be met.

\section{Special Cases}

\section{2-Digit Hydrologic Unit Consistency}

- New features collected within 12-digit hydrologic unit boundaries will evaluate inconsistencies in line density. New features shall be collected to be consistent with the most densely collected part of the 12-digit hydrologic unit.

- Where geomorphology, geology, or other terrain features create actual differences in stream density, the natural representation of features that depicts the disparity in density should be captured.

- If a geographic area has an extremely dense stream network collected to meet local needs, a less detailed depiction of adjacent areas is allowed, but connectivity with major networks shall be maintained. 
Table 2.6. Feature type description, associated geometry, and use classification.

[Desc, description; FCode, feature code; EClass, feature class (elevation); FClass, feature class; 3D, three dimensional; NHD, National Hydrography Dataset]

Feature type descriptions, associated geometry, and coding

\begin{tabular}{|c|c|c|c|c|c|c|}
\hline \multicolumn{7}{|c|}{ Feature type descriptions, associated geometry, and coding } \\
\hline \multirow[b]{2}{*}{ Desc } & \multirow[b]{2}{*}{ FCode } & \multirow[b]{2}{*}{ Geometry type } & \multicolumn{2}{|c|}{ EClass } & \multicolumn{2}{|r|}{ FClass } \\
\hline & & & $\begin{array}{l}\text { Domain } \\
\text { value }\end{array}$ & Feature attribute & $\begin{array}{l}\text { Domain } \\
\text { value }\end{array}$ & Feature attribute \\
\hline Artificial path & 55800 & 3D line, polyline Z & 2 & $\begin{array}{l}\text { Hydrographic feature used for eleva- } \\
\text { tion purposes, other than culverts or } \\
\text { those used for hydroflattening }\end{array}$ & 1 & $\begin{array}{l}\text { NHD feature (will be used for confla- } \\
\text { tion). }\end{array}$ \\
\hline \multirow[t]{2}{*}{ Canal/ditch } & 33600 & $\begin{array}{l}\text { 3D line, polylineZ } \\
\text { (does not connect } \\
\text { primary network } \\
\text { features) }\end{array}$ & 0 & Not used for elevation derivatives & 2 & $\begin{array}{l}\text { Non-NHD feature (outside of collection } \\
\text { criteria). }\end{array}$ \\
\hline & & $\begin{array}{l}\text { 3D line, polylineZ } \\
\text { (creates network } \\
\text { connectivity) }\end{array}$ & 2 & $\begin{array}{l}\text { Hydrographic feature used for eleva- } \\
\text { tion purposes, other than culverts or } \\
\text { those used for hydroflattening }\end{array}$ & 1 & $\begin{array}{l}\text { NHD feature (will be used for confla- } \\
\text { tion). }\end{array}$ \\
\hline $\begin{array}{l}\text { Area of complex } \\
\text { channels }\end{array}$ & 53700 & $3 \mathrm{D}$ polygon, polygonZ & 0 & Not used for elevation derivatives & 1 & $\begin{array}{l}\text { NHD feature (will be used for confla- } \\
\text { tion). }\end{array}$ \\
\hline Connector & 33400 & 3D line, polyline Z & 2 & $\begin{array}{l}\text { Hydrographic feature used for eleva- } \\
\text { tion purposes, other than culverts or } \\
\text { those used for hydroflattening }\end{array}$ & 1 & $\begin{array}{l}\text { NHD feature (will be used for confla- } \\
\text { tion). }\end{array}$ \\
\hline Culvert & $\begin{array}{l}\text { Dependent on } \\
\text { connecting } \\
\text { features }\end{array}$ & 3D line, polylineZ & 3 & Culvert—used for hydroenforcement & 1 & $\begin{array}{l}\text { NHD feature (will be used for confla- } \\
\text { tion). }\end{array}$ \\
\hline \multirow[t]{3}{*}{ Dam/weir } & 34300 & $3 \mathrm{D}$ point, point $\mathrm{Z}$ & 0 & Not used for elevation derivatives & 2 & $\begin{array}{l}\text { Non-NHD feature (outside of collection } \\
\text { criteria). }\end{array}$ \\
\hline & & 3D line, polyline Z & 0 & Not used for elevation derivatives & 1 & $\begin{array}{l}\text { NHD feature (will be used for confla- } \\
\text { tion). }\end{array}$ \\
\hline & & $3 \mathrm{D}$ polygon, polygonZ & 0 & Not used for elevation derivatives & 1 & $\begin{array}{l}\text { NHD feature (will be used for confla- } \\
\text { tion). }\end{array}$ \\
\hline Drainageway & 46800 & 3D line, polylineZ & 2 & $\begin{array}{l}\text { Hydrographic feature used for eleva- } \\
\text { tion purposes, other than culverts or } \\
\text { those used for hydroflattening }\end{array}$ & 1 & $\begin{array}{l}\text { NHD feature (will be used for confla- } \\
\text { tion). }\end{array}$ \\
\hline Ice mass & 37800 & 3D polygon, polygonZ & 0 & Not used for elevation derivatives & 1 & $\begin{array}{l}\text { NHD feature (will be used for confla- } \\
\text { tion). }\end{array}$ \\
\hline Lake/pond & 39000 & 3D polygon, polygonZ & 1 & Used for hydroflattening & 1 & $\begin{array}{l}\text { NHD feature (will be used for confla- } \\
\text { tion). }\end{array}$ \\
\hline $\begin{array}{l}\text { Low-confidence area } \\
\text { (predetermined) }\end{array}$ & 991 & $\begin{array}{l}\text { 3D polygon, polygonZ } \\
\text { (accurate } \mathrm{z} \text {-values } \\
\text { not required) }\end{array}$ & 9 & Elevation dataset limitation & 9 & $\begin{array}{l}\text { Nonhydrography feature (elevation } \\
\text { dataset limitation). }\end{array}$ \\
\hline
\end{tabular}


Table 2.6. Feature type description, associated geometry, and use classification.-Continued

[Desc, description; FCode, feature code; EClass, feature class (elevation); FClass, feature class; 3D, three dimensional; NHD, National Hydrography Dataset]

\begin{tabular}{|c|c|c|c|c|c|c|}
\hline \multicolumn{7}{|c|}{ Feature type descriptions, associated geometry, and coding } \\
\hline \multirow[b]{2}{*}{ Desc } & \multirow[b]{2}{*}{ FCode } & \multirow[b]{2}{*}{ Geometry type } & \multicolumn{2}{|c|}{ EClass } & \multicolumn{2}{|r|}{ FClass } \\
\hline & & & $\begin{array}{c}\text { Domain } \\
\text { value }\end{array}$ & Feature attribute & $\begin{array}{l}\text { Domain } \\
\text { value }\end{array}$ & Feature attribute \\
\hline $\begin{array}{l}\text { Low-confidence area } \\
\text { (snow covered) }\end{array}$ & 993 & $\begin{array}{l}\text { 3D polygon, polygon } \mathrm{Z} \\
\text { (accurate } \mathrm{Z} \text {-values } \\
\text { not required) }\end{array}$ & 9 & Elevation dataset limitation & 9 & $\begin{array}{l}\text { Nonhydrography feature (elevation } \\
\text { dataset limitation). }\end{array}$ \\
\hline $\begin{array}{l}\text { Low-confidence area } \\
\text { (sparse bare earth) }\end{array}$ & 992 & $\begin{array}{l}\text { 3D polygon, polygon } \mathrm{Z} \\
\text { (accurate } \mathrm{z} \text {-values } \\
\text { not required) }\end{array}$ & 9 & Elevation dataset limitation & 9 & $\begin{array}{l}\text { Nonhydrography feature (elevation } \\
\text { dataset limitation). }\end{array}$ \\
\hline \multirow[t]{2}{*}{ Pipeline } & 42800 & $\begin{array}{l}\text { 3D line, polylineZ } \\
\text { (does not connect } \\
\text { primary network } \\
\text { features) }\end{array}$ & 0 & Not used for elevation derivatives & 1 & $\begin{array}{l}\text { NHD feature (will be used for confla- } \\
\text { tion). }\end{array}$ \\
\hline & & $\begin{array}{l}\text { 3D line, polylineZ } \\
\text { (creates network } \\
\text { connectivity) }\end{array}$ & 2 & $\begin{array}{l}\text { Hydrographic feature used for eleva- } \\
\text { tion purposes, other than culverts or } \\
\text { those used for hydroflattening }\end{array}$ & 1 & $\begin{array}{l}\text { NHD feature (will be used for confla- } \\
\text { tion). }\end{array}$ \\
\hline Playa & 36100 & 3D polygon, polygonZ & 0 & Not used for elevation derivatives & 1 & $\begin{array}{l}\text { NHD feature (will be used for confla- } \\
\text { tion). }\end{array}$ \\
\hline \multirow[t]{2}{*}{ Reservoir } & 43600 & $\begin{array}{l}\text { Polygon (less than } 2 \\
\text { acres) }\end{array}$ & 0 & Not used for elevation derivatives & 1 & $\begin{array}{l}\text { NHD feature (will be used for confla- } \\
\text { tion). }\end{array}$ \\
\hline & & $\begin{array}{l}\text { Polygon (greater than } \\
\text { or equal to } 2 \text { acres) }\end{array}$ & 1 & Used for hydroflattening & 1 & $\begin{array}{l}\text { NHD feature (will be used for confla- } \\
\text { tion). }\end{array}$ \\
\hline Sea/ocean & 44500 & 3D polygon, polygonZ & 1 & Used for hydroflattening & 1 & $\begin{array}{l}\text { NHD feature (will be used for confla- } \\
\text { tion). }\end{array}$ \\
\hline Sink/rise & 45000 & 3D point, point $Z$ & 0 & Not used for elevation derivatives & 1 & $\begin{array}{l}\text { NHD feature (will be used for confla- } \\
\text { tion). }\end{array}$ \\
\hline \multirow[t]{2}{*}{ Stream/river } & 46000 & 3D line, polylineZ & 2 & $\begin{array}{l}\text { Hydrographic feature used for eleva- } \\
\text { tion purposes, other than culverts or } \\
\text { those used for hydroflattening }\end{array}$ & 1 & $\begin{array}{l}\text { NHD feature (will be used for confla- } \\
\text { tion). }\end{array}$ \\
\hline & & 3D polygon, polygonZ & 1 & Used for hydroflattening & 1 & $\begin{array}{l}\text { NHD feature (will be used for confla } \\
\text { tion). }\end{array}$ \\
\hline
\end{tabular}


Table 2.7. Examples of acceptable ancillary datasets.

[NHD, National Hydrography Dataset; EDH-AS, Elevation-Derived Hydrography Acquisition Specifications; FCode, feature code; $\leq$, less than or equal to; DOT, Department of Transportation]

\begin{tabular}{|c|c|c|c|c|}
\hline \multicolumn{2}{|c|}{ Acceptable ancillary datasets table } & \multirow[b]{2}{*}{ Resolution } & \multirow[b]{2}{*}{ Comments } & \multirow[b]{2}{*}{ Use } \\
\hline $\begin{array}{l}\text { Required/ } \\
\text { recommended }\end{array}$ & Source & & & \\
\hline Required & $\begin{array}{l}\text { Elevation surfaces, bare-earth } \\
\text { digital elevation model }\end{array}$ & 1 meter & $\begin{array}{l}\text { Should be created from bare-earth } \\
\text { lidar points. }\end{array}$ & $\begin{array}{l}\text { All features collected must } \\
\text { match the surface of the } \\
\text { lidar bare-earth surface. }\end{array}$ \\
\hline Required & $\begin{array}{l}\text { Watershed Boundary Dataset, } \\
\text { 12-digit hydrologic units }\end{array}$ & $\begin{array}{l}1: 24,000 \text { or } \\
\text { better }\end{array}$ & $\begin{array}{l}\text { Download most recent version } \\
\text { from The National Map }\end{array}$ & $\begin{array}{l}\text { Use as a guide for mini- } \\
\text { mum density of features } \\
\text { that must be collected. } \\
\text { Buffer the watershed areas } \\
\text { to capture a complete } \\
\text { network. }\end{array}$ \\
\hline Recommended & $\begin{array}{l}\text { Intensity images from same } \\
\text { source as lidar surfaces }\end{array}$ & 1 meter & $\begin{array}{l}\text { Should be created from bare-earth } \\
\text { intensity values }\end{array}$ & $\begin{array}{l}\text { From the same source as the } \\
\text { elevation surface. Can be } \\
\text { used as imagery. Water } \\
\text { and wet areas are often } \\
\text { visible. }\end{array}$ \\
\hline Recommended & Leaf-off orthoimagery & $\leq 1$ meter & $\begin{array}{l}\text { Image date should be as close } \\
\text { to the lidar collection date as } \\
\text { possible }\end{array}$ & $\begin{array}{l}\text { Visible features below tree } \\
\text { canopy. Helpful to identify } \\
\text { roads and stream intersec- } \\
\text { tions. }\end{array}$ \\
\hline Recommended & Transportation layer & $\begin{array}{l}1: 24,000 \text { or } \\
\text { better }\end{array}$ & $\begin{array}{l}\text { State or local government data } \\
\text { tends to be higher resolution } \\
\text { and more current than Federal } \\
\text { road and highway datasets }\end{array}$ & $\begin{array}{l}\text { Used for identification of } \\
\text { culvert features, and for } \\
\text { delineation of headwater } \\
\text { streams near roads or rail- } \\
\text { roads (see "Culverts" and } \\
\text { "Headwaters at Roads" } \\
\text { subsections of "Special } \\
\text { Cases" in the "Delineation } \\
\text { of Hydrographic Features" } \\
\text { section). }\end{array}$ \\
\hline
\end{tabular}


Table 2.7. Examples of acceptable ancillary datasets.-Continued

[NHD, National Hydrography Dataset; EDH-AS, Elevation-Derived Hydrography Acquisition Specifications; FCode, feature code; $\leq$, less than or equal to; DOT, Department of Transportation]

\begin{tabular}{|c|c|c|c|c|}
\hline \multicolumn{2}{|c|}{ Acceptable ancillary datasets table } & \multirow[b]{2}{*}{ Resolution } & \multirow[b]{2}{*}{ Comments } & \multirow[b]{2}{*}{ Use } \\
\hline $\begin{array}{l}\text { Required/ } \\
\text { recommended }\end{array}$ & Source & & & \\
\hline Recommended & Dam locations & $\begin{array}{l}1: 24,000 \text { or } \\
\text { better }\end{array}$ & $\begin{array}{l}\text { National dataset coarser than } \\
\text { lidar; for example, National } \\
\text { Inventory of Dams }\end{array}$ & $\begin{array}{l}\text { Use as a guide for dam iden- } \\
\text { tification. }\end{array}$ \\
\hline Recommended & $\begin{array}{l}\text { Storm sewer systems and un- } \\
\text { derground systems in urban } \\
\text { areas }\end{array}$ & $\begin{array}{l}1: 24,000 \text { or } \\
\text { better }\end{array}$ & $\begin{array}{l}\text { Source date should be as close } \\
\text { to the lidar collection date as } \\
\text { possible }\end{array}$ & $\begin{array}{l}\text { Use to identify subsurface } \\
\text { connections, pipelines, } \\
\text { culverts. }\end{array}$ \\
\hline Recommended & Wetlands or hydric soil layers & $\begin{array}{l}1: 24,000 \text { or } \\
\text { better }\end{array}$ & $\begin{array}{l}\text { National datasets (National } \\
\text { Wetlands Inventory or Soil } \\
\text { Survey Geographic Database ) } \\
\text { are coarser than lidar. }\end{array}$ & $\begin{array}{l}\text { Use as a guide for wetlands } \\
\text { and possible channel iden- } \\
\text { tification. Wetlands can } \\
\text { also be used to identify } \\
\text { possible sinks or losing } \\
\text { streams. }\end{array}$ \\
\hline
\end{tabular}

\section{Culverts}

- A culvert must be a separate feature, nodematched (snapped) at each end to the up and downstream hydrographic features. Elevation attribution (EClass=3) will identify the culvert separately.

- If FCodes are the same for the upstream and downstream connecting features as the culvert, the FCode of the culvert will be equal to the FCode of connecting features.

- If a polygon feature contains a culvert within it, the polygon should not be split. The culvert feature shall be delineated on the artificial path of the polygon feature.

- If FCodes are not the same for upstream and downstream connecting features, table 2.8 will be used to determine the appropriate FCode.

\section{Drainageway}

- Overmapping features to include some features that are not actual streams may be necessary and cost effective.

- When a high degree of uncertainty exists, a feature code (FCode 46800, drainageway) should be used. This code indicates that further investigation is necessary to determine if a hydrographic feature exists on the ground.

- The drainageway FCode is primarily used for headwaters but may be used to map areas that are highly urbanized, or other areas of uncertainty that connect an upstream defined channel feature. 
Table 2.8. Attribution rules for culvert feature code when two features are connected by a culvert.

[When a culvert separates two features with different FCodes, the FCode of the culvert should be coded based on the "priority ranking for two features separated by a culvert" ranked list. Whichever one of the two features separated by a culvert has a higher priority on the list should be used as the FCode for the culvert. When a culvert separates more than two features that form a confluence or divergence, maintain the connection of the primary feature. If no feature exists on both sides of the culvert, follow priority ranking for two features separated by a culvert, else the FCode of the culvert should be coded based on the "priority ranking for more than two features separated by a culvert" ranked list.]

\begin{tabular}{ccc}
\hline Ranked priority & Feature & FCode \\
\hline 1 & Priority ranking for two features separated by a culvert & 33400 \\
2 & Connector & 42800 \\
3 & Pipeline & 33600 \\
4 & Canal/ditch & 46000 \\
5 & Stream/river & 46800 \\
6 & Drainageway & 55800 \\
\hline & Artificial path through 2D polygon features & 46000 \\
2 & Priority ranking for more than two features separated by a culvert & 33600 \\
4 & Stream/river & 42800 \\
\end{tabular}

\section{Headwaters at Roads}

1. Identify any stream whose initiation point (headwater point) is within 100 feet (ft) or $30 \mathrm{~m}$ of a road.

2. If a stream channel is visible (in imagery or a lidar surface) upstream from the road, extend the stream/river through the road using the rules described for delineation of culverts, and extend the stream/river at least $100 \mathrm{ft}$ or $30 \mathrm{~m}$ upstream from the road intersection.

3. If a stream channel is not visible upstream from the road, but there are other indications that a culvert is at the intersection of the road that allows flow to continue into the stream/river, extend the stream/river to the road and add a culvert through the road feature. Extending the stream/river upstream from the culvert is not necessary if a channel is not visible.

4. If a stream channel is not visible upstream from the road, and no other indications of a connection between the upstream area and the headwater exist, then no action is required.
2. If a canal/ditch is needed to provide network connectivity, it should be captured.

3. If a canal/ditch feature is within agricultural fields, is less than $300 \mathrm{~m}$, and drains to another canal/ditch or other hydrologic feature, it should not be captured.

4. Isolated canal/ditch features or networks should not be collected unless they are of particular significance to the regional hydrology.

5. If a project has a special need for canal/ditch features not covered by these capture conditions, a separate UserCode attribute should be added to allow those features to be removed from an NHD conflation process.

a. Coding should follow the rules for additional userdefined features:

FClass, EClass, and FCode should be coded as 2, 0 , and 0 , respectively. The Desc field may be used to provide a text description. A unique user-defined code should be added to the UserCode field. Codes should not duplicate other defined features or coding needed for NHD conflation.

\section{Canals and Ditches}

1. If a canal/ditch is named, or if a canal/ditch is greater than or equal to $984 \mathrm{ft}(300 \mathrm{~m})$ along the longest axis, then it should be captured. 


\section{A-2 Topology}

Topology is a set of rules and behaviors that define the spatial relation between the features in the hydrographic network. To prepare for the conflation of hydrographic features into the NHD, topology rules must be followed. The NHD relies on the topology of the features to maintain a continuous network and to support functions such as network navigation.

\section{Topology Rules}

1. Remove vertices that are closer than $1.5 \mathrm{~m}$ apart.

a. Caution should be exercised to not compromise positional accuracy by removing more vertices than necessary.

b. All features should have a smooth, nonrasterized appearance and maintain horizontal and vertical accuracy.

2. Split all line features at polygon boundaries.

a. Code flowlines within a waterbody polygon as "artificial paths."

b. Any artificial path must be completely within the waterbody polygon, starting and ending at the nodes that are coincident with inflowing features and outflowing features.

3. All line features should be one segment, with no breaks within the feature.

a. The exception to this rule is for "culvert" features. Culverts may split another feature but must use the same FCode as the feature that flows into or out of the culvert. The EClass will be equal to the "culvert-used for hydroenforcement" code of 3.

4. All intersections of features shall have a node (a start/beginning, or end/terminating, vertex) at that intersection.

a. Features that change FCodes within a flowline segment shall be split at that point.

b. Line features that intersect shall be split at that intersection, unless there is evidence that the features do not interact (pipelines, for instance).

c. Lines that meet polygons shall be split at the point where they intersect the polygon. The vertex will exist on the polygon boundary at the connection. Avoid splitting the polygon feature. d. Artificial paths within a polygon shall have an end or start node that is snapped to incoming linework. The vertex will exist on the polygon boundary at the connection. Avoid splitting the polygon feature.

e. No lines shall have self-intersections or cutbacks.

f. Polygon features shall not overlap, but they may share edges.

5. The linear features of the dataset shall create a complete network.

a. Flow shall be from upstream to downstream.

i. Elevation values shall descend from upstream to downstream.

b. Isolated pieces of the network may be present where a DPA does not match a hydrologic unit.

c. Isolated pieces of the network may be present if a sink or other known break in the hydrologic network exists.

i. A sink point shall be used to identify these locations.

6. Features smaller than $1.5 \mathrm{~m}$ shall be removed or merged in with a longer feature.

7. All features shall have a complete set of attributes associated with them.

\section{Z-Values}

1. Features shall be delivered in shapefile, file geodatabase, or Open Geospatial Consortium GeoPackage formats, as pointZ, polylineZ, or polygonZ feature classes.

2. All features shall conform to the defined georeference information defined in the "Spatial Reference System" section of this report.

a. A file with appropriate projection information shall accompany all hydrographic feature deliveries.

3. Lakes/ponds and reservoir waterbody polygons shall be at an elevation at or below the immediately surrounding terrain.

4. Lakes/ponds and reservoir waterbody polygons shall be flat and level with a single elevation value for every shoreline vertex.

5. Stream/river polygons or downstream flowing lakes/ ponds and reservoirs shall present a flat and level water surface bank to bank. 
6. Stream/river polygons or downstream flowing lakes/ ponds and reservoirs shall have a downstream gradient water surface, at or below the immediately surrounding terrain.

a. In cases of sharp turns of rapidly moving water, where the natural water surface is notably not level bank to bank, the water surface shall be represented as it exists while maintaining an aesthetic cartographic appearance.

7. Stream/river lines shall have a downstream gradient, at or just below the immediately surrounding terrain.

a. Each vertex in a line shall be at the same or a lower elevation value than the preceding vertex.

8. Nontidal boundary waterbodies shall be flat and level for lakes and reservoirs, or maintain a downhill gradient for wide rivers and lakes, with the elevation at or just below the immediately surrounding terrain.

9. Tidal waterbodies will be flat and level with the elevation at or just below the immediately surrounding terrain.

a. Some vertical discontinuities are acceptable if caused by tidal variations during the collection process.

10. At all intersections, regardless of feature type, the geometry of all intersection vertices shall match exactly in $\mathrm{x}$, $\mathrm{y}$, and $\mathrm{z}$, unless there is evidence that there is no interaction between the features (pipelines, for example).

11. Features that are used to traverse surface terrain features (culverts, connectors) or are underground (culverts, connectors, pipelines) shall have the elevation values of the connecting features at the end points. The elevation values of the surface above the culvert, connector, or pipeline will not be used.

12. Pipelines that are above ground and visible on the elevation surface shall use the elevation of the lidarderived surface.

\section{A-2 Positional Assessment}

The goal of the positional assessment is to create a hydrography product that is vertically and horizontally integrated with the 3D Elevation Program bare-earth DEM. In general, existing NHD specifications and 3DEP LBS will be followed to ensure accuracy and completeness. Positional assessment of the EDH is always measured against the bare earth DEM source.

\section{Elevation-Derived Hydrography Positional Evaluation and Reporting}

Ideally, all features, or as many features as possible, should be visually inspected to make sure that they meet the accuracy standards described in this specification. If a complete review is impossible, a stratified random sample may be used to select a subset of features to determine the accuracy of the dataset.

To do a holistic review of the dataset, the features reviewed should be

1. Representative of all features in the dataset, so they should contain at least one feature for each EClass and FCode present in the dataset;

2. Representative of the complete geographic area of the dataset, so they should have features distributed within each 12-digit hydrologic unit that intersects the DPA;

3. Representative of the special cases that make up features, including, but not limited to,
a. Headwaters,
b. Confluences between stream/river reaches,
c. Intersections with polygons and stream features,
d. Canal/ditch features,
e. Isolated networks,
f. Drainageways,
g. Intersections near roads,
h. Culverts,
i. Islands within polygon features;

4. Representative of land cover and geologic types or geophysical regions, including but not limited to
a. Urban areas,
b. Low slope areas.

\section{Positional Assessment and Reporting}

Positional assessment results shall be reported for vertical and horizontal geometry of the hydrographic features relative to the 3DEP bare-earth DEM (see hydroflattening exception below).

- Positional assessment is meant to indicate how accurately the vector hydrographic feature is positioned relative to the feature as represented on the DEM. 
- This measure is always represented as (plus or minus) meters.

\section{Hydroflattening Polygon Exception}

- An exception to the reporting requirement is for vertices that have been adjusted to maintain monotonicity for hydroflattening.

- Vector features used for hydroflattening must follow the requirements of the LBS.

- Vector features used for hydroflattening purposes shall be integrated into the elevation-derived hydrography dataset and shall follow the Elevation-Derived Hydrography Acquisition Specifications other than the requirement for positional assessment and reporting.

\section{Vertical Positional Assessment of Hydrographic Features Relative to the Digital Elevation Model}

- All lines and water surface edges shall be at or just below the elevation value of the immediately surrounding terrain, within $1 \mathrm{~m}$ of the location on the bareearth DEM.

- Exceptions to this requirement are features that are used to traverse surface terrain (culverts, connectors), are underground conduits (culverts, connectors, pipelines), or are overland pipelines (pipelines).

\section{Horizontal Positional Assessment of Elevation-Derived Hydrography}

The horizontal positional assessment evaluates the placement of vector hydrographic features against the bare-earth DEM from which they were derived. Linear, polygonal and point features shall be within the visible channels or other hydrographic features visible on the elevation surface.

\section{Linear Features}

Stream and other linear channel features shall stay within the apparent channels in the elevation data and shall not leave the channel.
Hydrographic feature positional assessment.-Whereby streams and other linear channel features will stay within the apparent channels in the elevation data and will not leave the channel.

\section{Polygonal Features}

Lake/pond and other polygonal features shall match the apparent boundary of the feature in the elevation data and shall not vary from the boundary of the feature.

Hydrographic feature positional assessment.-Whereby lake/ pond and other polygonal features will match the apparent boundary of the feature in the elevation data and will not vary from the boundary of the feature.

\section{Point Features}

Point features shall remain within $3 \mathrm{~m}$ of the apparent location of the feature in the elevation data.

Hydrographic feature positional assessment.-Whereby point features will remain within $3 \mathrm{~m}$ of the apparent location of the feature in the elevation data.

\section{Alignment}

\section{Horizontal Alignment}

1. New features shall align appropriately with existing NHD features outside of the collection area. For instance, if a stream is added to an existing stream channel, it should "snap" to the stream network nodes.

2. Features shall be aligned in accordance with topology rules.

3. Features shall edge match exactly across tile and project boundaries in the horizontal (x,y) spatial dimensions.

4. Delivered data shall be sufficient for the USGS to effectively use as breaklines for hydroflattening or conflation into the NHD without substantial editing.

5. Lines shall be oriented from upstream to downstream.

6. No lines shall have pseudonodes (other than headwater beginning nodes) or breaks within reaches.

7. Polygonal water features shall begin and end at the upstream end of that polygon's centerline (artificial path). 
8. Where any other features intersect, the intersection shall be coincident with vertices of each feature.

9. At all intersections, regardless of feature type, the geometry of all intersection vertices shall match exactly in $\mathrm{x}, \mathrm{y}$, and $\mathrm{z}$, unless there is no evidence for interaction between the features (pipelines for instance).

10. Features shall align horizontally with the lidar-derived bare-earth DEM they were derived from, within the positional assessment limits described in the "Accuracy" section.

11. Horizontal discontinuities along the shoreline of a waterbody resulting from tidal variations during the collection are considered normal and shall be retained in the final DEM.

\section{Vertical Alignment}

1. Features shall edge match exactly across tile and project boundaries in the vertical (z) spatial dimensions.

2. Delivered data shall be sufficient for the USGS to effectively use as breaklines for hydroflattening or conflate into the NHD without substantial editing.

3. Each vertex in a line shall be at the same or a lower elevation value than the preceding vertex in the direction of flow from upstream to downstream.

4. At all intersections, regardless of feature type, the geometry of all intersection vertices shall match exactly in $\mathrm{x}, \mathrm{y}$, and $\mathrm{z}$, unless there is evidence of no interaction between features (pipelines for instance).

5. Features shall align vertically with the lidar-derived bare-earth DEM they were derived from, within the positional assessment limits described in the "Accuracy" section.

6. All lines shall be at or just below the elevation of the immediately surrounding terrain, as defined by the lidar points classified as bare earth.

7. Flattened waterbodies shall present a flat and level water surface (a single elevation for every bank vertex defining the waterbody's perimeter).

8. Long impoundments that are considered lake/pond or reservoirs, whose water surface elevations decrease with downstream travel, shall present a gradient downhill water surface, following the immediately surrounding terrain.
9. The entire water surface edge shall be at or below the immediately surrounding terrain (the presence of floating waterbodies will be cause for rejection of the deliverable).

10. Flattened streams and rivers shall present a flat and level water surface bank to bank (perpendicular to the apparent flow centerline).

11. Flattened streams and rivers shall present a gradient downhill water surface, following the immediately surrounding terrain.

12. In cases of sharp turns of rapidly moving water, where the natural water surface is notably not level bank to bank, the water surface will be represented as it exists while maintaining an aesthetic cartographic appearance.

13. The entire water surface edge shall be at or below the immediately surrounding terrain.

14. If a polygon is incomplete because it is on the boundary of the collection area, the water surface shall be flat and level, as appropriate for the type of waterbody (level for lakes, gradient for rivers, and so forth).

15. All landward water surface edges shall be at or below the immediately surrounding terrain.

16. Unusual changes in the water surface elevation that may take place over the course of the collection (for example, different river stages because of increased or decreased discharge from an upstream dam) shall be documented in the project metadata.

17. Vertical discontinuities within a waterbody resulting from tidal variations during the collection are considered normal and shall be retained in the final DEM.

\section{Completeness}

1. All features shall be collected to form a complete stream network without breaks, unless there is evidence a break should occur (for example, isolated waterbodies or subterranean streamflow). All topology rules shall be followed.

2. All features shall be coded with the appropriate FClass, EClass, FCode, Desc, source, and method.

3. UserCodes shall be used where applicable.

4. Domains shall match those specified within the "Elevation-Derived Hydrography—Representation, Extraction, Attribution, and Delineation Rules" (Archuleta and Terziotti, 2020). 


\section{A-2 Metadata}

1. Metadata for the breaklines shall be provided in Extensible Markup Language (commonly known as XML; formatted files (Bray and others, 2008) compliant with the Federal Geographic Data Committee Content Standard for Digital Geospatial Metadata (Federal Geographic Data Committee, 1998a). The USGS may offer additional or alternative metadata formats in the future.

2. Metadata shall document the following:

- Methods used to delineate features;

- Minimum feature length;

- Format of elevation data (lidar derivatives);

- Source of elevation data (where the data were acquired);

- Date of source elevation data;

- Quality level of source elevation data;

- Ancillary datasets used, including source, date, and resolution;

- Spatial reference system, including horizontal and vertical units, and horizontal and vertical datum used;

- Results of relative accuracy assessment of hydrographic data;

- Method for relative accuracy assessment;

- Field definitions for tables associated with geospatial data (explanation of what type of information the field contains); and

- Contact information for data collector.

\section{A-2 Delivered Products and Formats}

Delivered products shall include the following:

1. A polygon defining the complete boundary of the DPA,

a. Polygons defining any areas within the DPA that were not included in the hydrography collection.

2. A hydrography dataset that adheres to all specifications herein,

a. Data will be delivered as a current version of shapefile, file geodatabase, or Open Geospatial Consortium GeoPackage. b. Points, lines, and polygons will have $3 \mathrm{D}$ geometry.

3. Metadata describing the final dataset,

4. A summary of any accuracy assessments completed on the data. The USGS National Geospatial Program is the maintenance authority for this document.

\section{References Cited}

Archuleta, C.M., and Terziotti, S., 2020, Elevation-Derived Hydrography_Representation, Extraction, Attribution, and Delineation Rules: U.S. Geological Survey Techniques and Methods, book 11, chap. B12, 60 p., https://doi.org/10.3133/ tm11B12.

Bray, T., Paoli, J., Sperberg-McQueen, C.M., Maler, E., and Yergeau, F., eds., 2008, Extensible Markup Language (XML) 1.0 (5th ed.) (W3C Recommendation 26 November 2008): W3C web page, accessed December 2019 at https://www.w3.org/TR/2008/REC-xml-20081126/.

Federal Geographic Data Committee, 1998, Content standard for digital geospatial metadata (revised June 1998): Washington, D.C., Federal Geographic Data Committee FGDC-STD-001-1998, 90 p., accessed April 7, 2017, at https://www.fgdc.gov/standards/projects/FGDC-standardsprojects/metadata/base-metadata/v2_0698.pdf.

U.S. Geological Survey, 2019, NGP standards and specifications: U.S. Geological Survey web page, accessed May 2020 at https://www.usgs.gov/core-science-systems/ngp/ss/ product-standards. 
For more information about this publication, contact: Director, USGS National Geospatial Technical Operations Center 1400 Independence Road

Rolla, MO 65401

573-308-3500

or

P.0 Box 25046, MS 510

Denver, CO 80225

For additional information, visit: https://www.usgs.gov/core-science-systems/ngp/ngtoc

Publishing support provided by the Rolla Publishing Service Center 


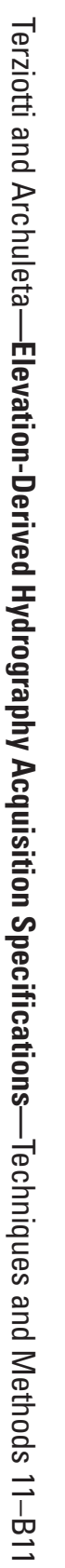

